\title{
AIS Transactions on Human-Computer Interaction
}

Fall 9-2009

\section{The Intellectual Advancement of Human-Computer Interaction Research: A Critical Assessment of the MIS Literature (1990-2008)}

Ping Zhang

Syracuse University, pzhang@syr.edu

$\mathrm{Na} \mathrm{Li}$

BakerCollege, nli01@baker.edu

Michael Scialdone

mjsciald@syr.edu,mjsciald@syr.edu

Jane Carey

Arizona State University West, jcarey@asu.edu

Follow this and additional works at: https://aisel.aisnet.org/thci

\section{Recommended Citation}

Zhang, P., Li, N., Scialdone, M., \& Carey, J. (2009). The Intellectual Advancement of Human-Computer Interaction Research: A Critical Assessment of the MIS Literature (1990-2008). AIS Transactions on Human-Computer Interaction, 1(3), 55-107. Retrieved from https://aisel.aisnet.org/thci/vol1/iss3/1 DOI: 

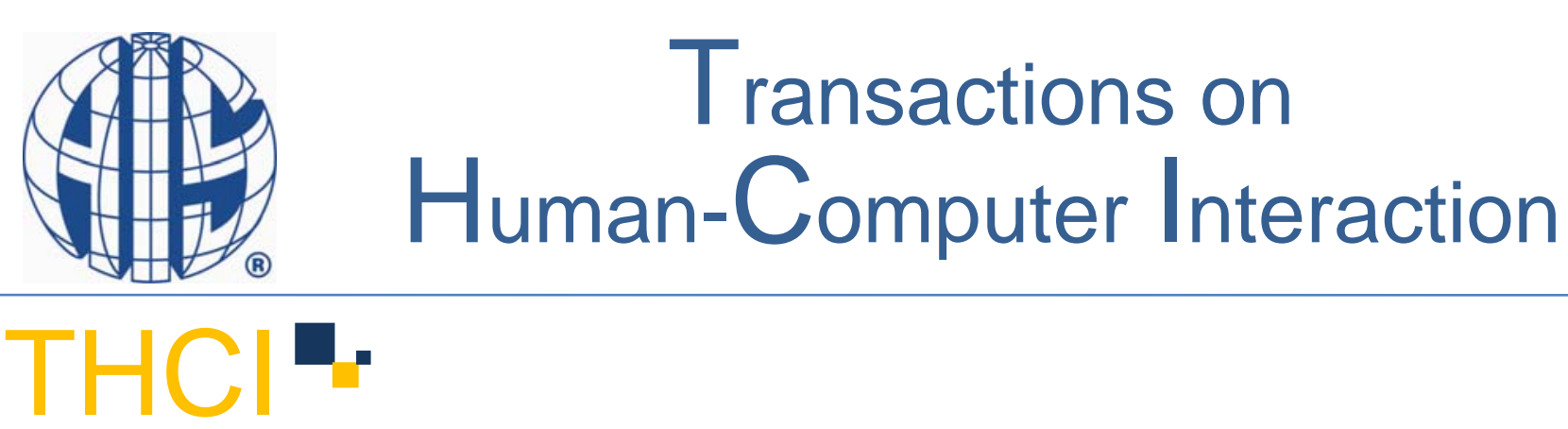

Theory \& Review

\section{The Intellectual Advancement of Human-Computer Interaction Research: A Critical Assessment of the MIS Literature (1990-2008)}

\author{
Ping Zhang \\ Syracuse University \\ pzhang@syr.edu
}

Michael J. Scialdone

Syracuse University

mjsciald@syr.edu
$\mathrm{Na}$ "Lina" Li

Baker College

nli01@baker.edu

Jane Carey

Arizona State University

jcarey@asu.edu

This paper assesses the intellectual advancement of Human-Computer Interaction $(\mathrm{HCl})$ scholarship as one of the five research streams of the Management Information Systems (MIS) discipline. It particularly demonstrates the vitality and maturity that the $\mathrm{HCl}$ stream (or sub-discipline) has achieved in recent years, and adds to the few studies that draw an overarching picture of $\mathrm{HCl}$. This study uses the same approach as that of Zhang and Li (2005), and delineates the intellectual development of $\mathrm{HCl}$ research in MIS by employing a multifaceted assessment of the published $\mathrm{HCl}$ articles over a period of 19 years (1990-2008) in eight primary MIS journals. In addition, this study includes several journal special issues and two book collections in the assessment. Twenty-four specific questions are addressed to answer the following five mega-research questions about the $\mathrm{HCl}$ sub-discipline: (1) What constitutes HCl's intellectual substance? (2) What relationships does $\mathrm{HCl}$ have with other disciplines? (3) How is $\mathrm{HCl}$ evolving? (4) What are the patterns of $\mathrm{HCl}$ publication in the primary MIS journals? And, (5) Who are the contributing scholars? A number of areas for future research are predicted, along with a discussion of potential future directions for the sub-discipline. This study is of interest to researchers in the $\mathrm{HCl}$ sub-discipline, the MIS discipline, and other related disciplines to inform future research, collaboration, publication, and education. It should also be of interest to doctoral students for identifying potential topics for dissertation research and to identify academic institutions for future employment where such research is understood, appreciated, and encouraged.

Keywords: Human-Computer Interaction $(\mathrm{HCl}$ ), Human Factors in Information Systems (HFIS), scientific fields, intellectual development, literature assessment, subject topics, research methods, study contexts, individual characteristics, levels of analysis, contributing disciplines, IT and service, Management Information Systems (MIS)

Dennis Galletta was the accepting Senior Editor. This article was submitted on 7/10/2009 and accepted on 8/17/2009. It was with the authors ten days for 2 revisions.

Zhang, P, N. Li, M. J. Scialdone, and J. Carey (2009) "The Intellectual Advancement of Human-Computer Interaction Research: A Critical Assessment of the MIS Literature (1990-2008)," AIS Transactions on Human-Computer Interaction, (1) 3, pp. 55-107 


\section{INTRODUCTION}

Empirical evidence demonstrates that Human-Computer Interaction ( $\mathrm{HCl}$ ) studies comprise a significant subdiscipline within the MIS discipline (Zhang and Li 2005). $\mathrm{HCl}$ studies in MIS are "concerned with the ways humans interact with information, technologies, and tasks, especially in business, managerial, organizational, and cultural contexts" (Zhang et al. 2002). A key aspect of these studies is the concern about humans, not in a sense that would interest a pure psychologist, but in the ways that humans interact with technologies for various purposes. Although $\mathrm{HCl}$ studies have always been a significant part of the MIS literature (Culnan 1986; Culnan 1987; Sidorova, et al. 2008; Zhang and Li 2005), interest in the $\mathrm{HCl}$ research stream within the MIS discipline should continue to surge as predicted (Banker and Kauffman 2004).

Several articles have provided various views of the $\mathrm{HCl}$ sub-discipline thus far. Such overviews include a top down perspective on research issues and directions of $\mathrm{HCl}$ studies in MIS (Zhang et al. 2002), a call to action for including $\mathrm{HCl}$ topics in the MIS curricula (Carey et al. 2004), a proposition for considering MIS as the home of $\mathrm{HCl}$ studies (Kutzschan and Webster 2006), a limited data-driven view based on an assessment of two MIS journals (MISQ and ISR) on two facets (subject topic and research method) (Zhang and Li 2004), and a comprehensive and critical literature assessment of seven primary MIS journals' publications during 1990-2002 by Zhang and Li (2005), which systematically characterized the intellectual state and development of the $\mathrm{HCl}$ sub-discipline, with the support of literature up to the year 2002.

$\mathrm{HCl}$ studies in MIS have surged significantly since 2002, coinciding with the establishment of the Association for Information Systems (AIS) Special Interest Group on Human-Computer Interaction (SIGHCI) in 2001. AIS SIGHCI has attracted a large number of scholars, making it one of the largest SIGs within AIS. In addition, SIGHCI has sponsored conference tracks and mini-tracks in all major IS conferences including the International Conference on Information Systems (ICIS), the Americas Conference on Information Systems (AMCIS), the Pacific Conference on Information Systems (PACIS), and the European Conference on Information Systems (ECIS). Additionally, the Hawaii International Conference on System Sciences (HICSS) has $\mathrm{HCl}$ mini-tracks; and there is a designated research workshop, the pre-ICIS Annual Workshop on $\mathrm{HCl}$ Research in MIS. There have also been 11 special issues in top MIS and $\mathrm{HCl}$ journals, two edited volumes of research studies by leading MIS and $\mathrm{HCl}$ scholars (Galletta and Zhang 2006; Zhang and Galletta 2006), the inclusion of $\mathrm{HCl}$ materials in the AIS/ACM model curriculum for Masters in Information Systems (Gorgone et al. 2005), a specially written textbook for MIS students on HCI topics (Te'eni et al. 2007), and a new AIS journal designated to $\mathrm{HCl}$ research: AIS Transactions on Human-Computer Interaction (http://thci.aisnet.org). Figure 1 depicts the major activities and outcomes sponsored by AIS SIGHCI from 2001 to 2008. Along with SIGHCl-related activities, the interest in the $\mathrm{HCl}$ sub-discipline has experienced a true surge over the past several years, as evidenced by publications in primary MIS journals. Thus, it is necessary to re-examine the $\mathrm{HCl}$ in MIS sub-discipline to reflect where it has been, where it is, and what the trend of movement is, if any. This is the primary goal of this present study.

Specifically, in this study, we expand the literature coverage to update the findings of Zhang and Li (2005). We start with a set of mega-research questions similar to those in Zhang and Li's study that can be decomposed into lower level or more detailed questions. We then address these questions by using the same classification approach to examine a collection of $\mathrm{HCl}$ articles from the same seven prime MIS journals, plus one additional MIS journal (CAIS), 11 journal special issues sponsored by SIGHCI since 2002, and two edited volumes, together to cover a period of 19 years (1990-2008) of the MIS literature. We take the same multifaceted view to reveal the detailed characteristics of the dynamics and richness of the $\mathrm{HCl}$ sub-discipline. To maintain consistency and ensure comparison, we use the same organizing framework, the same boundary for $\mathrm{HCl}$ research in MIS, and the same seven facets to assess the literature. We also conduct analyses similar to those in Zhang and Li (2005). For example, co-occurrence and crossfacet analyses can reveal interesting patterns by answering questions such as "what topics are often studied together," and "what methods are used to study what topics?" To reveal the social and academic side of the subdiscipline, we reexamine publication patterns and the most prolific authors and their institutions. Finally, we provide particular analyses to depict movement trends among various periods of time.

To avoid unnecessary repetition, this paper will focus primarily on research questions, methodology, data collection, data analyses, and discussions and implications. We suggest that readers review Zhang and Li (2005) for detailed background information, conceptualization of the sub-discipline, and justifications for the research method, among many other aspects.

The paper is organized as follows: research questions, methodologies, data analyses, results, syntheses, conclusions, and future research directions. 


\section{RESEARCH QUESTIONS}

Table 1 lists the research questions that can be used to assess the intellectual dimensions of the $\mathrm{HCl}$ sub-discipline (Zhang and Li 2005). The first three mega-questions (RQ1-RQ3) address three dimensions for examining the intellectual development of a scientific field: (1) the field itself in terms of its substance; (2) relationships with other scientific fields; and (3) the evolution or changes of the first two dimensions over time. In addition, RQ4 is about the primary publication patterns of $\mathrm{HCl}$ studies. RQ5 is about one important component of a scientific field: its members or knowledge contributors. Together, RQ1, RQ2, and RQ3 are largely about the intellectual side of the sub-discipline, while RQ4 and RQ5 focus more on the social side.

Each mega-question is decomposed further into detailed questions that can be answered directly by the literature assessment. Because of the sensitive difference between the terms "field" and "discipline," in the latter part of this paper, starting from the section on Classification for Contributing Disciplines, we use "discipline" to represent MIS as we have discussed it so far, and "sub-discipline" for the $\mathrm{HCl}$ research we are assessing.

One particular goal of this paper is to depict the surge or "movement" aspect of the sub-field, which will be primarily addressed by RQ3.

Table 1: Research Questions on the Intellectual Development of the HCI Sub-Discipline

\begin{tabular}{|c|c|}
\hline RQ1 & What constitutes the intellectual substance? \\
\hline & $\begin{array}{l}\text { RQ1.1: What are the contexts of studies? } \\
\text { RQ1.2: What are the research areas or subject topics? } \\
\text { RQ1.3: What topics are often co-studied? } \\
\text { RQ1.4: What are the research methods? } \\
\text { RQ1.5: What methods are often used to study what topics? } \\
\text { RQ1.6: What are the levels of analysis? } \\
\text { RQ1.7: To what extent does the } \mathrm{HCl} \text { sub-discipline consider IT/service as a research component? } \\
\text { RQ1.8: To what extent does the } \mathrm{HCl} \text { sub-discipline consider individual characteristics? }\end{array}$ \\
\hline \multirow[t]{2}{*}{ RQ2 } & What are the relationships with other disciplines? \\
\hline & $\begin{array}{l}\text { RQ2.1: What are the disciplines contributing to the } \mathrm{HCl} \text { studies? } \\
\text { RQ2.2: What contributing disciplines are often co-cited in } \mathrm{HCl} \text { studies? } \\
\text { RQ2.3: What contributing disciplines are often used to support what subject topics? }\end{array}$ \\
\hline \multirow[t]{2}{*}{ RQ3 } & What are the evolutions? \\
\hline & $\begin{array}{l}\text { RQ3.1: What are the changes in the contexts of study over the years? } \\
\text { RQ3.2: What are the changes in the subject topics over the years? } \\
\text { RQ3.3: What are the changes in the research methods over the years? } \\
\text { RQ3.4: What are the changes in the level of analysis over the years? } \\
\text { RQ3.5: What are the changes in considering IT or service as a research component? } \\
\text { RQ3.6: What are the changes in considering individual characteristics as a research component? } \\
\text { RQ3.7: What are the changes in the contributing disciplines over the years? }\end{array}$ \\
\hline \multirow[t]{2}{*}{ RQ4 } & What are the patterns of publishing $\mathrm{HCl}$ studies in various sources? \\
\hline & $\begin{array}{l}\text { RQ4.1: What\%age of published works are } \mathrm{HCl} \text { studies? What is the trend in such\%age? } \\
\text { RQ4.2: What topics are "preferred" by which sources? } \\
\text { RQ4.3: What methods are "preferred" by which sources? } \\
\text { RQ4.4: Which contributing disciplines are cited more frequently in which sources? }\end{array}$ \\
\hline \multirow[t]{2}{*}{ RQ5 } & Who are the contributing members? \\
\hline & $\begin{array}{l}\text { RQ5.1: Who are the most prolific authors? } \\
\text { RQ5.2: What are the most prolific institutions housing } \mathrm{HCl} \text { researchers? }\end{array}$ \\
\hline
\end{tabular}

\section{METHODOLOGY}

In order to build on and expand Zhang and Li's 2005 study, we use the same classification-based approach. Specifically, we consider the same set of seven journals, plus another journal that has been publishing $\mathrm{HCl}$ articles, the journal special issues sponsored by $\mathrm{SIGHCl}$, and two book collections of $\mathrm{HCl}$ studies. We also use the same coding schemes for analyzing the new $\mathrm{HCl}$ articles selected (those published since 2002), combining these results 


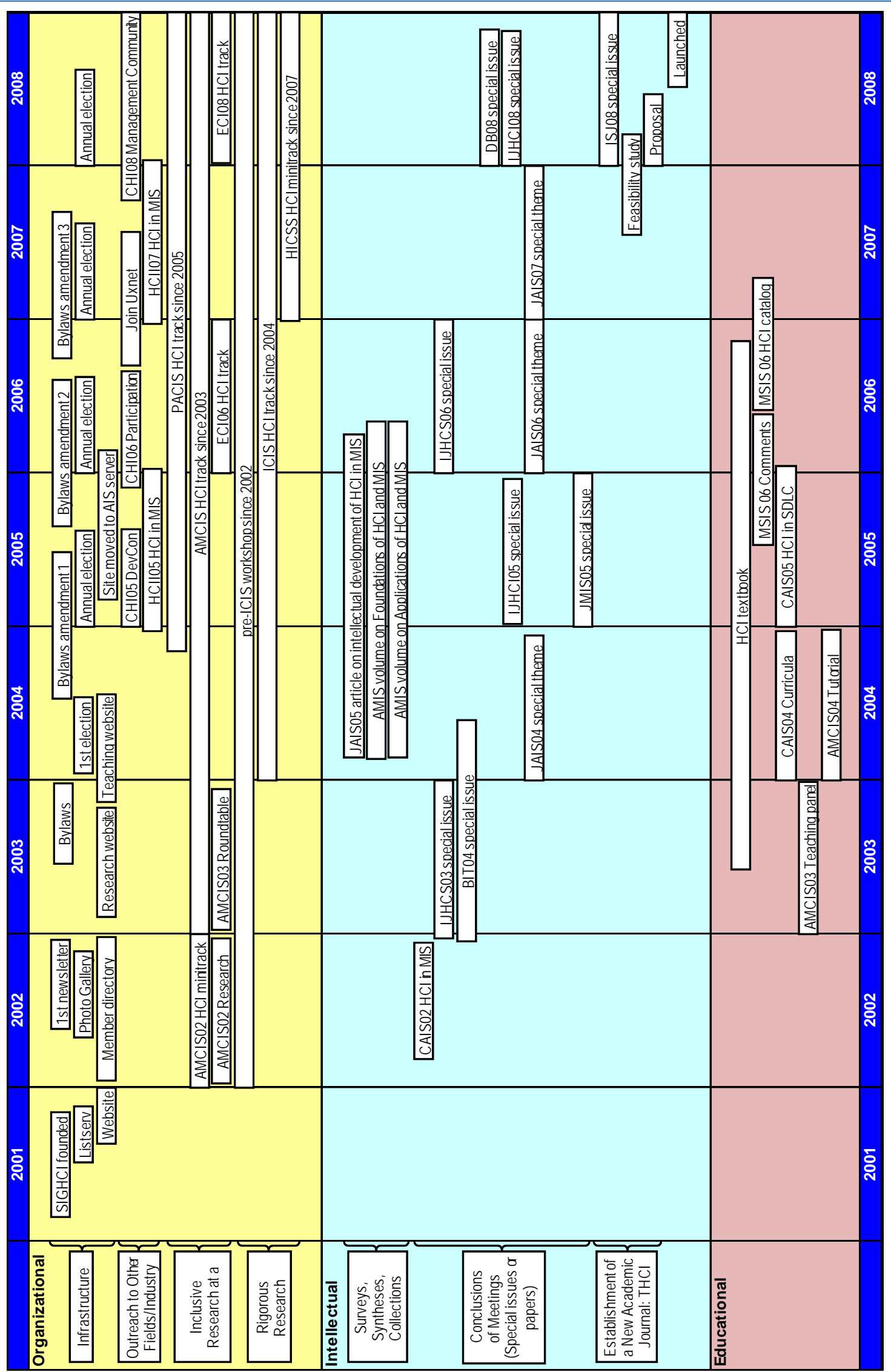

Figure 1: SIGHCI Sponsored Activities and Outcomes 
with those in Zhang and Li (2005), which covered from 1990 until 2002. Thus, our coverage period is expanded to 19 years (1990-2008), much longer than the normal length of time covered in this type of research (Chua, et al. 2003).

In this section we describe the article selection criteria and process, review the classification schemes with notes on whether certain classifications need to be adjusted to reflect new studies since 2002, depict the coding procedure, and present the reliability test. Readers interested in the development and justifications of the classification schemes should read Zhang and Li ( 2005).

\section{Journal and Article Selections}

Our journal selection criteria are similar to those in Zhang and Li's 2005 paper. That is, we continue to cover the seven primary MIS journals in this study: Management Information Systems Quarterly (MISQ), Information Systems Research (ISR), Journal of Management Information Systems (JMIS), Management Science (MS), Decision Sciences (DS), The Data Base for Advances in Information Systems (DB), and Journal of the Association for Information Systems (JAIS). Among these journals, Management Science and Decision Sciences are not primarily IS journals; they have IS departments within the journals but also publish research articles in other areas such as management, decision science, and operations research, to name a few. These journals are included because they have published a good amount of $\mathrm{HCl}$ research from IS scholars, especially when there was a limited number of outlets for such research. In fact, as will be demonstrated in answering research question RQ4.1 (Figure 17 in particular), a very high\%age of published IS articles in DS and $\mathrm{MS}$ are $\mathrm{HCl}$ articles, making these journals important outlets for $\mathrm{HCl}$ research. One additional MIS journal included in this study is the Communications of the Association for Information Systems (CAIS). Similar to JAIS, CAIS is a young journal and was founded in 1999 as a communications vehicle for the Association for Information Systems. Over the years, CAIS has published a large number of papers. Although CAIS is designed as the communications journal for AIS, among the many published papers are research articles that went through a rigorous review process and have been well cited. CAIS has been ranked highly consistently among IS scholars (Mylonopoulos and Theoharakis 2001; Peffers and Tang 2003; Rainer and Miller 2005), making it one of the important research resources in the IS field. In particular, CAIS has been very supportive of $\mathrm{HCI}$ research and has functioned as an effective outlet for $\mathrm{HCl}$ scholars and $\mathrm{SIGHCl}$ during its early years. Thus, it is reasonable to include CAIS in this study. We acknowledge that there are other important IS journals that can be included for the study. For example, in recent years, AIS announced a basket of six journals as top IS journals (MISQ, ISR, JMIS, JAIS, Information Systems Journal, and European Journal of Information Systems), especially for promotion and tenure evaluation purposes. Four of these six journals are included in this study. Because of their strategic focus, we excluded Information Systems Journal (ISJ) and European Journal of Information Systems (EJIS) from this study.

Additional inclusions are the special issues in various journals that are sponsored by $\mathrm{SIGHCl}$, and all the chapters in two edited books on $\mathrm{HCl}$ in MIS in the Advances in MIS series. Since 2003, SIGHCI has fast-tracked expansions of the best complete papers from all of its sponsored conference sessions, workshops, tracks or mini-tracks to various $\mathrm{HCl}$ and MIS journals. Up to 2008, a total of 11 such special issues have been published in the following journals: International Journal of Human-Computer Studies (IJHCS, 2003, 2006), Behaviour and Information Technology (BIT, 2004), International Journal of Human-Computer Interaction (IJHCl, 2005, 2008), JAIS (2004, 2006-2007, 2008), JMIS (2005), Information Systems Journal (ISJ, 2008), and DB (2008). Two edited books of $\mathrm{HCl}$ research in MIS (Galletta and Zhang 2006; Zhang and Galletta 2006) were published in 2006. These two books contained a total of 37 chapters that were authored by some of the most well-known and respected scholars in the field. These articles addressed timely topics and were intended to guide research in the $\mathrm{HCl}$ sub-discipline; thus, they add significant contributions to the current state of the sub-discipline and have strong research implications. Similar to journal articles, these chapters went through a rigorous peer review process including multiple rounds of revisions. Therefore, we feel that the works published in these books are legitimate inclusions in this paper.

The 337 papers in the previous study by Zhang and Li (2005) are included in this study. We selected new papers using the same two-step process. The first step was to form a pool of all IS research articles published in the eight MIS journals. Among these journals, six are mainly IS journals: MISQ, ISR, JMIS, DB, JAIS, and CAIS. Thus, we considered all research articles published in these journals as IS articles. For Management Science and Decision Sciences, only IS articles were considered. The pool of candidate articles excludes editorial introductions, editorial notes, executive summaries, book reviews, dissertation abstracts, letters, and announcements. We included Issues and Opinion articles only if they were closely related to research.

In the second step, we formed a pool of $\mathrm{HCl}$ articles from the IS article pool discussed above, plus all the research articles in the special issues and all the articles in the two volumes of AMIS books. An $\mathrm{HCl}$ paper should address one or more human-computer interaction issue (Zhang and Li 2005). A paper was excluded if: (1) it was about pure system design or development methods or processes without linking to human considerations; (2) it was concerned with group support systems but did not approach it from a human perspective either at the individual or group level; or (3) it was purely concerned with the personnel or human resource management issues related to IT.

We then coded each paper in the $\mathrm{HCl}$ pool according to the classification schemes to be reviewed below. During the 
coding process, each paper was evaluated again for its relevance to $\mathrm{HCl}$. As a result, we included 421 additional $\mathrm{HCl}$ articles, making a total of 758 articles for the final analysis in this study. Appendix A provides a list of these 758 articles by sources.

\section{Classification for Context}

Context refers to the setting or environment where a study is conducted, and for this paper we considered only the immediate context. The following six contexts are applicable for examining $\mathrm{HCl}$ studies (Table 2).

\section{Table 2: Context Classification Scheme}

\begin{tabular}{c|l}
\hline A & $\begin{array}{l}\text { Organizational or workplace setting. This also includes colleges or universities if students are subjects and the tasks are related to } \\
\text { their studies or schoolwork }\end{array}$ \\
\hline B & Market place, where commerce, banking, and marketing take place \\
\hline C & Home setting, where issues such as home PC adoption and use behavior are examined \\
\hline D & $\begin{array}{l}\text { Social environment, which differs from the former three categories in that it refers to a general setting in a less organizationally } \\
\text { constrained environment. For example, studies on online communities tend to be conducted in a social setting }\end{array}$ \\
\hline E & $\begin{array}{l}\text { Cultural, national, and geographical context if such are specifically concerned in studies. A good example of this category would be } \\
\text { a cross-culture /cross-nation study of IT acceptance or the relationship between email use and Japanese character input method }\end{array}$ \\
\hline F & Other context for those papers whose contexts do not fit in any of the above five \\
\hline
\end{tabular}

\section{Classification for Level of Analysis}

Level of analysis refers to the level at which data are collected and analyzed, or main issues and discussions are addressed. Our assessment on level of analysis includes individual and group. Examples of analysis at the individual level can be those relevant to cognitive styles, individual reactions toward IT, and individual productivity or performance related to IT. Group performance in decision-making and group member conflict/agreement are typical topics for analysis at the group level. Analyses might also be conducted at both individual and group levels.

\section{Classification for Individual Characteristics}

Individual characteristics refer to individual differences in two categories: the predetermined disposition or personality and the demographics of individuals. Table 3 details the individual characteristics considered in this study. Typically, if these characteristics are covered in the articles, they are used as independent variables or moderating factors, although there are some situations where personality traits or other individual factors are the targets or dependent variables of the studies (Agarwal and Prasad 1998; Webster and Martocchio 1992).

\section{Table 3: Individual Characteristics Classification Scheme}

\begin{tabular}{l|l|l}
\hline A & Disposition/personality & $\begin{array}{l}\text { Personality, affective trait, cognitive style (e.g. visual vs. verbal oriented, } \\
\text { field dependent/independent), locus of control, learning style }\end{array}$ \\
\hline B & Demographics & $\begin{array}{l}\text { Age, gender, education, cultural background, experience, knowledge, } \\
\text { socioeconomic status }\end{array}$ \\
\hline
\end{tabular}

\section{Classification for Topic}

Zhang and Li (2005) presented a topic classification scheme that has proven to be adequate for examining $\mathrm{HCl}$ studies in the MIS field up to 2002. In this paper, we reuse Zhang and Li's classification scheme to reflect the unique interest IS scholars have in $\mathrm{HCl}$. IS/ $\mathrm{HCl}$ researchers are not particularly interested in humans per se, which would be the interest of psychologists, and they are not particularly interested in artifacts per se either, which would engage computer scientists. IS/HCl researchers apply a unique perspective to study humans interacting with technologies in certain contexts. One way of classifying related research topics would be to consider the human interactions or human interventions during the lifecycle of an IT artifact. The IT artifact lifecycle can be divided into two main stages: during IT development and after IT development (Whitten et al. 2004). In the MIS literature, issues occurring during IT development include programmer or analyst cognition studies, user participation, user-analyst interaction, and information presentation designs and evaluation, to name a few. This is the Design stage. In the topic classification scheme, the phase "IT Development" is used to cover a broad range of issues related to the development stage. After development, IT is used in real contexts, and has impacts on individuals, groups, organizations, and societies. This is 
the Use and Impact stage. There are many MIS issues arising during this stage, such as an individual's reactions toward technology, IT use behavior and attitude, trust, user satisfaction, and group task performance or conflict, to name a few.

Table 4 represents the topic classification scheme, which reflects the issues during and after development discussed above. Within each stage, we further categorized the topics into various aspects. As in several existing literature assessment studies, we included one broad category to classify articles that are concerned with general research issues such as future research directions, methodology, or education-related issues. The topic classification scheme in Table 4 has proven to be able to reflect the topical coverage of the $\mathrm{HCl}$ studies during the 19 years.

Two points are worthy of mention. First, Motivation (B04) was in the original coding scheme for topics (Zhang and Li 2005). Since very few empirical studies addressed motivational concerns during 1990-2002, this code was dropped from the final result in the Zhang and Li 2005 paper. In this study, there are more empirical articles addressing motivational concerns. Thus, we have reintroduced the code and reapplied it to those applicable articles from 19902002. Second, as more studies on education-related matters have emerged, we have created a sub-category under $\mathrm{C}$ to consider those papers that detail Education.

\section{Table 4: Topic Classification Scheme}

\begin{tabular}{|c|c|c|c|}
\hline ID & & Category & Description and Examples \\
\hline \multirow[t]{8}{*}{$A$} & & IT Development & $\begin{array}{l}\text { Concerned with issues that occur at the stage of IT development and/or implementation that are relevant to the } \\
\text { relationship between human and technology. Focus on the process where IT is developed or implemented. The } \\
\text { artifact is being worked on before actual use. }\end{array}$ \\
\hline & A01 & $\begin{array}{l}\text { Development methods and } \\
\text { tools }\end{array}$ & $\begin{array}{l}\text { Structured approaches, Object-oriented approaches, CASE tools, Social-cognitive approaches for developing IT } \\
\text { that consider users/lT personnel's roles. }\end{array}$ \\
\hline & A02 & User analyst involvement & User involvement, User participation, User-analyst difference, User-analyst interaction \\
\hline & A03 & $\begin{array}{l}\text { Software/hardware } \\
\text { development }\end{array}$ & $\begin{array}{l}\text { Programmer/analyst cognition studies, Design and development of specific or general applications or devices } \\
\text { that consider some human aspects }\end{array}$ \\
\hline & A04 & Software/hardware evaluation & $\begin{array}{l}\text { System effectiveness, efficiency, quality, reliability, flexibility, and Information quality evaluations that consider } \\
\text { people as part of the factors. }\end{array}$ \\
\hline & A05 & $\begin{array}{l}\text { User interface design \& } \\
\text { development }\end{array}$ & Interface metaphors, Information presentations, multimedia \\
\hline & A06 & User interface evaluation & $\begin{array}{l}\text { Instrumental usability (e.g. ease of use, error rate, ease of learning, retention rate, satisfaction), Accessibility, } \\
\text { Information presentation evaluation }\end{array}$ \\
\hline & A07 & User training & User training issues during IT development (prior product release or use) \\
\hline \multirow[t]{12}{*}{$B$} & & IT Use and Impact & $\begin{array}{l}\text { Concerned with issues that occur when humans use and/or evaluate IT; issues related to the reciprocal } \\
\text { influences between IT and humans. The artifact is released and in use in real context. }\end{array}$ \\
\hline & B01 & Cognitive belief and behavior & $\begin{array}{l}\text { Self-Efficacy, Perception, Belief, Cognition, Mental process, Incentives, Expectation, Intention, Behavior, } \\
\text { Acceptance, Adoption, Resistance, Use }\end{array}$ \\
\hline & B02 & Attitude & Attitude, Satisfaction, Preference \\
\hline & B03 & Learning & $\begin{array}{l}\text { Learning models, Learning processes, Training in general (different from user training as part of system } \\
\text { development) }\end{array}$ \\
\hline & B04* & Motivation & Motivation (intrinsic, extrinsic), Expectancy, Incentives \\
\hline & B05 & Emotion & Emotion, Affect, Hedonic quality, Flow, Enjoyment, Humor, Intrinsic motivation \\
\hline & B06 & Performance & Performance, Productivity, Effectiveness, Efficiency \\
\hline & B07 & Trust & Trust, Risk, Loyalty, Security, Privacy \\
\hline & B08 & Ethics & Ethical belief, Ethical behavior, Ethics \\
\hline & B09 & Interpersonal relationship & Conflict, Interdependence, Agreement/Disagreement, Interference, Tension, Leadership, Influence, Norms \\
\hline & B10 & User support & Issues related to information center, end-user computing support, general user support \\
\hline & B11 & Other & \\
\hline \multirow[t]{3}{*}{$C^{*}$} & \multicolumn{2}{|c|}{ Generic Research Topics } & Concerned with general research or education issues and concerns \\
\hline & C01 & Research & \\
\hline & C02 & Education & \\
\hline
\end{tabular}

*slightly different from that in Zhang and Li (2005)

\section{Classification for Method}

At the highest level, the method framework distinguishes between empirical and non-empirical articles. The empirical articles capture the essence of research relying on observation and are further classified into those that describe objects and those that describe events or processes. Non-empirical articles are those that are primarily based on ideas, frameworks, and speculation rather than on systematic observation. Table 5 provides descriptions of method classification and some specific examples from the papers collected for this study. 
Table 5: Method Classification Scheme

\begin{tabular}{|c|c|c|}
\hline ID & Category Name and Description & Examples of $\mathrm{HCl}$ Papers \\
\hline 1 & Non-Empirical & \\
\hline 1.1 & Conceptual Orientation & \\
\hline 1.1.1 & $\begin{array}{l}\text { Frameworks: Proposes a framework for defining the content and scope of } \mathrm{HCl} \text { in an MIS context, and provides } \\
\text { directions. }\end{array}$ & \\
\hline 1.1.2 & $\begin{array}{l}\text { Conceptual model of a process or structure: presents an integrated, schematic representation of an } \mathrm{HCl} \text { - } \\
\text { related process, structure, behavior, activity, organization, method, etc. }\end{array}$ & $\begin{array}{l}\text { (Orlikowski and lacono 2001), } \\
\text { (Zigurs and Buckland 1998) }\end{array}$ \\
\hline 1.1 .3 & $\begin{array}{l}\text { Conceptual overviews of ideas, theories, concepts, etc.: contains an overview of many concepts or theories in } \\
\text { one or more areas, and does not propound or support any individual theory, idea, or approach. }\end{array}$ & \begin{tabular}{|l|}
$\begin{array}{l}\text { (Gerlach and Kuo 1991), } \\
\text { (Melone 1990) }\end{array}$ \\
\end{tabular} \\
\hline 1.1.4 & $\begin{array}{l}\text { Theory from reference disciplines: presents theory or theories drawn from outside the } \mathrm{HCl} \text { sub-discipline but } \\
\text { applied within an } \mathrm{HCl} \text { context }\end{array}$ & \\
\hline 1.2 & Illustration & \\
\hline 1.2 .1 & $\begin{array}{l}\text { Opinion (pure, or supported by examples): gives advice and guidance for practice, in the form of rules and } \\
\text { recommendations, steps or procedures to be followed, hints and warnings, etc. May be supported by } \\
\text { examples and applications. }\end{array}$ & $\begin{array}{l}\text { (Silver 1991), (Hawk and Raju } \\
\text { 1991) }\end{array}$ \\
\hline 1.2 .2 & $\begin{array}{l}\text { Opinion (supported by personal experiences): as for 1.2.1., but also describes the author's experience in some } \\
\text { relevant context. }\end{array}$ & \\
\hline 1.2 .3 & $\begin{array}{l}\text { Description of a tool, technique, method, model, etc.: usually highly specific and detailed, as well as technically } \\
\text { or methodologically precise. }\end{array}$ & $\begin{array}{l}\text { (Tan and Hunter 2002), (Gordon } \\
\text { and Moore 1999) }\end{array}$ \\
\hline 1.3 & Applied Concepts & \\
\hline 1.3 .1 & $\begin{array}{l}\text { Conceptual frameworks and applications: contains both conceptual and illustrative elements. May present } \\
\text { some concept or framework and then describe an application of it. }\end{array}$ & (Vessey 1991), (Te'eni 2001) \\
\hline 2 & Empirical & \\
\hline 2.1 & Objects & \\
\hline 2.1 .1 & Descriptions of types or classes of products, technologies, systems, etc. & \\
\hline 2.1.2 & Descriptions of a specific application, system, installation, program, etc. & $\begin{array}{l}\text { (Chen 1995), (Shibata, et al. } \\
\text { 1997) }\end{array}$ \\
\hline 2.2 & Events/process & \\
\hline 2.2 .1 & $\begin{array}{l}\text { Lab experiment: manipulates independent variable; controls for intervening variables; conducted in controlled } \\
\text { settings. }\end{array}$ & \begin{tabular}{|l|} 
(Zhang 2000), (Morris, et al. \\
1999)
\end{tabular} \\
\hline 2.2 .2 & Field experiment: as for lab experiment, but in a natural setting of the phenomenon under study. & $\begin{array}{l}\begin{array}{l}\text { (Hunton 1996), (Webster and Ho } \\
\text { 1997) }\end{array} \\
\end{array}$ \\
\hline 2.2 .3 & $\begin{array}{l}\text { Field study: No manipulation of independent variables, involves experimental design but no experimental } \\
\text { controls, is carried out in the natural settings of the phenomenon of interest. }\end{array}$ & $\begin{array}{l}\text { (Barki and Hartwick 1994), (Lee, } \\
\text { et al. 1995) }\end{array}$ \\
\hline 2.2 .4 & $\begin{array}{l}\text { Positivist case study: investigates one or a few cases in detail from a positivist perspective, assumes an } \\
\text { objective reality existing independent of humans, may involve hypothesis testing to discover the reality. }\end{array}$ & $\begin{array}{l}\text { (Hitt and Frei 2002), (Lawrence } \\
\text { and Low 1993) }\end{array}$ \\
\hline 2.2 .5 & $\begin{array}{l}\text { Interpretive case study: studies one or a few cases from an interpretive perspective, assumes interactions } \\
\text { between researchers and the phenomenon under investigation, attempts to understand the phenomenon } \\
\text { through assessing meanings. }\end{array}$ & $\begin{array}{l}\text { (Kawalek and Wood-Harper } \\
\text { 2002), (Davidson 2002) }\end{array}$ \\
\hline 2.2 .6 & Action research & \\
\hline 2.2 .7 & Survey: Involves large numbers of observations with no manipulations of variables. & $\begin{array}{l}\text { (Compeau, et al. 1999), (Carr } \\
\text { 2002) }\end{array}$ \\
\hline 2.2 .8 & $\begin{array}{l}\text { Development of instruments: description of development of instrument/measurement or classification scheme, } \\
\text { validation of instruments. }\end{array}$ & $\begin{array}{l}\text { (Gefen 2002), (McKinney, et al. } \\
\text { 2002) }\end{array}$ \\
\hline 2.2 .9 & $\begin{array}{l}\text { Ex-post description of some project or event: interest in reporting the results of the project develops after the } \\
\text { project is complete (or is partially complete) }\end{array}$ & \\
\hline 2.2.10 & $\begin{array}{l}\text { Secondary data: Uses data from secondary sources, i.e., data collected by sources other than the } \\
\text { researchers. }\end{array}$ & $\begin{array}{l}\text { (Dennis, et al. 2001), (Beath and } \\
\text { Orlikowski 1994) }\end{array}$ \\
\hline 2.2.11 & Interview: conducted on an individual basis. & \begin{tabular}{|l|}
$\begin{array}{l}\text { (Srinivasan and Te'eni 1995), } \\
\text { (Geissler, et al. 2001) }\end{array}$ \\
\end{tabular} \\
\hline 2.2.12 & Delphi study (evolving and iterative developing surveys) & \begin{tabular}{|l|} 
(Nambisan, et al. 1999), \\
(Conrath and Sharma 1992)
\end{tabular} \\
\hline 2.2.13 & Focus group & $\begin{array}{l}\text { (Geissler, et al. 2001), (Kekre, et } \\
\text { al. 1995) }\end{array}$ \\
\hline 2.2.14 & Other & \\
\hline
\end{tabular}




\section{Classification for Technology or Service}

Zhang and Li (2005) classified technologies into two groups: end-user computing technologies and organizational computing technologies. The former supports individual needs such as productivity and communication, while the latter supports organizational functions, usually centralized or across organizations, and sometimes in group settings. Besides technologies, services have become a focus of inquiry during recent years, owing to the shift of IS/IT departments' responsibilities in some organizations and Internet-based services. During this study, we found that this classification is still applicable, in general, yet some technologies might be better considered social computing technology, as they support society or community functions and characteristics. Thus, we changed the second category into Organizational or Social Computing. The classification scheme is shown in Table 6.

Table 6: Classification Scheme for IT and Service

\begin{tabular}{|c|c|c|}
\hline ID & Category & Description and Example \\
\hline$T A$ & End User Computing & Mainly supporting individual needs such as communication and productivity \\
\hline TA1 & Individual communication & email, voice mail, instant messaging (IM), chat rooms \\
\hline TA2 & Individual productivity & MS office suites, word processors, presentation software, spreadsheets, GUls, windows, linux \\
\hline TA3* & Web & World Wide Web (WWW), specific websites \\
\hline TA4 & Other & Digital libraries, personal assistants, mobile devices, PCs, or others that belong to end-user computing \\
\hline$T B^{\star}$ & Organization or Social Computing* & Mainly supporting organizational or social functions and reflecting organizational or social characteristics or nature \\
\hline TB1 & Group/org communication & Listservs, BBS's, audio/video conferencing, LANs, Intranet, telecommuting \\
\hline TB2 & DSS & $\begin{array}{l}\text { DSS, EIS, Intelligent systems, expert systems, knowledge systems and repositories that support people's } \\
\text { productivity }\end{array}$ \\
\hline TB3 & MIS & $\begin{array}{l}\text { ERP, MIS, organizational database systems to support organization productivity. Community database systems to } \\
\text { support community functions }\end{array}$ \\
\hline TB4 & CSCW, GDSS & Mainly for supporting group productivity and performance \\
\hline TC & Service & Internet service, Information center \\
\hline
\end{tabular}

\section{Classification for Contributing Disciplines}

Contributing disciplines refer to the disciplines that support or contribute to the development of research questions, theories, models, and hypotheses. Thus, not all references in a paper should be counted toward contributing disciplines. Zhang and Li (2005) used the Research Fields, and Courses and Disciplines Classification (RFCD 2002), which was developed for higher education study programs and sponsored research funding purposes. RFCD 2002 is sponsored by the Australian Research Council. It has a comprehensive coverage of 24 divisions/fields, 139 disciplines and 898 subjects. To illustrate the RFCD codes, Table 7 lists the 24 divisions, the disciplines inside the 280000 division, and the subjects inside the 280100 discipline. Although there are efforts to develop new codes to replace RFCD, to maintain consistency with the coding in Zhang and Li, we have decided to keep the same discipline scheme. In coding the papers for our study, we focused only on the disciplinary level, not the subject level, although we used subjects to justify a discipline when necessary. A discipline $D$ is considered a contributing discipline for article A only if one or more referenced papers used in A (a subset of the entire set of references of A) support the conceptual and theoretical development of the study in A and address issues rooted in discipline D.

\section{Classification Procedure and Coding Reliability}

As in the previous work by Zhang and Li (2005), we allow each of the seven facets to have multiple codes assigned to a single paper if they are all primarily important in the study (such as multiple research topics, multiple research methods, etc.). The coding of these articles required an evaluation of textual material, making the raw agreement and inter-rater reliability appropriate indicators in assessing the reliability of the coding results (Miles and Huberman 1994; Boudreau et al. 2001). In this study, to calculate inter-rater reliability, we consider each paper to have seven judgments (corresponding to the seven facets), although the actual code numbers can be higher due to multiple codes assigned to each facet. The raw agreement score is calculated at this facet level, even though each facet can have multiple values in a single paper. Such an agreement is a conservative estimate of inter-rater reliability.

Due to the workload of handling a large number of papers with seven facets for each paper, we decided to code the papers in the following way. We four authors formed two groups; each included a new coder and an experienced 
coder. The 421 new articles were divided into two sets, and each group handled one set of papers. For each group, a subset of articles (fewer than 10) was used for training purposes. Then raw-agreement scores were calculated for this subset. We discussed disagreements to reach consensus. The process was repeated for another subset of papers until the raw-agreement within the group reached $95 \%$ or higher. From this point on, each member coded a separate subset of the remaining papers. After each member finished his or her own subset, one experienced coder sampled several articles from each of the other three researchers' subsets and found that the lowest raw-agreement score was $92 \%$. This largely satisfied the acceptable inter-rater reliability level, which is normally $75 \%$ raw agreement. Given our raw agreement score is more conservative than the actual number of judgments involved, we are confident that our coding results have high reliability and validity.

\section{Table 7: The Research Field, Discipline, and Subject code (RFCD) - Partial List}

\begin{tabular}{|c|c|}
\hline $\begin{array}{l}\text { Broad Research } \\
\text { Fields/Divisions }\end{array}$ & $\begin{array}{l}230000 \text { MATHEMATICAL SCIENCES } \\
240000 \text { PHYSICAL SCIENCES } \\
250000 \text { CHEMICAL SCIENCES } \\
260000 \text { EARTH SCIENCES } \\
270000 \text { BIOLOGICAL SCIENCES } \\
280000 \text { INFORMATION, COMPUTING AND COMMUNICATION SCIENCES } \\
290000 \text { ENGINEERING AND TECHNOLOGY } \\
300000 \text { AGRICULTURAL, VETERINARY AND ENVIRONMENTAL SCIENCES } \\
310000 \text { ARCHITECTURE, URBAN ENVIRONMENT AND BUILDING } \\
320000 \text { MEDICAL AND HEALTH SCIENCES } \\
330000 \text { EDUCATION } \\
340000 \text { ECONOMICS } \\
350000 \text { COMMERCE, MANAGEMENT, TOURISM AND SERVICES } \\
360000 \text { POLICY AND POLITICAL SCIENCE } \\
370000 \text { STUDIES IN HUMAN SOCIETY } \\
380000 \text { BEHAVIOURAL AND COGNITIVE SCIENCES } \\
390000 \text { LAW, JUSTICE AND LAW ENFORCEMENT } \\
400000 \text { JOURNALISM, LIBRARIANSHIP AND CURATORIAL STUDIES } \\
410000 \text { THE ARTS } \\
420000 \text { LANGUAGE AND CULTURE } \\
430000 \text { HISTORY AND ARCHAEOLOGY } \\
440000 \text { PHILOSOPHY AND RELIGION }\end{array}$ \\
\hline $\begin{array}{c}\text { Disciplines for INFORMATION, } \\
\text { COMPUTING AND } \\
\text { COMMUNICATION SCIENCES } \\
(280000)\end{array}$ & $\begin{array}{l}280100 \text { INFORMATION SYSTEMS } \\
280200 \text { ARTIFICIAL INTELLIGENCE AND SIGNAL AND IMAGE PROCESSING } \\
280300 \text { COMPUTER SOFTWARE } \\
280400 \text { COMPUTATION THEORY AND MATHEMATICS } \\
280500 \text { DATA FORMAT } \\
289900 \text { OTHER INFORMATION, COMPUTING AND COMMUNICATION SCIENCES }\end{array}$ \\
\hline $\begin{array}{c}\text { Subjects for the } \\
\text { INFORMATION SYSTEMS } \\
\text { discipline (280100) }\end{array}$ & $\begin{array}{l}280101 \text { INFORMATION SYSTEMS ORGANISATION } \\
280102 \text { INFORMATION SYSTEMS MANAGEMENT } \\
280103 \text { INFORMATION STORAGE, RETRIEVAL AND MANAGEMENT } \\
280104 \text { COMPUTER-HUMAN INTERACTION } \\
280105 \text { INTERFACES AND PRESENTATION (EXCL. COMPUTER-HUMAN INTERACTION) } \\
280106 \text { INTERORGANISATIONAL INFORMATION SYSTEMS } \\
280107 \text { GLOBAL INFORMATION SYSTEMS } \\
280108 \text { DATABASE MANAGEMENT } \\
280109 \text { DECISION SUPPORT AND GROUP SUPPORT SYSTEMS } \\
280110 \text { SYSTEMS THEORY } \\
280111 \text { CONCEPTUAL MODELLING } \\
280112 \text { INFORMATION SYSTEMS DEVELOPMENT METHODOLOGIES } \\
280199 \text { INFORMATION SYSTEMS NOT ELSEWHERE CLASSIFIED }\end{array}$ \\
\hline
\end{tabular}

\section{ANALYSES AND RESULTS}

This section presents analyses and results, organized around the research questions (see Table 1). Within each of the five mega-research questions, we present the answers to the specific questions. To address RQ1 and its specific questions, we present aggregated data showing any trends of movement over three periods of time: 1990-1995, 1996-2002, and 2003-2008. These periods correspond to some significant events in the field that created profound impact on research in the sub-discipline. For example, studies on the World Wide Web (available in 1994) began being published in 1996; the first special issue sponsored by the AIS SIGHCI was published in 2003. 


\section{RQ1: What Constitutes the Intellectual Substance?}

\section{RQ1.1: What are the contexts of studies?}

Table 8 summarizes the frequencies of various contexts employed in the collected studies. Among the 758 papers, 671 or $88 \%$ considered one context, 32 or $4 \%$ considered two contexts, three papers considered three contexts, and 52 or nearly $7 \%$ had no context specified in their studies. The last column indicates among all 758 papers, the percentage of papers considering a particular context or a combination of contexts. For example, $62.3 \%$ of the 758 papers consider organization and workplace as the only context of study.

The predominant context was organizations and workplace, considered by about $66 \%$ of papers (all rows of Table 8 that contain A, that is, $62.3 \%+1.7 \%+0.5 \%+0.9 \%+0.5 \%+0.1 \%+0.3 \%)$. This is consistent with the nature of most IS studies being situated in the organizational and workplace context. The second most dominant setting was the marketplace, considered by about $21 \%$ of the papers. This is also consistent with the overall IS focus on firms and their profit concerns. The low frequencies of other settings indicate that IS researchers paid much less attention to issues that are relevant to contexts such as home, social environment, and cultural/geographical settings. The frequency of no-context studies (56 or $7 \%$ of the articles) ranks third in Table 8 , right after the marketplace. It is a bit surprising to see that studies with no particular context specified could get published in high quality MIS journals. Social context has started to attract research interest since 1997, and has been steadily increasing since 2004 , though the total number of papers considering this context is still small.

\section{Table 8: Frequency of Contexts}

\begin{tabular}{|c|c|c|c|c|c|c|c|c|c|c|c|c|c|c|c|c|c|c|c|c|c|c|}
\hline & & 90 & 91 & 92 & 93 & 94 & 95 & 96 & 97 & 98 & 99 & 00 & 01 & 02 & 03 & 04 & 05 & 06 & 07 & 08 & Total & $\begin{array}{c}\% \text { by no. } \\
\text { papers }\end{array}$ \\
\hline A & $\begin{array}{l}\text { Organization, } \\
\text { work place }\end{array}$ & 17 & 15 & 15 & 13 & 25 & 30 & 29 & 27 & 22 & 21 & 19 & 27 & 13 & 39 & 26 & 29 & 44 & 23 & 41 & 475 & $62.3 \%$ \\
\hline B & Market place & & 1 & & 2 & & 1 & 1 & & 2 & 1 & 1 & 4 & 14 & 5 & 16 & 16 & 30 & 22 & 27 & 143 & $18.8 \%$ \\
\hline C & Home & & & & & & & & & & 1 & & 1 & & & 2 & 1 & & & & 5 & $0.7 \%$ \\
\hline D & Social & & & & & & & & 1 & & 1 & 1 & 1 & & & 3 & 4 & 6 & 6 & 9 & 32 & $4.2 \%$ \\
\hline E & $\begin{array}{l}\text { Cultural, } \\
\text { national, geo. }\end{array}$ & & & & & 1 & & & & 1 & & & & & & & 2 & 1 & 3 & 1 & 9 & $1.2 \%$ \\
\hline $\mathrm{F}$ & Other & & & & & & & & & & 2 & 2 & 2 & & & & & & 1 & & 7 & $0.9 \%$ \\
\hline$A, B$ & & & & & & & & & & 1 & & & & & 2 & 2 & 1 & 3 & & 4 & 13 & $1.7 \%$ \\
\hline$A, D$ & & & & & & & & & 1 & & & & 1 & & & & 1 & & & 1 & 4 & $0.5 \%$ \\
\hline $\mathrm{A}, \mathrm{E}$ & & & & & & & & & & 1 & & 1 & & & & & & 5 & & & 7 & $0.9 \%$ \\
\hline$A, F$ & & & & & & & & & & & & & & 3 & 1 & & & & & & 4 & $0.5 \%$ \\
\hline$B, D$ & & & & & & & & & & & & & & & & & & 1 & & & 1 & $0.1 \%$ \\
\hline $\mathrm{B}, \mathrm{E}$ & & & & & & & & & & & & 1 & & & & & & 1 & & & 2 & $0.3 \%$ \\
\hline$D, E$ & & & & & & & & & & & & & & & & & & 1 & & & 1 & $0.1 \%$ \\
\hline$A, B, D$ & & & & & & & & & & & & & & 1 & & & & & & & 1 & $0.1 \%$ \\
\hline$A, B, E$ & & & & & & & & & & & & & & & & & & 2 & & & 2 & $0.3 \%$ \\
\hline \multirow[t]{2}{*}{ Blank } & No context & 2 & 5 & 1 & 3 & & & & 3 & 1 & 2 & & 1 & 2 & 1 & & 2 & 20 & 7 & 2 & 52 & $6.8 \%$ \\
\hline & Total & 19 & 21 & 16 & 18 & 26 & 31 & 30 & 32 & 28 & 28 & 25 & 37 & 33 & 48 & 49 & 56 & 114 & 65 & 86 & 758 & \\
\hline
\end{tabular}

\section{RQ1.2: What are the research areas or subject topics?}

Table 9 summarizes the frequencies of topics from 1990 - 2008. We draw the following observations from the table:

1. Among the 1,974 times all the 20 topics were studied, the most dominant topics fell within the IT Use and Impact category (83.3\% of the overall topics studied). About $12.2 \%$ of the topics fell in the category of IT development. Only $4.6 \%$ of the topics addressed issues surrounding research or education.

2. The percentage of papers considering each particular topic is represented by "\% by \# of papers" (the last column) in Table 9 . It shows that $61.7 \%$ of the articles addressed Cognitive belief and behavior (B01), followed by $35.9 \%$ on Attitude (B02), $35.1 \%$ on Performance and productivity (B06), $19.5 \%$ on Motivation (B04), and $14.4 \%$ on Trust (B07), all within the IT Use and Impact category. User Interface design and 
development (A05) was the most studied topic in the IT Development area, involving $7.1 \%$ of the papers, followed by User interface evaluation (A06, 6.7\% of the papers). The other two relatively well-studied topics within this category were Software/hardware development with human considerations (A03, 5.3\%) and User analyst involvement (A02, 5 \%). In Generic Topics, Research and Education issues were studied in $9.9 \%$ of the papers.

3. All topics are currently active in the literature, although some are much more active than others. For example, Development methods and tools (A01), Software/Hardware evaluation (A04), User training (A07), Ethics (B08), User Support (B10), and Education (C02) are less active than other topics. Several topics, such as Motivation (B04), Trust (B07), and Ethics (B08), did not start until about the mid-90's, and have gradually gained more attention during recent years.

Table 9: Frequency of Topics

\begin{tabular}{|c|c|c|c|c|c|c|c|c|c|c|c|c|c|c|c|c|c|c|c|c|c|c|c|}
\hline & & 90 & 91 & 92 & 93 & 94 & 95 & 96 & 97 & 98 & 99 & 00 & 01 & 02 & 03 & 04 & 05 & 06 & 07 & 08 & Total & $\begin{array}{l}\% \text { by \# } \\
\text { topics }\end{array}$ & $\begin{array}{l}\% \text { by \# } \\
\text { papers }\end{array}$ \\
\hline$A$ & IT Development & 7 & 7 & 7 & 8 & 11 & 8 & 11 & 12 & 14 & 6 & 3 & 8 & 11 & 9 & 10 & 23 & 31 & 19 & 13 & 218 & $12.2 \%$ & \\
\hline $\mathrm{A} 01$ & Dev. methods \& tools & & & & & 1 & & & 1 & 1 & & & & 1 & 1 & 2 & 3 & 2 & 1 & & 13 & $0.7 \%$ & $1.7 \%$ \\
\hline $\mathrm{A} 02$ & User analyst involvement & 2 & 1 & & 1 & 6 & 1 & 3 & 4 & 3 & & & 1 & 3 & & 2 & 2 & 5 & 2 & 2 & 38 & $2.1 \%$ & $5.0 \%$ \\
\hline $\mathrm{A} 03$ & SW/HW development & 2 & 2 & & 4 & & 5 & 5 & 2 & 3 & 3 & & & 1 & & & 3 & 5 & 2 & 3 & 40 & $2.2 \%$ & $5.3 \%$ \\
\hline A04 & SW/HW evaluation & & & 1 & & & & 1 & 1 & & & & & & & & 1 & 2 & 1 & & 7 & $0.4 \%$ & $0.9 \%$ \\
\hline A05 & User interface design \& dev. & 1 & 3 & 1 & & 1 & 1 & 1 & & 2 & 2 & 1 & 2 & 2 & 4 & 5 & 7 & 10 & 7 & 4 & 54 & $3.0 \%$ & $7.1 \%$ \\
\hline A06 & User interface evaluation & 2 & 1 & 3 & 2 & 2 & 1 & & 4 & 5 & 1 & 2 & 4 & 4 & 1 & 1 & 5 & 6 & 5 & 2 & 51 & $2.8 \%$ & $6.7 \%$ \\
\hline $\mathrm{A} 07$ & User training & & & 2 & 1 & 1 & & 1 & & & & & 1 & & 3 & & 2 & 1 & 1 & 2 & 15 & $0.8 \%$ & $2.0 \%$ \\
\hline$B$ & IT Use \& Impact & 29 & 29 & 22 & 20 & 33 & 41 & 34 & 40 & 34 & 42 & 46 & 67 & 45 & 121 & 125 & 143 & 246 & 137 & 240 & 1494 & $83.3 \%$ & \\
\hline B01 & Cognitive beliefs \& behavior & 8 & 11 & 10 & 9 & 12 & 14 & 13 & 13 & 11 & 12 & 21 & 21 & 17 & 35 & 35 & 42 & 80 & 36 & 68 & 468 & $26.1 \%$ & $61.7 \%$ \\
\hline B02 & Attitude & 7 & 10 & 4 & 3 & 10 & 12 & 5 & 8 & 5 & 8 & 3 & 14 & 10 & 22 & 22 & 26 & 37 & 27 & 39 & 272 & $15.2 \%$ & $35.9 \%$ \\
\hline B03 & Learning & 3 & 1 & 3 & & 4 & 2 & 4 & 5 & & 4 & 2 & 5 & 4 & 3 & 2 & 3 & 7 & 3 & 8 & 63 & $3.5 \%$ & $8.3 \%$ \\
\hline B04 & Motivation & & & & & & 1 & 1 & 2 & 2 & 2 & 2 & 3 & 2 & 18 & 13 & 21 & 25 & 22 & 34 & 148 & $8.2 \%$ & $19.5 \%$ \\
\hline B05 & Emotion & 1 & 1 & 1 & & & 2 & 1 & 3 & 2 & 1 & 3 & 2 & 3 & 5 & 7 & 7 & 18 & 4 & 9 & 70 & $3.9 \%$ & $9.2 \%$ \\
\hline B06 & Performance & 7 & 4 & 3 & 7 & 3 & 8 & 6 & 8 & 10 & 8 & 9 & 16 & 2 & 21 & 22 & 23 & 41 & 27 & 41 & 266 & $14.8 \%$ & $35.1 \%$ \\
\hline B07 & Trust & & & & 1 & & & 1 & & 2 & 1 & 1 & 1 & 5 & 7 & 13 & 10 & 31 & 9 & 27 & 109 & $6.1 \%$ & $14.4 \%$ \\
\hline B08 & Ethics & & & & & & & 1 & & 1 & 2 & & 1 & & 1 & & & 1 & 3 & 1 & 11 & $0.6 \%$ & $1.5 \%$ \\
\hline B09 & Interpersonal relationship & 2 & 1 & & & 1 & 2 & 1 & 1 & 1 & 2 & 4 & 4 & 1 & 8 & 9 & 11 & 6 & 6 & 13 & 73 & $4.1 \%$ & $9.6 \%$ \\
\hline B10 & User support & 1 & 1 & 1 & & 3 & & 1 & & & 2 & 1 & & 1 & & 2 & & & & & 13 & $0.7 \%$ & $1.7 \%$ \\
\hline B11 & Other & & & & & & & & & & & & & & 1 & & & & & & 1 & $0.1 \%$ & $0.1 \%$ \\
\hline C & Generic Topics & 1 & 2 & 0 & 1 & 1 & 2 & 2 & 3 & 3 & 4 & 1 & 2 & 3 & 6 & 5 & 3 & 30 & 9 & 4 & 82 & $4.6 \%$ & \\
\hline $\mathrm{C} 01$ & Research & 1 & 2 & & 1 & 1 & 2 & 1 & 3 & 3 & 3 & 1 & 1 & 3 & 5 & 3 & 3 & 29 & 9 & 4 & 75 & $4.2 \%$ & $9.9 \%$ \\
\hline \multirow[t]{10}{*}{$\mathrm{CO2}$} & Education & & & & & & & 1 & & & 1 & & 1 & & 1 & 2 & & 1 & & & 7 & $0.4 \%$ & $0.9 \%$ \\
\hline & Total & 37 & 38 & 29 & 29 & 45 & 51 & 47 & 55 & 51 & 52 & 50 & 77 & 59 & 136 & 140 & 169 & 307. & 165 & 257 & 1794 & $100 \%$ & \\
\hline & 1 topic & 8 & 6 & 7 & 9 & 12 & 15 & 16 & 16 & 11 & 12 & 11 & 16 & 16 & 10 & 12 & 13 & 26 & 18 & 20 & 254 & & $33.5 \%$ \\
\hline & 2 topics & 6 & 13 & 7 & 7 & 10 & 13 & 11 & 10 & 12 & 10 & 6 & 8 & 10 & 10 & 9 & 14 & 31 & 14 & 20 & 221 & & $29.2 \%$ \\
\hline & 3 topics & 3 & 2 & 1 & 2 & 3 & 2 & 3 & 5 & 4 & 4 & 6 & 9 & 5 & 13 & 13 & 6 & 31 & 7 & 11 & 130 & & $17.2 \%$ \\
\hline & 4 topics & 2 & & & & 1 & 1 & & 1 & 1 & 2 & 1 & 2 & 2 & 10 & 7 & 9 & 8 & 18 & 11 & 76 & & $10.0 \%$ \\
\hline & 5 topics & & & 1 & & & & & & & & 1 & 2 & & 3 & 6 & 11 & 14 & 4 & 19 & 61 & & $8.0 \%$ \\
\hline & 6 topics & & & & & & & & & & & & & & 2 & 1 & 2 & 4 & 1 & 3 & 13 & & $1.7 \%$ \\
\hline & 7 topics & & & & & & & & & & & & & & & 1 & 1 & & & 1 & 3 & & $0.4 \%$ \\
\hline & Average topics/paper & 1.9 & 1.8 & 1.8 & 1.6 & 1.7 & 1.6 & 1.6 & 1.7 & 1.8 & 1.9 & 2.0 & 2.1 & 1.8 & 2.8 & 2.9 & 3.0 & 2.7 & 2.7 & 3.0 & 2.4 & & \\
\hline
\end{tabular}


4. Table 9 also shows the number of papers that covered between 1 and 7 topics in each year, and the average number of topics per paper per year. Overall, the average topics per paper is 2.4 (1,794 divided by 758). There is a trend of covering more topics in a single paper over the years. For example, the average number of topics per paper increased from under two in early 1990 s to close to three in 2003 , and has since remained relatively consistent.

\section{RQ1.3: What topics are often co-studied?}

Since more than half of the papers covered more than one topic, it is interesting to see which topics were studied alone and which were studied together. Table 10 shows the frequency of topics that were studied alone, that is, each of them was the only topic in a paper. The most studied-alone topics include Cognitive belief and behavior (B01, with 77 papers), Research (C01, with 34 papers), Software/Hardware development (A03, with 30 papers), Performance (B06, with 25 papers), and Learning (B03, with 20 papers).

Table 10: Frequency of the Topics that were Studied Alone

\begin{tabular}{l|c}
\hline \multicolumn{1}{c|}{ Topic } & $\begin{array}{c}\text { Total } \\
\text { Number }\end{array}$ \\
\hline A01: Dev. methods \& tools & 3 \\
A02: User analyst involvement & 10 \\
A03: Software/Hardware dev. & 30 \\
A04: Software/Hardware evaluation & 2 \\
A05: User interface design \& dev. & 8 \\
A06: User interface evaluation & 2 \\
A07: User training & 4 \\
\hline B01: Cog. belief \& behavior & 77 \\
B02: Attitude & 8 \\
B03: Learning & 20 \\
B04: Motivation & 0 \\
B05: Emotion & 3 \\
B06: Performance & 25 \\
B07: Trust & 12 \\
B08: Ethics & 5 \\
B09: Interpersonal relationship & 3 \\
B10: User support & 4 \\
\hline C01: Research & 34 \\
C02: Education & 4 \\
\hline & 254 \\
\hline
\end{tabular}

For the co-studied topics, we focused only on pairs of topics because of the complexity of analysis and interpretation. For example, for those articles that studied three topics, we considered each two-topic combination among the three, thus yielding three pairs of two-topic co-occurrence. Table 11 depicts the results of any pair of co-studied topics. We found 1,935 pairs, which involved 3,870 occurrences of topics. The last column is the total for any topic that is studied with any one of the other topics. The table shows that:

1. B01 (Cognitive beliefs and behavior), B02 (Attitude), B04 (Motivation), and B06 (Performance) were the most paired topics, occurring more than 490 times each, followed by B07 (Trust), B09 (Interpersonal relationship), B05 (Emotion), and B03 (Learning), occurring more than 100 times each.

2. B topics were mostly co-studied with other B topics; the frequency of such co-studies was $1,600(82.6 \%$ of the 1,935 pairs).

3. Among the A topics, A05 (User interface design and development) and A06 (User interface evaluation) paired the most (14 times).

4. A05 (User interface design and development) and A06 (User interface evaluation) were also the two A topics that paired the most with B topics. The co-occurring frequency among A and B topics was 209, 
about $10.84 \%$ of the total 1,935 pairs. That is, about $11 \%$ of the total co-studied topics encompassed the two stages of the IT life cycle.

Table 11: Frequency of Co-Studied Topics

\begin{tabular}{|c|c|c|c|c|c|c|c|c|c|c|c|c|c|c|c|c|c|c|c|}
\hline & & $\mathrm{A} 01$ & $\mathrm{~A} 02$ & $\mathrm{~A} 03$ & A04 & A05 & A06 & A07 & B01 & B02 & B03 & B04 & B05 & B06 & B07 & B08 & B11 & B12 & Total \\
\hline $\mathrm{A} 01$ & $\begin{array}{l}\text { Dev. methods } \\
\text { \& tools }\end{array}$ & & & & & & & & & & & & & & & & & & 22 \\
\hline $\mathrm{A} 02$ & $\begin{array}{l}\text { User analyst } \\
\text { involvement }\end{array}$ & 4 & & & & & & & & & & & & & & & & & 50 \\
\hline $\mathrm{A} 03$ & $\begin{array}{l}\text { SW/HW } \\
\text { development }\end{array}$ & 1 & 2 & & & & & & & & & & & & & & & & 21 \\
\hline $\mathrm{A} 04$ & $\begin{array}{l}\text { SW/HW } \\
\text { evaluation }\end{array}$ & 1 & 1 & 1 & & & & & & & & & & & & & & & 11 \\
\hline A05 & $\begin{array}{l}\text { User interface } \\
\text { design \& dev. }\end{array}$ & 2 & 6 & 2 & 1 & & & & & & & & & & & & & & 90 \\
\hline A06 & $\begin{array}{l}\text { User interface } \\
\text { evaluation }\end{array}$ & 1 & 3 & 1 & 3 & 14 & & & & & & & & & & & & & 92 \\
\hline $\mathrm{A} 07$ & User training & 1 & 2 & 2 & 1 & 1 & 2 & & & & & & & & & & & & 35 \\
\hline B01 & $\begin{array}{l}\text { Cog. beliefs \& } \\
\text { behavior }\end{array}$ & 3 & 13 & 4 & 1 & 17 & 18 & 5 & & & & & & & & & & & 894 \\
\hline B02 & Attitude & 2 & 12 & 1 & 1 & 12 & 12 & 5 & 228 & & & & & & & & & & 683 \\
\hline B03 & Learning & 1 & & 1 & & 5 & 2 & 3 & 31 & 16 & & & & & & & & & 113 \\
\hline B04 & Motivation & 2 & 1 & 1 & & 4 & 2 & 5 & 145 & 119 & 13 & & & & & & & & 494 \\
\hline B05 & Emotion & & & & & 1 & 5 & 2 & 61 & 27 & 6 & 25 & & & & & & & 179 \\
\hline B06 & Performance & & 2 & 3 & & 18 & 24 & 5 & 196 & 141 & 19 & 108 & 25 & & & & & & 628 \\
\hline B07 & Trust & & 1 & 2 & & 2 & & & 86 & 58 & 3 & 53 & 7 & 48 & & & & & 281 \\
\hline B08 & Ethics & & & & & & & & 3 & 1 & & 1 & & & 3 & & & & 10 \\
\hline B09 & $\begin{array}{l}\text { Interpersonal } \\
\text { relationship }\end{array}$ & 2 & 3 & & & 2 & 4 & & 60 & 33 & 7 & 12 & 15 & 28 & 12 & & & & 181 \\
\hline B10 & User support & & & & & & & & 2 & 6 & & & & & & & & & 10 \\
\hline B11 & Others & & & & & & & & 1 & & & & & & 1 & & & & 2 \\
\hline $\mathrm{C} 01$ & Research & 2 & & & 1 & 2 & 1 & & 20 & 9 & 3 & 3 & 5 & 11 & 5 & 2 & 3 & 2 & 69 \\
\hline $\mathrm{CO} 2$ & Education & & & & & 1 & & 1 & & & 3 & & & & & & & & 5 \\
\hline
\end{tabular}

RQ1.4: What are the research methods?

Table 12 summarizes research methods utilized in the articles. Among the 758 papers, the majority (680 or $89.7 \%)$ used one method, 76 papers (10\%) used two, and two papers used three methods. Among the total methods used, Empirical methods (700 uses, 83.5\%) dramatically exceeded Non-Empirical ones (138 uses, 16.5\%).

The frequency of Non-Empirical studies has been consistently low over the years. Empirical studies have been conducted almost entirely on Events/Processes. In particular, Survey (29\% of the papers), Lab Experiment (28.5\%), and Field study (10.4\%) were the three most utilized methods. This indicates that positivist research has been conducted more often than other forms of research.

It is noteworthy that in the 1990-2002 HCl field review (Zhang and Li, 2005), five methods (Framework [1.1.1]; Theory from reference disciplines [1.1.4]; Opinion with personal experience [1.2.2]; Description of types/classes of systems [2.1.1]; and Ex-post description [2.2.9]) were not utilized. In 2003-2008, Framework, Theory from reference disciplines, and Opinion with personal experience have been utilized by a number of papers. Description of types/classes of systems (2.1.1) and Ex-post description (2.2.9) remained unused. 
Table 12 Frequency of Methods

\begin{tabular}{|c|c|c|c|c|c|c|c|c|c|c|c|c|c|c|c|c|c|c|c|c|c|c|c|}
\hline & & 90 & 91 & 92 & 93 & 94 & 95 & 96 & 97 & 98 & 99 & 00 & 01 & 02 & 03 & 04 & 05 & 06 & 07 & 08 & Total & $\begin{array}{l}\% \text { by \# of } \\
\text { methods }\end{array}$ & $\begin{array}{c}\% \text { by \# of } \\
\text { papers }\end{array}$ \\
\hline 1 & Non-Empirical & 6 & 6 & 0 & 0 & 1 & 3 & 2 & 4 & 3 & 6 & 0 & 5 & 4 & 9 & 11 & 9 & 42 & 17 & 10 & 138 & $16.5 \%$ & \\
\hline 1.1 & Conceptual Orientation & 3 & 1 & 0 & 0 & 1 & 0 & 1 & 0 & 2 & 2 & 0 & 2 & 1 & 8 & 11 & 8 & 22 & 14 & 7 & 83 & $9.9 \%$ & \\
\hline 1.1 .1 & Framework & & & & & & & & & & 1 & & 1 & & 1 & 3 & 4 & 11 & 2 & 2 & 25 & $3.0 \%$ & $3.3 \%$ \\
\hline 1.1 .2 & Conceptual model & 1 & & & & 1 & & 1 & & 2 & 1 & & 1 & & 7 & 8 & 3 & 9 & 8 & 3 & 45 & $5.4 \%$ & $5.9 \%$ \\
\hline 1.1 .3 & Conceptual overview & 2 & 1 & & & & & & & & & & & 1 & & & 1 & 2 & & 1 & 8 & $1.0 \%$ & $1.1 \%$ \\
\hline 1.1 .4 & Theory & & & & & & & & & & & & & & & & & & 4 & 1 & 5 & $0.6 \%$ & $0.7 \%$ \\
\hline 1.2 & Illustration & 1 & 2 & 0 & 0 & 0 & 1 & 0 & 4 & 1 & 3 & 0 & 1 & 1 & 1 & 0 & 1 & 16 & 2 & 2 & 36 & $4.3 \%$ & \\
\hline 1.2 .1 & Opinion (pure) & 1 & 2 & & & & 1 & & 4 & 1 & 1 & & 1 & & 1 & & & 8 & 1 & 1 & 22 & $2.6 \%$ & $2.9 \%$ \\
\hline 1.2 .2 & Opinion (personal exp) & & & & & & & & & & & & & & & & & 4 & & & 4 & $0.5 \%$ & $0.5 \%$ \\
\hline 1.2 .3 & Description of tool, technique & & & & & & & & & & 2 & & & 1 & & & 1 & 4 & 1 & 1 & 10 & $1.2 \%$ & $1.3 \%$ \\
\hline 1.3 & Applied concepts & 2 & 3 & 0 & 0 & 0 & 2 & 1 & 0 & 0 & 1 & 0 & 2 & 2 & 0 & 0 & 0 & 4 & 1 & 1 & 19 & $2.3 \%$ & \\
\hline 1.3 .1 & Frameworks \& appl. & 2 & 3 & & & & 2 & 1 & & & 1 & & 2 & 2 & & & & 4 & 1 & 1 & 19 & $2.3 \%$ & $2.5 \%$ \\
\hline 2 & Empirical & 14 & 18 & 18 & 21 & 28 & 32 & 31 & 30 & 30 & 25 & 27 & 36 & 35 & 46 & 41 & 52 & 86 & 47 & 83 & 700 & $83.5 \%$ & \\
\hline 2.1 & Objects & 0 & 0 & 0 & 2 & 0 & 1 & 0 & 1 & 1 & 0 & 0 & 1 & 2 & 0 & 0 & 1 & 0 & 0 & 0 & 9 & $1.1 \%$ & \\
\hline 2.1 .1 & Description of class of systems & & & & & & & & & & & & & & & & & & & & 0 & $0.0 \%$ & $0.0 \%$ \\
\hline 2.1 .2 & Description of specific application & & & & 2 & & 1 & & 1 & 1 & & & 1 & 2 & & & 1 & & & & 9 & $1.1 \%$ & $1.2 \%$ \\
\hline 2.2 & Events/Process & 14 & 18 & 18 & 19 & 28 & 31 & 31 & 29 & 29 & 25 & 27 & 35 & 33 & 46 & 41 & 51 & 86 & 47 & 83 & 691 & $82.5 \%$ & \\
\hline 2.2 .1 & Lab experiment & 6 & 4 & 7 & 12 & 6 & 10 & 11 & 8 & 13 & 10 & 14 & 15 & 5 & 13 & 11 & 12 & 25 & 11 & 23 & 216 & $25.8 \%$ & $28.5 \%$ \\
\hline 2.2 .2 & Field experiment & 2 & 1 & 1 & & 4 & & 3 & 4 & 1 & & 1 & 2 & 2 & 3 & & 3 & 4 & 2 & 6 & 39 & $4.7 \%$ & $5.1 \%$ \\
\hline 2.2 .3 & Field study & 4 & 3 & 2 & & 3 & 7 & 4 & 7 & 1 & 3 & 3 & 1 & 5 & 5 & 7 & 9 & 8 & 1 & 6 & 79 & $9.4 \%$ & $10.4 \%$ \\
\hline 2.2 .4 & Positivist case study & & & & 1 & & 1 & & & 2 & & 1 & & 1 & 1 & 3 & 3 & 1 & 7 & 1 & 22 & $2.6 \%$ & $2.9 \%$ \\
\hline 2.2 .5 & Interpretive case study & 1 & & 1 & 1 & & & 1 & & 2 & & 2 & 1 & 3 & 2 & & & & 1 & 1 & 16 & $1.9 \%$ & $2.1 \%$ \\
\hline 2.2 .6 & Action research & & & & & & & & & & & & & & & & & & & 2 & 2 & $0.2 \%$ & $0.3 \%$ \\
\hline 2.2 .7 & Survey & & 7 & 4 & 3 & 9 & 8 & 9 & 8 & 7 & 8 & 5 & 11 & 9 & 14 & 15 & 18 & 36 & 17 & 32 & 220 & $26.3 \%$ & $29.0 \%$ \\
\hline 2.2 .8 & Instrument development & & 2 & 2 & & 3 & 1 & 1 & 1 & 3 & 1 & & 1 & 4 & 2 & 2 & 2 & 4 & 2 & 3 & 34 & $4.1 \%$ & $4.5 \%$ \\
\hline 2.2 .9 & Ex-post description & & & & & & & & & & & & & & & & & & & & 0 & $0.0 \%$ & $0.0 \%$ \\
\hline 2.2 .10 & Secondary data & 1 & & & 1 & 1 & 2 & & & & 2 & 1 & 1 & 2 & & 1 & 1 & 4 & 2 & 4 & 23 & $2.7 \%$ & $3.0 \%$ \\
\hline 2.2 .11 & Interview & & 1 & & 1 & 2 & 1 & 1 & 1 & & & & 2 & 2 & 4 & 1 & 2 & 4 & 4 & 2 & 28 & $3.3 \%$ & $3.7 \%$ \\
\hline 2.2 .12 & Delphi & & & 1 & & & & 1 & & & 1 & & & & & & & & & & 3 & $0.4 \%$ & $0.4 \%$ \\
\hline 2.2 .13 & Focus group & & & & & & 1 & & & & & & 1 & & 1 & & 1 & & & 2 & 6 & $0.7 \%$ & $0.8 \%$ \\
\hline 2.2 .14 & Other & & & & & & & & & & & & & & 1 & 1 & & & & 1 & 3 & $0.4 \%$ & $0.4 \%$ \\
\hline Total & & 20 & 24 & 18 & 21 & 29 & 35 & 33 & 34 & 33 & 31 & 27 & 41 & 39 & 55 & 52 & 61 & 128 & 64 & 93 & 838 & $100.0 \%$ & \\
\hline
\end{tabular}

\section{RQ1.5: What methods are often used to study what topics?}

The results of cross-facet analysis of method and topic are shown in Table 13. Each pair represents one method and one topic that appeared in one article. We limited our analysis to one to one pairing due to the complexity of analysis. For example, those articles that studied three topics using two methods would yield six method-topic pairs. The last column of the table shows the total frequencies of each method's usage. For example, Survey (2.2.7) was used 553 times to study all the topics (except Topic B11, Other). Similarly, the last row shows how many times each topic was studied with various methods. For instance, Cognitive beliefs and behaviors (B01) was studied a total of 518 times, with all types of methods showing in the table except Opinion (1.2.2) and Description of a specific application (2.1.2).

The most frequently occurring pairings were between Empirical methods and IT Use and Impact (B category) topics. In particular, the four largest pairings between topics and methods are:

1. Cognitive belief and behavior (B01) by Survey (2.2.7)

2. Cognitive belief and behavior (B01) by Lab experiment (2.2.1)

3. Performance (B06) by Lab experiment (2.2.1) 
4. Attitude (B02) by Survey (2.2.7).

The most used methods (Survey [2.2.7], Lab experiment [2.2.1], Field study [2.2.3]) were used to study almost all topics. In addition, one conceptual method, Conceptual model (1.1.3), was used intensively.

Table 13 also depicts what methods were utilized most for each topic. For example, Cognitive belief and behavior (B1) was studied mostly by using Survey (2.2.7). Emotion (B05) was also studied mostly by survey, while Learning (B03) was studied mostly by Lab experiment (2.2.1).

Table 13: Pair Frequency of Methods and Topics

\begin{tabular}{|c|c|c|c|c|c|c|c|c|c|c|c|c|c|c|c|c|c|c|c|c|c|c|}
\hline \multirow{3}{*}{\multicolumn{2}{|c|}{ Method }} & \multicolumn{21}{|c|}{ Topic } \\
\hline & & 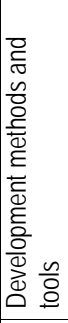 & 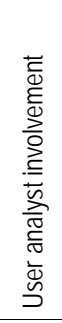 & 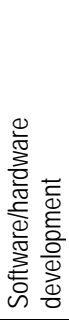 & 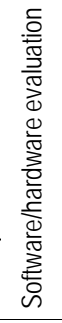 & 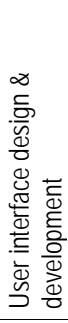 & 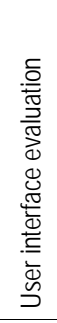 & 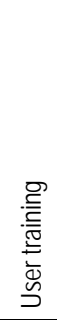 & 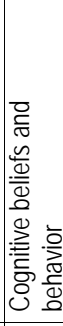 & $\begin{array}{l}\frac{0}{3} \\
\frac{1}{2}\end{array}$ & 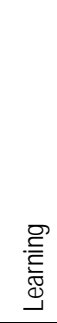 & 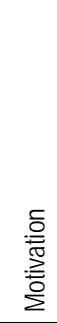 & $\begin{array}{l}\text { 흠 } \\
\overline{\tilde{z}} \\
\text { है }\end{array}$ & $\begin{array}{l}8 \\
\bar{\sigma} \\
\bar{g} \\
\overline{0} \\
0 \\
0\end{array}$ & $\stackrel{\underline{\underline{H}}}{\underline{F}}$ & $\begin{array}{l}\frac{y}{2} \\
\frac{1}{1}\end{array}$ & 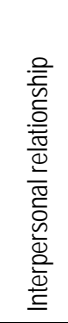 & $\begin{array}{l}\frac{\pi}{0} \\
\frac{8}{3} \\
\overline{3} \\
\overline{\$} \\
3\end{array}$ & $\frac{\bar{\Phi}}{\bar{\delta}}$ & $\begin{array}{l}\frac{c}{0} \\
\mathbb{\Xi} \\
\mathbb{W} \\
\mathbb{Q} \\
\square\end{array}$ & 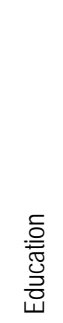 & \begin{tabular}{|l} 
Total \\
Paring
\end{tabular} \\
\hline & & A01 & A02 & $\mathrm{A} 03$ & A04 & A05 & A06 & $\mathrm{A} 07$ & B01 & B02 & B03 & B04 & B05 & B06 & B07 & B08 & B09 & B10 & B11 & $\mathrm{CO1}$ & $\mathrm{CO2}$ & \\
\hline 1.1 .1 & Framework & 2 & 3 & 1 & 1 & 4 & 3 & 2 & 9 & 7 & & 7 & 1 & 6 & 6 & & 1 & & & 9 & 1 & 63 \\
\hline 1.1 .2 & Conceptual model & 1 & 1 & 1 & & 4 & 2 & & 29 & 21 & 3 & 17 & 7 & 26 & 8 & & 6 & & & 11 & 2 & 139 \\
\hline 1.1 .3 & Conceptual overview & & 1 & 1 & & 2 & & & 3 & 1 & 1 & 1 & 2 & 2 & & & & & & 4 & & 18 \\
\hline 1.1 .4 & Theory & & & & & & & & 1 & 1 & & 1 & & 1 & & 1 & & & & 4 & & 9 \\
\hline 1.2.1 & Opinion (pure) & 1 & & 2 & & & 1 & & 5 & 1 & 1 & & 1 & 3 & 2 & 1 & & 1 & & 15 & 1 & 35 \\
\hline 1.2 .2 & Opinion (personal exp) & & & & & & & & & & & & & & & & & & & 4 & & 4 \\
\hline 1.2 .3 & Desc. a tool, technique & & 1 & 1 & & 4 & 2 & 1 & 5 & 2 & 1 & 2 & 1 & 3 & & & 1 & & & 4 & 1 & 29 \\
\hline 1.3.1 & Frameworks \& appl. & 1 & 2 & 2 & & 6 & 1 & & 8 & 4 & 1 & & 1 & 5 & 1 & 1 & 3 & & & 5 & & 41 \\
\hline 2.1 .2 & Desc. of a specific appl. & & & 6 & & 3 & 2 & 1 & & 1 & & & & 2 & & & & & & & & 15 \\
\hline 2.2 .1 & Lab experiment & 3 & 3 & 20 & 1 & 25 & 29 & 2 & 121 & 63 & 23 & 35 & 12 & 118 & 25 & & 17 & 1 & & 2 & & 500 \\
\hline 2.2 .2 & Field experiment & & 5 & 4 & & 2 & 3 & 2 & 23 & 12 & 7 & 6 & 1 & 12 & 6 & & 1 & & 1 & 1 & & 86 \\
\hline 2.2 .3 & Field study & 1 & 5 & & & 2 & 3 & 1 & 58 & 35 & 8 & 11 & 10 & 18 & 12 & & 14 & 2 & & 2 & 1 & 183 \\
\hline 2.2 .4 & Positivist case study & & 3 & & 2 & 2 & & & 14 & 10 & & 4 & 1 & 6 & 2 & 1 & 4 & 1 & & 1 & & 51 \\
\hline 2.2 .5 & Interpretive case study & 1 & 5 & & & & 1 & 1 & 10 & 6 & & 2 & 1 & 4 & 1 & & 3 & 1 & & 1 & & 37 \\
\hline 2.2 .6 & Action research & & 1 & & & & & & 2 & 1 & 1 & 1 & & 1 & 1 & & & & & & & 8 \\
\hline 2.2 .7 & Survey & 2 & 7 & 3 & 2 & 3 & 3 & 4 & 175 & 107 & 14 & 57 & 28 & 57 & 44 & 6 & 22 & 6 & & 12 & 1 & 553 \\
\hline 2.2 .8 & Instrument development & & 2 & & 2 & & 4 & 1 & 20 & 17 & 4 & 4 & 5 & 4 & 7 & & 2 & 2 & & 6 & & 80 \\
\hline 2.2 .10 & Secondary data & 1 & 2 & 3 & & & 2 & & 10 & 6 & 1 & 1 & & 7 & 2 & & 1 & & & 4 & & 40 \\
\hline 2.2.11 & Interview & 1 & 2 & 1 & & 4 & 3 & 2 & 15 & 7 & 6 & 6 & 2 & 7 & 3 & 1 & 2 & & & & & 62 \\
\hline 2.2.12 & Delphi & & & & 1 & & 1 & & 2 & & & & & & & & & & & & & 4 \\
\hline 2.2 .13 & Focus group & & & & & 2 & 1 & 2 & 5 & 5 & 1 & 4 & 1 & 4 & 1 & & 1 & & & & & 27 \\
\hline 2.2.14 & Other & & & & & 1 & & & 3 & & & & 1 & 2 & & & 1 & & & 1 & & 9 \\
\hline & Total Pairing & 14 & 43 & 45 & 9 & 64 & 61 & 19 & 518 & 307 & 72 & 159 & 75 & 288 & 121 & 11 & 79 & 14 & 1 & 86 & 7 & 1993 \\
\hline
\end{tabular}

RQ1.6: What are the levels of analysis?

As shown in Table 14, 618 papers (or 81.5\%) addressed the individual level only, 48 papers (6.3\%) the group level only, and 59 papers (7.8\%) addressed both individual and group levels. That is, the majority of papers in this collection were concerned with individual level of analysis. 
Table 14: Frequency of Levels of Analysis

\begin{tabular}{|c|c|c|c|c|c|c|c|c|c|c|c|c|c|c|c|c|c|c|c|c|c|c|}
\hline & & 90 & 91 & 92 & 93 & 94 & 95 & 96 & 97 & 98 & 99 & 00 & 01 & 02 & 03 & 04 & 05 & 06 & 07 & 08 & Total & $\begin{array}{c}\% \text { by no. } \\
\text { papers }\end{array}$ \\
\hline A & Individual & 16 & 20 & 16 & 18 & 24 & 28 & 29 & 30 & 24 & 26 & 21 & 28 & 30 & 34 & 36 & 42 & 80 & 46 & 70 & 618 & $81.5 \%$ \\
\hline$B$ & Group & 2 & 1 & & & 1 & 1 & & & 2 & 1 & 3 & 4 & 1 & 3 & 4 & 3 & 5 & 11 & 6 & 48 & $6.3 \%$ \\
\hline \multirow[t]{3}{*}{$A / B$} & Both & 1 & & & & & 2 & & 1 & 2 & 1 & 1 & 3 & 1 & 10 & 8 & 10 & 8 & 3 & 8 & 59 & $7.8 \%$ \\
\hline & Blank & & & & & 1 & & 1 & 1 & & & & 2 & 1 & 1 & 1 & 1 & 21 & 2 & 1 & 33 & $4.4 \%$ \\
\hline & Total & 19 & 21 & 16 & 18 & 26 & 31 & 30 & 32 & 28 & 28 & 25 & 37 & 33 & 48 & 49 & 56 & 114 & 62 & 85 & 758 & \\
\hline
\end{tabular}

\section{RQ1.7: To what extent does the $\mathrm{HCl}$ sub-discipline consider IT/ service as a research component?}

Table 15 summarizes the frequencies of technologies or services being studied. It shows that $79.9 \%$ (606 papers) studied one type of technology or service, 4.6\% two types, 0.8\% three types, 0.3\% four types, and $14.4 \%$ (109) did not specify technology/service in the studies. Among the 702 times technologies and services were studied, 50.3\% were End-user computing tools, $46 \%$ were Organizational computing tools, and 3.7\% were Services. Among the 758 papers, $23.1 \%$ studied the Web in general, some types of websites, or some specific websites, followed by $15.4 \%$ papers on Decision support systems (DSS), $12.1 \%$ on Management information systems (MIS), and $11.6 \%$ on Other types.

Table 15: Frequency of Technologies or Services

\begin{tabular}{l|l|c|c|c|c|c|c|c|c|c|c|c|c|c|c|c|c|c|c|c|c|c|c}
\hline & $\mathbf{9 0}$ & $\mathbf{9 1}$ & $\mathbf{9 2}$ & $\mathbf{9 3}$ & $\mathbf{9 4}$ & $\mathbf{9 5}$ & $\mathbf{9 6}$ & $\mathbf{9 7}$ & $\mathbf{9 8}$ & $\mathbf{9 9}$ & $\mathbf{0 0}$ & $\mathbf{0 1}$ & $\mathbf{0 2}$ & $\mathbf{0 3}$ & $\mathbf{0 4}$ & $\mathbf{0 5}$ & $\mathbf{0 6}$ & $\mathbf{0 7}$ & $\mathbf{0 8}$ & \begin{tabular}{c} 
Total \\
\hline
\end{tabular} & $\begin{array}{c}\text { \% by \# of } \\
\text { tech }\end{array}$ & $\begin{array}{c}\text { \% by \# of } \\
\text { papers }\end{array}$ \\
\hline TA & $\begin{array}{l}\text { End-user } \\
\text { computing }\end{array}$ & 4 & 7 & 9 & 6 & 11 & 3 & 7 & 13 & 7 & 11 & 9 & 10 & 17 & 14 & 29 & 38 & 77 & 32 & 49 & 353 & $50.3 \%$ & \\
\hline TA1 & Ind. Comm. & & & 1 & 1 & 3 & 1 & 2 & 4 & 1 & 3 & & 1 & 1 & 4 & 3 & 4 & 5 & 2 & 1 & 37 & $5.3 \%$ & $4.9 \%$ \\
\hline TA2 & Ind. Productivity & 3 & 1 & 4 & 5 & 3 & 1 & 3 & 4 & 3 & 6 & 3 & 3 & & 2 & 1 & 3 & 4 & 2 & 2 & 53 & $7.5 \%$ & $7.0 \%$ \\
\hline TA3 & Web & & & & & & & 1 & 2 & 2 & 1 & 4 & 4 & 11 & 8 & 18 & 21 & 42 & 24 & 37 & 175 & $24.9 \%$ & $23.1 \%$ \\
\hline TA4 & Other & 1 & 6 & 4 & & 5 & 1 & 1 & 3 & 1 & 1 & 2 & 2 & 5 & & 7 & 10 & 26 & 4 & 9 & 88 & $12.5 \%$ & $11.6 \%$ \\
\hline TB & $\begin{array}{l}\text { Org/Social } \\
\text { computing }\end{array}$ & 8 & 6 & 6 & 7 & 8 & 17 & 18 & 10 & 14 & 11 & 14 & 25 & 10 & 35 & 18 & 20 & 30 & 31 & 35 & 323 & $46.0 \%$ & \\
\hline TB1 & $\begin{array}{l}\text { Group/Org } \\
\text { communication }\end{array}$ & & & 1 & & & & 1 & 1 & 4 & 0 & 1 & 5 & 1 & 1 & 1 & 1 & 0 & 1 & 2 & 20 & $2.8 \%$ & $2.6 \%$ \\
\hline TB2 & DSS & 4 & 5 & 5 & 3 & 5 & 9 & 7 & 4 & 8 & 4 & 3 & 9 & 1 & 14 & 6 & 8 & 9 & 6 & 7 & 117 & $16.7 \%$ & $15.4 \%$ \\
\hline TB3 & MIS, ERP & 1 & & & 3 & 2 & 3 & 7 & 3 & & 4 & 2 & 4 & 4 & 16 & 8 & 7 & 11 & 7 & 10 & 92 & $13.1 \%$ & $12.1 \%$ \\
\hline TB4 & CSCW, GDSS & 3 & 1 & & & & 4 & 2 & 2 & 2 & 3 & 6 & 5 & 4 & 1 & 1 & 2 & 3 & 1 & 6 & 46 & $6.6 \%$ & $6.1 \%$ \\
\hline TB5 & Other & & & & 1 & 1 & 1 & 1 & & & & 2 & 2 & & 3 & 2 & 2 & 7 & 16 & 10 & 48 & $6.8 \%$ & $6.3 \%$ \\
\hline TC & $\begin{array}{l}\text { Internet service, } \\
\text { info center }\end{array}$ & 1 & 1 & & & 3 & 1 & 1 & 3 & 3 & 2 & & & 2 & 2 & 3 & 1 & 2 & 1 & & 26 & $3.7 \%$ & \\
\hline Total & & 13 & 14 & 15 & 13 & 22 & 21 & 26 & 26 & 24 & 24 & 23 & 35 & 29 & 51 & 50 & 59 & 109 & 64 & 84 & 702 & $100.0 \%$ & \\
\hline Blank & No tech/service & 7 & 7 & 2 & 5 & 6 & 11 & 6 & 7 & 7 & 5 & 2 & 4 & 6 & 3 & 3 & 4 & 17 & 1 & 6 & 109 & & $14.4 \%$ \\
\hline
\end{tabular}

\section{RQ1.8: To what extent does the $\mathrm{HCl}$ sub-discipline consider individual characteristics?}

Table 16 summarizes the frequencies of individual characteristics. Among the 758 articles, only 219 or $28.9 \%$ of articles considered explicitly individual characteristics, including personality (7.9\%), demographics (14\%), and both (7\%). The majority (539 papers or $71.1 \%$ ) didn't consider individual characteristics as primary factors in their studies.

Table 16: Frequency of Individual Characteristics

\begin{tabular}{l|l|c|c|c|c|c|c|c|c|c|c|c|c|c|c|c|c|c|c|c|c|c}
\hline & & $\mathbf{9 0}$ & $\mathbf{9 1}$ & $\mathbf{9 2}$ & $\mathbf{9 3}$ & $\mathbf{9 4}$ & $\mathbf{9 5}$ & $\mathbf{9 6}$ & $\mathbf{9 7}$ & $\mathbf{9 8}$ & $\mathbf{9 9}$ & $\mathbf{0 0}$ & $\mathbf{0 1}$ & $\mathbf{0 2}$ & $\mathbf{0 3}$ & $\mathbf{0 4}$ & $\mathbf{0 5}$ & $\mathbf{0 6}$ & $\mathbf{0 7}$ & $\mathbf{0 8}$ & Total & $\begin{array}{c}\text { \% by \# } \\
\text { papers }\end{array}$ \\
\hline A & Personality & 1 & 1 & 2 & & 1 & & 2 & 1 & 4 & 1 & 2 & 3 & 2 & 5 & 3 & 5 & 13 & 3 & 11 & 60 & $7.9 \%$ \\
\hline B & Demographics & 1 & 1 & & 1 & 2 & 2 & 1 & 5 & 1 & 1 & 5 & 1 & 2 & 11 & 7 & 14 & 20 & 11 & 20 & 106 & $14.0 \%$ \\
\hline A, B & Both & 1 & 1 & 1 & & & 1 & & 1 & 2 & 1 & & & 1 & 3 & 3 & 5 & 16 & 8 & 9 & 53 & $7.0 \%$ \\
\hline & Blank & 16 & 18 & 13 & 17 & 23 & 28 & 27 & 25 & 21 & 25 & 18 & 33 & 28 & 29 & 36 & 32 & 65 & 40 & 45 & 539 & $71.1 \%$ \\
\hline & Total & 19 & 21 & 16 & 18 & 26 & 31 & 30 & 32 & 28 & 28 & 25 & 37 & 33 & 48 & 49 & 56 & 114 & 62 & 85 & 758 & $100 \%$ \\
\hline
\end{tabular}




\section{Summary for RQ1}

Several observations can be drawn from the above analyses on the intellectual substance of the $\mathrm{HCl}$ sub-discipline, which is largely consistent with those in Zhang and Li (2005):

1. IS scholars are mainly interested in $\mathrm{HCl}$ issues that are concerned with IT use and impact at the individual level in organizational and work contexts. Other topics (i.e., IT development), other contexts (e.g., social), and other analysis level (i.e., group) are gaining more attention in recent years.

2. One paper is often dedicated to multiple topics.

3. A broad range of research methods is utilized, although the predominant ones are lab experiment, survey method, and field study. Different methods are often used to explore the same topics, while the same methods are often applied to studying different topics.

4. Individual characteristics do not gain the level of attention one would anticipate for studies on humans interacting with technologies.

5. IT artifacts and services, although considered more frequently than individual characteristics in studies, are not always clearly specified. The large number of studies that do not specify IT seems consistent with some researchers' observations and calls for more attention to the IT artifact in MIS research (Benbasat and Zmud 2003; Orlikowski and lacono 2001; Weber 2003).

\section{RQ2: What are the Relationships with Other Disciplines?}

\section{RQ2.1: What are the contributing disciplines?}

Table 17 shows the broad fields (one level higher than disciplines as shown in Table 7) that supported this set of 758 papers. Information, Computing, \& Communication Sciences (2800); Behavioral \& Cognitive Sciences (3800); and Commerce, Management, Tourism \& Services (3500) were the most frequently referenced fields that supported theoretical or conceptual development in $\mathrm{HCl}$ studies. This is fairly consistent with the top global IS supporting disciplines identified by Lowry et al. (2004), though the disciplines are classified slightly differently. The last column shows that about $97 \%$ of the papers used 2800 as a contributing field, $87 \%$ of the papers used $3800,42 \%$ of the papers used the 3500 field, and about $39 \%$ of papers used other fields.

Table 17: Frequency of Fields that Contribute to the Studies

\begin{tabular}{l|l|l|l|l|l|l|l|l|l|l|l|l|l|l|l|l|l|l|l|l|l|l|l}
\hline & $\mathbf{9 0}$ & $\mathbf{9 1}$ & $\mathbf{9 2}$ & $\mathbf{9 3}$ & $\mathbf{9 4}$ & $\mathbf{9 5}$ & $\mathbf{9 6}$ & $\mathbf{9 7}$ & $\mathbf{9 8}$ & $\mathbf{9 9}$ & $\mathbf{0 0}$ & $\mathbf{0 1}$ & $\mathbf{0 2}$ & $\mathbf{0 3}$ & $\mathbf{0 4}$ & $\mathbf{0 5}$ & $\mathbf{0 6}$ & $\mathbf{0 7}$ & $\mathbf{0 8}$ & $\mathbf{T o t a l}$ & $\begin{array}{l}\% \text { by \# } \\
\text { papers }\end{array}$ \\
\hline F2800 & $\begin{array}{l}\text { Information, Computing, \& } \\
\text { Communication Sciences }\end{array}$ & 21 & 22 & 18 & 20 & 28 & 39 & 34 & 39 & 30 & 33 & 24 & 30 & 33 & 43 & 37 & 53 & 110 & 47 & 76 & 737 & $97 \%$ \\
\hline F3500 & $\begin{array}{l}\text { Commerce, Management, } \\
\text { Tourism \& Services }\end{array}$ & 10 & 9 & 5 & 9 & 11 & 14 & 17 & 16 & 15 & 10 & 6 & 17 & 22 & 18 & 21 & 24 & 47 & 16 & 31 & 318 & $42 \%$ \\
\hline F3800 & $\begin{array}{l}\text { Behavioral \& Cognitive } \\
\text { Sciences }\end{array}$ & 14 & 12 & 14 & 12 & 17 & 22 & 22 & 27 & 18 & 19 & 24 & 31 & 18 & 46 & 45 & 60 & 112 & 63 & 82 & 658 & $87 \%$ \\
\hline & Other & 7 & 6 & 3 & 3 & 7 & 5 & 8 & 8 & 9 & 5 & 10 & 27 & 16 & 22 & 26 & 20 & 38 & 38 & 37 & 295 & $39 \%$ \\
\hline
\end{tabular}

A total of 38 disciplines functioned as contributing disciplines to the 758 articles for a total of 2,008 times. Table 18 summarizes the frequencies of the 14 disciplines that were considered as contributing disciplines by at least 10 papers. Among the 2,008 references to the 38 disciplines, the three most relied-upon disciplines were Information Systems (D2801, supported 711 articles, or 93.8\%), Psychology (D3801, supported 577 articles, or 76.1\%), and Business and Management (D3502, supported 299 articles, or 39.4\%). One caution is that D2801 is more than just MIS, as indicated in Table 7. The upper part of the last column of Table 18 (from D2302 - 1.3\% to D4401 - 1.8\%) demonstrates the percentages of the 758 papers supported by each discipline.

Table 18 also shows that out of the 758 articles, 58 (7.7\%) articles relied on just one discipline, 264 (34.8\%) articles drew upon two disciplines, 326 (43\%) built on three, $92(12.1 \%)$ on four, and $18(2.4 \%)$ on five disciplines. Together, the average number of supporting disciplines per paper is 2.7 for the entire 19 years. 
Table 18: Frequency of Top 14 Contributing Disciplines

\begin{tabular}{|c|c|c|c|c|c|c|c|c|c|c|c|c|c|c|c|c|c|c|c|c|c|c|}
\hline & & 90 & 91 & \begin{tabular}{|l|}
92 \\
\end{tabular} & \begin{tabular}{|l|}
93 \\
\end{tabular} & 94 & \begin{tabular}{|l|}
95 \\
\end{tabular} & \begin{tabular}{|l|}
96 \\
\end{tabular} & \begin{tabular}{|l|}
97 \\
\end{tabular} & 98 & \begin{tabular}{|l|l|}
99 \\
\end{tabular} & \begin{tabular}{|l|l|}
00 \\
\end{tabular} & \begin{tabular}{|l|}
01 \\
\end{tabular} & \begin{tabular}{|l|}
02 \\
\end{tabular} & \begin{tabular}{|l|}
03 \\
\end{tabular} & \begin{tabular}{|l|}
04 \\
\end{tabular} & \begin{tabular}{|l|}
05 \\
\end{tabular} & 06 & 07 & \begin{tabular}{|l|}
08 \\
\end{tabular} & Total & $\%$ by \# Papers \\
\hline D2302 & Statistics & 1 & 3 & & 1 & & 1 & & 2 & & & & & & 1 & 1 & & & & & 10 & $1.3 \%$ \\
\hline D2801 & Information Systems & 18 & 21 & 16 & 17 & 25 & 31 & 28 & 31 & 27 & 28 & 23 & 32 & 30 & 45 & 45 & 53 & 111 & 50 & 80 & 711 & $93.8 \%$ \\
\hline D2802 & Al and Image Processing & 2 & 1 & & 1 & 2 & 3 & 1 & 2 & & 1 & 2 & 1 & 1 & 2 & & 1 & 2 & 2 & & 24 & $3.2 \%$ \\
\hline D2803 & Computer Software & 1 & 2 & 3 & 4 & 5 & 6 & 7 & 8 & 9 & 10 & 11 & 12 & 13 & 14 & 15 & 16 & 17 & 18 & 19 & 20 & $2.6 \%$ \\
\hline D3301 & Education Studies & 1 & & 2 & & 3 & & 2 & & 1 & & 3 & 3 & 2 & 2 & 2 & 2 & 5 & 2 & 4 & 34 & $4.5 \%$ \\
\hline D3402 & Applied Economics & & & & & & & & & & & 1 & 1 & 3 & & 3 & 1 & 3 & & 3 & 15 & $2.0 \%$ \\
\hline D3502 & Business and Management & 10 & 9 & 4 & 9 & 11 & 14 & 16 & 16 & 15 & 9 & 6 & 17 & 22 & 16 & 21 & 23 & 43 & 10 & 28 & 299 & $39.4 \%$ \\
\hline D3599 & Other commerce, management & & & & & & & & & & & & & & 2 & & & 4 & 6 & 1 & 13 & $1.7 \%$ \\
\hline D3701 & Sociology & 3 & 1 & 1 & & 1 & 1 & 1 & 2 & 2 & & 1 & 5 & 4 & 9 & 8 & 8 & 9 & 12 & 15 & 83 & $10.9 \%$ \\
\hline D3801 & Psychology & 12 & 11 & 12 & 10 & 15 & 22 & 20 & 25 & 17 & 18 & 21 & 28 & 18 & 43 & 38 & 51 & 89 & 51 & 76 & 577 & $76.1 \%$ \\
\hline D3803 & Cognitive Science & 2 & 1 & 2 & 2 & 2 & & 1 & 1 & 1 & & 2 & 2 & & 3 & 7 & 8 & 21 & 12 & 6 & 73 & $9.6 \%$ \\
\hline D4001 & Journalism, Comm. and Media & 2 & 1 & & & 2 & 2 & 1 & 2 & 4 & 1 & 2 & 8 & 3 & 1 & 3 & 1 & 5 & 1 & 2 & 41 & $5.4 \%$ \\
\hline D4203 & Cultural Studies & & & & & & & & 2 & & & 1 & 1 & & & & 3 & 3 & 2 & 2 & 14 & $1.8 \%$ \\
\hline D4401 & Philosophy & & & & & 1 & & 2 & & 1 & 2 & & 1 & & & & & 3 & 4 & & 14 & $1.8 \%$ \\
\hline & 1 discipline & 1 & 4 & 2 & 3 & 7 & 3 & 4 & 1 & 7 & 0 & 1 & 3 & 2 & 2 & 3 & 1 & 6 & 6 & 2 & 58 & $7.7 \%$ \\
\hline & 2 disciplines & 6 & 9 & 7 & 7 & 7 & 10 & 7 & 11 & 5 & 18 & 14 & 10 & 12 & 19 & 18 & 16 & 37 & 16 & 35 & 264 & $34.8 \%$ \\
\hline & 3 disciplines & 9 & 5 & 4 & 5 & 7 & 15 & 13 & 14 & 10 & 9 & 6 & 14 & 13 & 18 & 22 & 32 & 58 & 33 & 39 & 326 & $43.0 \%$ \\
\hline & 4 disciplines & 2 & 3 & 3 & 3 & 4 & 3 & 6 & 5 & 5 & 1 & 3 & 7 & 5 & 8 & 4 & 6 & 11 & 6 & 7 & 92 & $12.1 \%$ \\
\hline & 5 disciplines & 1 & 0 & 0 & 0 & 1 & 0 & 0 & 1 & 1 & 0 & 1 & 3 & 1 & 0 & 3 & 1 & 2 & 1 & 2 & 18 & $2.4 \%$ \\
\hline & Average \# of disciplines per paper & 2.8 & 2.3 & 2.5 & 2.4 & 2.4 & 2.6 & 2.7 & 2.8 & 2.6 & 2.4 & 2.6 & 2.9 & 2.7 & 2.7 & 2.7 & 2.8 & 2.7 & 2.7 & 2.7 & 2.7 & \\
\hline
\end{tabular}

\section{RQ2.2: What contributing disciplines are often co-cited in HCl studies?}

Table 18 shows that only 58 papers (7.7\%) were built on just one discipline. The majority of papers relied on more than one supporting discipline. Hence, it is interesting to consider what disciplines are often used together to support conceptual and theoretical development in this set of research.

Similar to the co-occurrences analysis for topics, we focused on co-occurrence of two disciplines. For those articles that built on three disciplines, we considered combinations of two-discipline pairs. For example, if one study was built on disciplines $A, B$, and $C$, then this study has three pairs of co-citations of contributing disciplines: $A B, A C$, and $B C$. Among the 758 papers, there are a total of 1,974 pairs of disciplines co-cited. Table 19 summarizes the frequencies of co-citations of the top 14 disciplines (as in Table 18) with a total of 1,847 pairs (representing $94 \%$ of the 1,974 pairs). The "Total" column and the "Total" row of the table show the frequency of each discipline paired with another discipline. For example, Artificial Intelligence, Signal and Image Processing (2802) paired up with other top 14 disciplines $62(40+22)$ times.

Table 19: Frequency of Top Co-Occurring Disciplines

\begin{tabular}{|c|c|c|c|c|c|c|c|c|c|c|c|c|c|}
\hline & & 2801 & 2802 & 2803 & 3301 & 3402 & 3502 & 3599 & 3701 & 3801 & 3803 & 4001 & Total \\
\hline D2302 & Statistics & 10 & & 1 & & & 2 & & 1 & 7 & 1 & & 22 \\
\hline D2801 & Information Systems & & 22 & 41 & 33 & 13 & 287 & 11 & 75 & 551 & 71 & 39 & 1143 \\
\hline D2802 & Al \& Image Processing & & & 5 & 1 & & 9 & 1 & & 18 & 4 & 2 & 40 \\
\hline D2803 & Computer Software & & & & 1 & 1 & 5 & & 1 & 32 & 7 & 2 & 49 \\
\hline D3301 & Education Studies & & & & & & 5 & & 3 & 27 & 3 & 2 & 40 \\
\hline D3402 & Applied Economics & & & & & & 11 & & 6 & 7 & & 1 & 25 \\
\hline D3502 & Business and Management & & & & & & & 1 & 33 & 207 & 3 & 24 & 268 \\
\hline D3599 & Other commerce, Mgmt & & & & & & & & 2 & 11 & 1 & & 14 \\
\hline D3701 & Sociology & & & & & & & & & 63 & 5 & 8 & 76 \\
\hline D3801 & Psychology & & & & & 1 & 1 & 3 & 1 & 2 & 69 & 29 & 106 \\
\hline D3803 & Cognitive Science & & & & & & & 1 & & & & 1 & 2 \\
\hline D4001 & Journalism, Comm. \& Media & & & & & & & & & & & & 0 \\
\hline D4203 & Cultural Studies & 14 & & & & & 2 & & 1 & 11 & & 1 & 29 \\
\hline D4401 & Philosophy & 10 & & & 2 & & 4 & & 2 & 7 & & & 25 \\
\hline \multicolumn{2}{|c|}{ Total } & 37 & 22 & 48 & 37 & 15 & 328 & 17 & 125 & 945 & 164 & 109 & 1847 \\
\hline
\end{tabular}

The most often co-occurring discipline pairs were among the three most frequently cited disciplines: (2801 Information Systems, 3801 Psychology) appeared most frequently, followed by (2801 Information Systems, 3502 
Business and Management), and (3502 Business and Management, 3801 Psychology). These three disciplines (2801, 3502, \& 3801) also co-occurred with other disciplines the most, indicating that these three disciplines were often combined together or with other disciplines to support theoretical and conceptual development in $\mathrm{HCl}$ studies. Overall, the use of multiple disciplines in single studies and the number of different disciplines cited confirm the multidisciplinary nature of the $\mathrm{HCl}$ sub-discipline.

\section{RQ2.3: What contributing disciplines are often used to support what topics?}

Table 20 shows how frequently a particular topic appears in the same paper with a particular discipline (we only considered the top 14 disciplines, which represent 4,753 pairs with the topics, $98 \%$ of the 4,853 total pairs of topics, and 38 disciplines). The total in the last row for each discipline shows how many times the discipline appeared with all topics. For example, discipline 2302 (Statistics) appeared 21 times with various topics in the 758 articles. The last column shows the total frequency of each topic co-occurring with the top 14 contributing disciplines.

Table 20: Pair Frequency of Topics and Top 14 Contributing Disciplines

\begin{tabular}{|c|c|c|c|c|c|c|c|c|c|c|c|c|c|c|c|c|}
\hline \multicolumn{17}{|c|}{ Disciplines } \\
\hline \multicolumn{2}{|r|}{ Topics } & 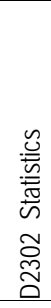 & 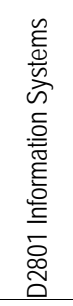 & 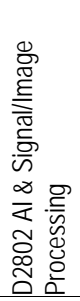 & 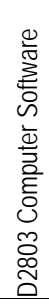 & 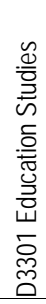 & 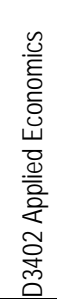 & 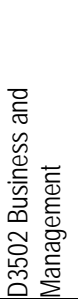 & 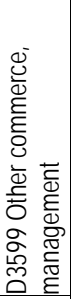 & $\begin{array}{l}8 \\
\frac{8}{0} \\
\frac{0}{8} \\
8 \\
8 \\
8 \\
8\end{array}$ & 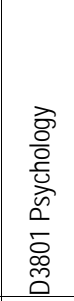 & 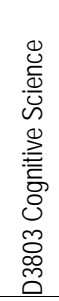 & 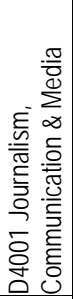 & 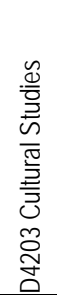 & $\begin{array}{l}\frac{7}{0} \\
\frac{0}{0} \\
\frac{0}{7} \\
\frac{1}{0} \\
\overline{0} \\
\frac{1}{0}\end{array}$ & Tota \\
\hline $\mathrm{A} 01$ & Dev. methods \& tools & \multirow{7}{*}{$\begin{array}{l}3 \\
3\end{array}$} & 12 & & 4 & & & 3 & \multirow{7}{*}{1} & 3 & 8 & 2 & \multirow{4}{*}{1} & \multirow{4}{*}{1} & 1 & 33 \\
\hline $\mathrm{A} 02$ & User analyst involvement & & 37 & & 4 & 2 & & 16 & & 5 & 26 & 3 & & & 1 & 95 \\
\hline $\mathrm{A} 03$ & SW/HW development & & 37 & 5 & 16 & 2 & 2 & 9 & & 1 & 29 & 7 & & & 1 & 111 \\
\hline $\mathrm{A} 04$ & Software/hardware evaluation & & 7 & & 3 & & & & & 1 & 2 & 1 & & & \multirow{4}{*}{1} & 14 \\
\hline A05 & User interface design \& dev. & & 51 & 7 & 9 & 1 & 2 & 17 & & 4 & 39 & 8 & 2 & 1 & & 145 \\
\hline A06 & User interface evaluation & & 49 & 3 & 10 & 2 & & 14 & & 1 & 34 & 4 & 5 & & & 126 \\
\hline A07 & User training & & 15 & & 2 & 7 & & 1 & & 2 & 14 & 4 & & & & 45 \\
\hline $\mathrm{B} 01$ & Cognitive beliefs \& behavior & 3 & 451 & 11 & 7 & 11 & 9 & 194 & 12 & 62 & 386 & 53 & 23 & 13 & 5 & 1240 \\
\hline $\mathrm{B} 02$ & Attitude & \multirow[t]{3}{*}{2} & 265 & 6 & 6 & 6 & 3 & 84 & 7 & 35 & 224 & 40 & 11 & 9 & 3 & 702 \\
\hline $\mathrm{B} 03$ & Learning & & 62 & 5 & 4 & 17 & & 18 & & 3 & 51 & 5 & 2 & & & 167 \\
\hline B04 & Motivation & & 144 & & 2 & 7 & 1 & 19 & 7 & 25 & 146 & 35 & 2 & 8 & 1 & 397 \\
\hline B05 & Emotion & \multirow{7}{*}{$\begin{array}{l}2 \\
5\end{array}$} & 67 & & & 2 & 1 & 28 & 1 & 13 & 67 & 6 & 6 & 2 & 1 & 196 \\
\hline B06 & Performance & & 254 & 7 & 14 & 14 & 4 & 81 & 5 & 30 & 233 & 50 & 12 & 8 & 2 & 720 \\
\hline B07 & Trust & & 104 & 2 & 2 & & 6 & 44 & 6 & 18 & 97 & 16 & 6 & 3 & 1 & 305 \\
\hline B08 & Ethics & & 9 & & & & & 4 & & 3 & 7 & & 1 & & 6 & 30 \\
\hline B09 & Interpersonal relationship & & 67 & 2 & 1 & & 4 & 39 & & 24 & 59 & 1 & 12 & 2 & & 211 \\
\hline B10 & User support & & 13 & & & & 1 & 8 & & & 2 & & & & & 24 \\
\hline B11 & Other & & 1 & & & & & 1 & & & 1 & & & & & 3 \\
\hline $\mathrm{C01}$ & Research & 3 & 71 & 2 & 3 & & & 32 & & 9 & 43 & 2 & 3 & 1 & 3 & 172 \\
\hline $\mathrm{CO} 2$ & Education & & 7 & & 1 & 4 & & 1 & & & 3 & 1 & & & & 17 \\
\hline & Total & 21 & 1723 & 50 & 88 & 75 & 33 & 613 & 39 & 239 & 1471 & 238 & 86 & 48 & 26 & 4753 \\
\hline
\end{tabular}

The IT Development topics (A topics) seemed to be built primarily on the fields of 2800 Information, Computing, \& Communication Sciences, 3500 Commerce, Management, Tourism \& Services, and 3800 Behavioral \& Cognitive Sciences. The overall IT Use and Impact topics (B topics) were built on much broader fields and disciplines. The three most frequently cited disciplines, Information Systems (2801), Business and Management (3502), and Psychology (3801), contributed to all the topics that were studied. The pairings of the most studied topics, Cognitive belief \& behavior (B1), Attitude (B2), and Performance (B5), and the most cited contributing disciplines, Information Systems (2801), Business and Management (3502), and Psychology (3801), were the most frequently used topicdiscipline pairs.

\section{Summary for RQ2}

The result continues to show that $\mathrm{HCl}$ studies in IS are truly multi- and interdisciplinary. The majority of studies cite more than one main supporting discipline. A large number of disciplines have contributed to the conceptual and theoretical development of the $\mathrm{HCl}$ sub-discipline as a whole, while the most influential disciplines are Information Systems, Business and Management, and Psychology. 


\section{RQ3: What are the evolutions?}

The evolutions or changes are demonstrated by comparing the data in the three periods when possible. Such comparisons are done for all seven facets.

\section{RQ3.1: What are the changes in the contexts of study over the years?}

Figure 2 shows comparisons of the three periods where we present aggregated data of a particular period. Several significant movements over the years can be identified:

1. The percentage of papers within the organization and workplace context decreased over the years.

2. The percentage of papers considering the market place context increased, which seems to coincide with ecommerce related research since the inception of the Web.

3. The percentage of papers considering the social context also increased, although the total number of such papers is still small.

4. The percentage of papers with two or three contexts increased slightly.

By looking at the most recent period of data (2003-2008), it seems that the contexts of studies are very diverse, and the most considered contexts are Organization/Workplace, Market place, and Social.

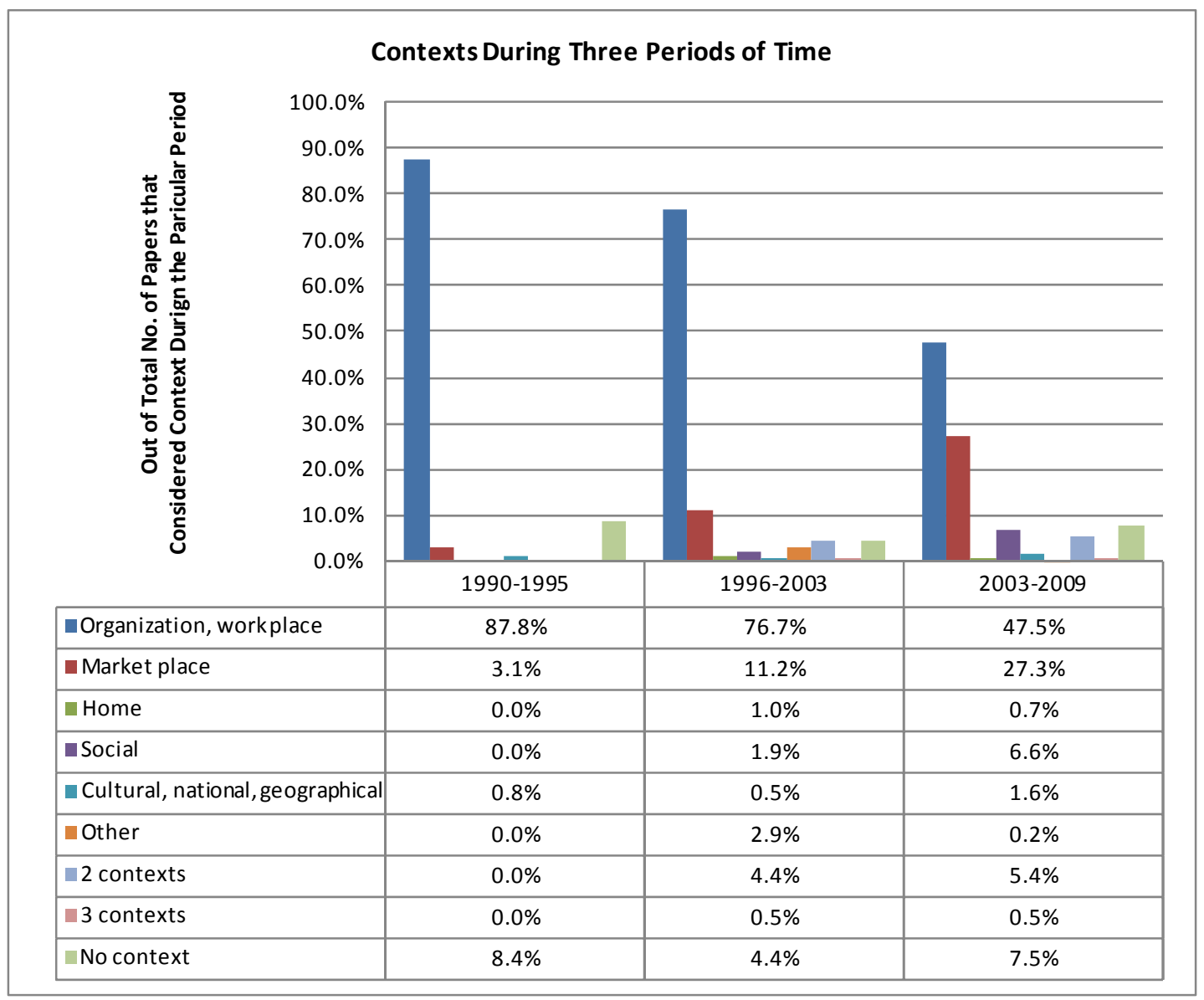

Figure 2: Contexts during the Three Periods of Time

RQ3.2: What are the changes in the subject topics over the years?

Figure 3 shows the frequencies of papers covering various numbers of topics per paper over the three time periods. It clearly shows a dramatic increase in the number of papers covering multiple topics over the years. In particular, it illustrates that as the field has continued to evolve, authors are increasingly including more topics in their papers. 


\begin{tabular}{|c|c|c|c|}
\hline \multicolumn{4}{|c|}{ Number of Topics per Paper } \\
\hline \multirow{8}{*}{$\begin{array}{l}\frac{n}{0} \\
\frac{0}{0} \\
\frac{0}{0} \\
\frac{0}{0} \\
\#\end{array}$} & & & 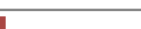 \\
\hline & & & - \\
\hline & & & 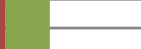 \\
\hline & & & \\
\hline & & & \\
\hline & & & \\
\hline & 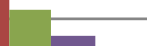 & $\square$ & \\
\hline & 1990-1995 & $1996-2002$ & 2003-2008 \\
\hline 1 topic & 57 & 98 & 99 \\
\hline 2 topics & 56 & 67 & 98 \\
\hline 3 topics & 13 & 36 & 81 \\
\hline 4 topics & 4 & 9 & 63 \\
\hline 5 topics & 1 & 3 & 57 \\
\hline 6 topics & 0 & 0 & 13 \\
\hline 7 topics & 0 & 0 & 3 \\
\hline
\end{tabular}

Figure 3: Frequencies of Papers Covering Various Numbers of Topics during the Three Periods

Several topics have gained increasing attention in recent years. Figure 4 shows seven such topics: Cognitive beliefs/behavior (B01), Attitudes (B02), Motivation (B04), Emotion (B05), Performance (B06), Trust (B07), and Interpersonal Relationship (B09).

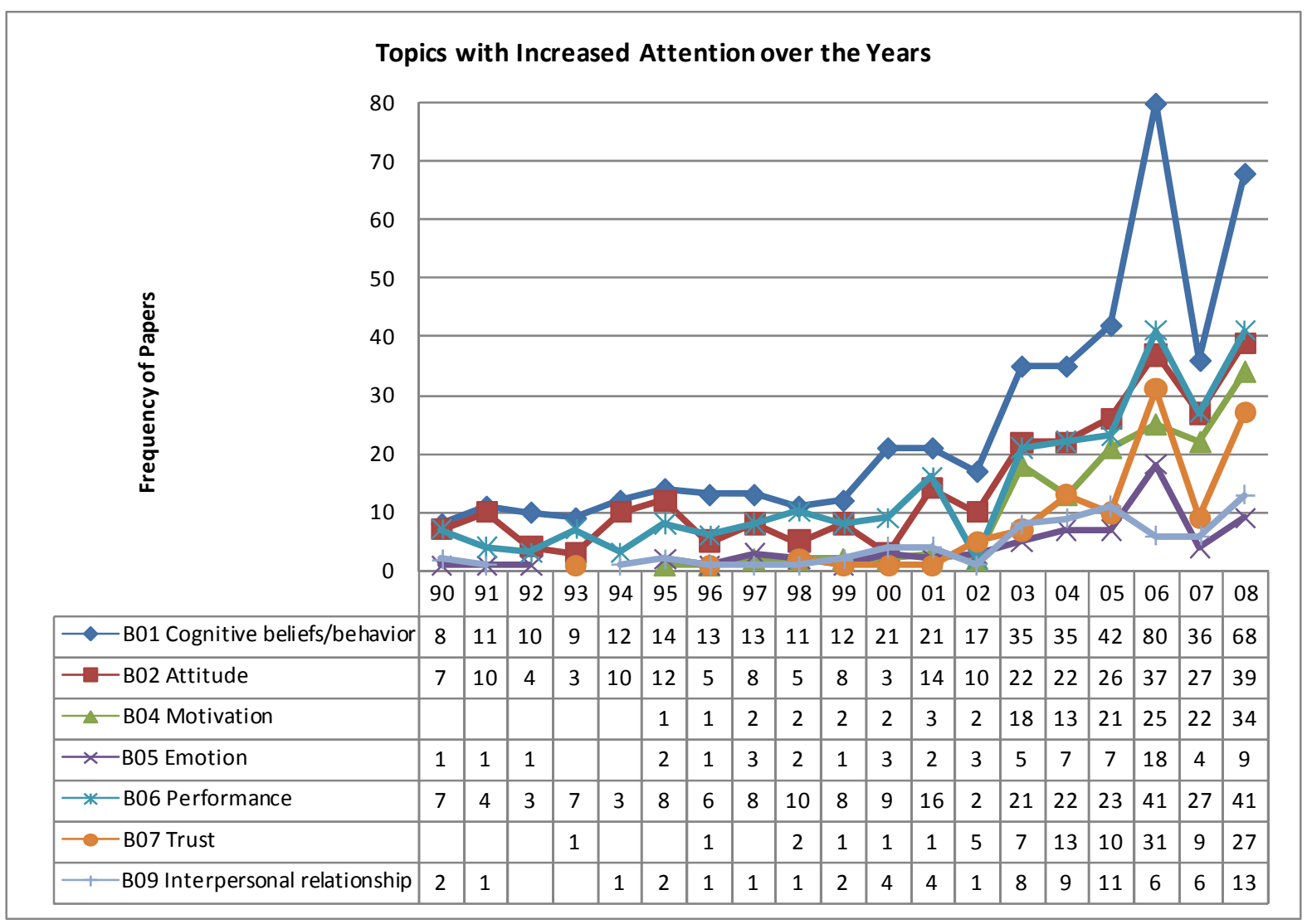

Figure 4: Topics with Increased Attention over the Years 
Figure 5 depicts the topic frequencies of the three categories (IT Development, IT Use and Impact, and General Topics related to Research or Education) over the years. It indicates that this collection of papers has a strong emphasis on issues during the Use/Impact stage where IT is post-development. This trend is also depicted by Figure 6 and Figure 7, the former indicating the frequencies of studies, and the latter, the distributions among the total number of studies within a period (thus, reporting on percentage). Although the total number of papers on IT Development has increased as shown in Figure 6, Figure 7 indicates that such studies constitute a smaller percent of all studies during each of the two recent periods.

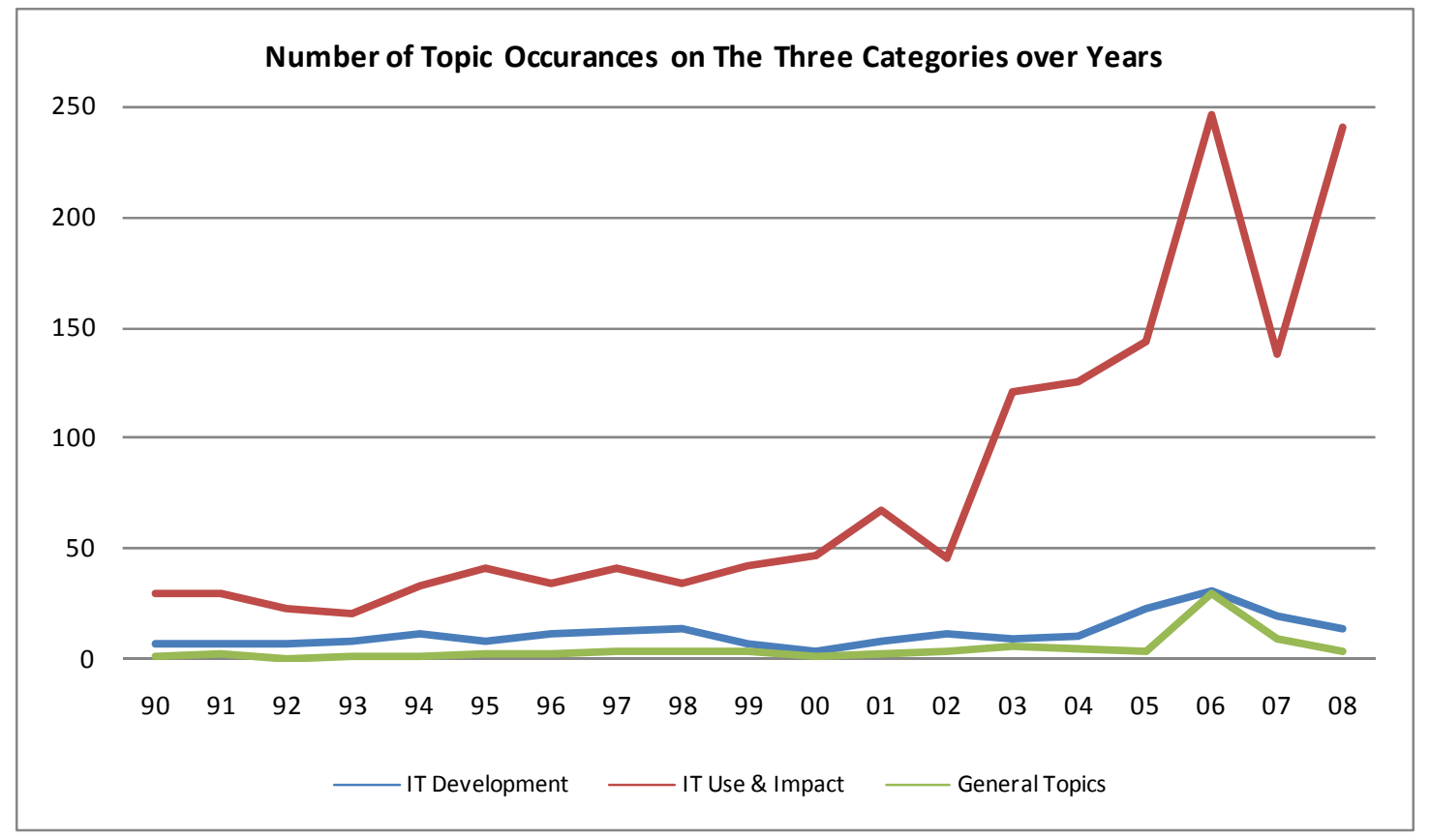

Figure 5: Number of Topic Occurrences in the Three Topic Categories over the Years

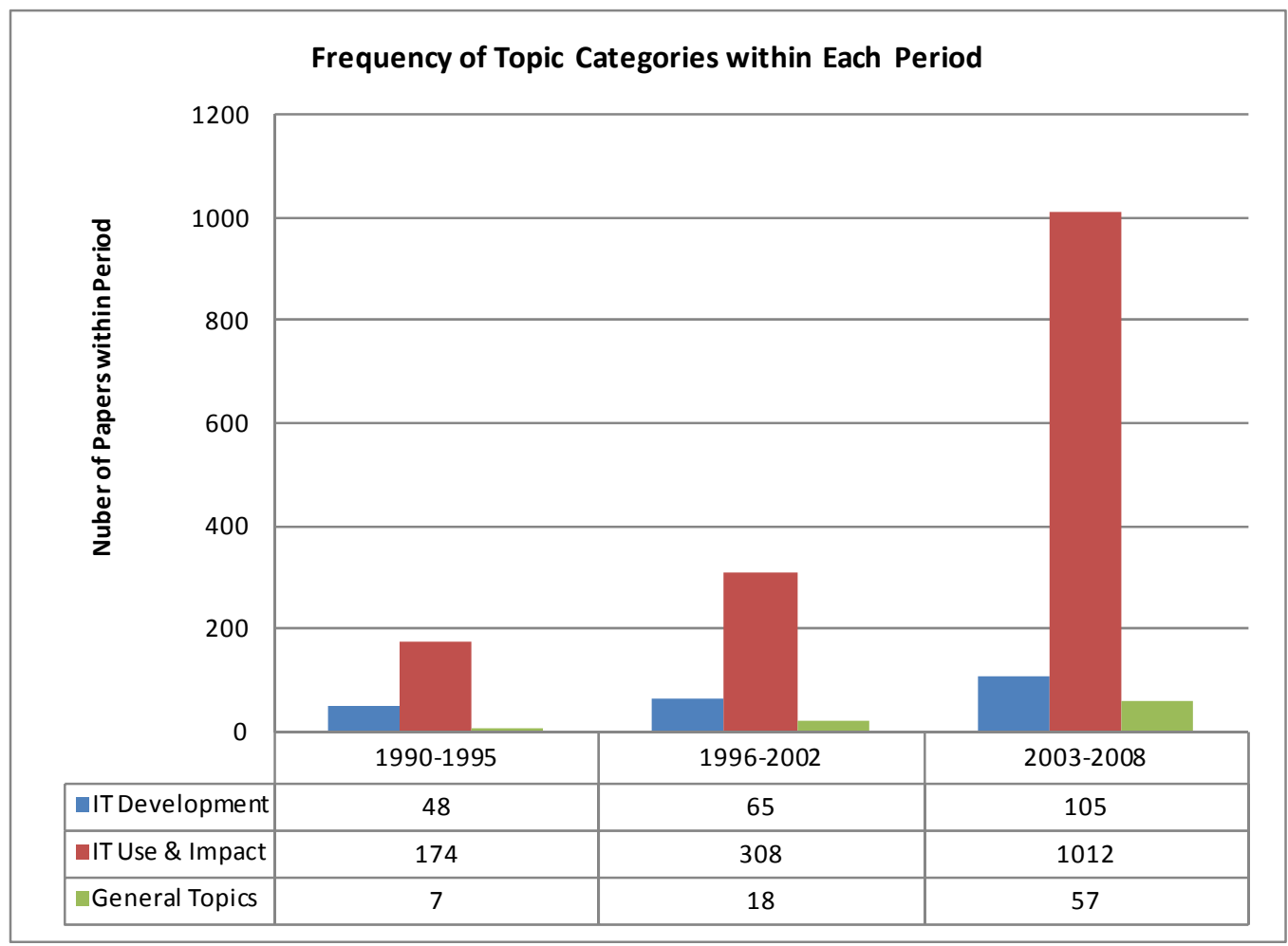

Figure 6: Frequencies of Topic Categories within Each Period 


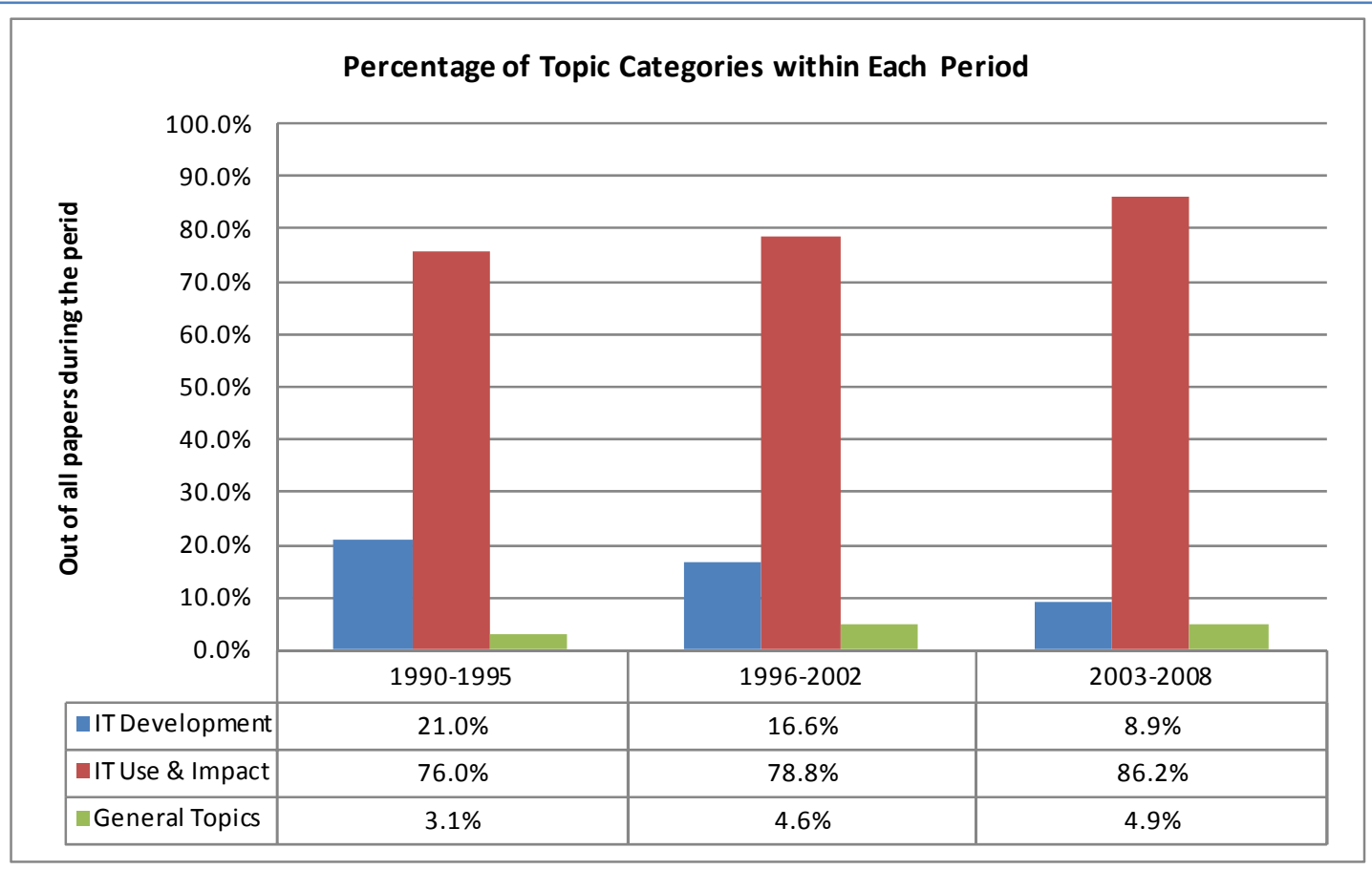

Figure 7: Percentage of Topic Categories within Each Period

\section{RQ3.3: What are the changes in the research methods over the years?}

Figure 8 depicts the distributions of method categories among the total number of studies within each period (thus percentage). The proportion of papers using empirical methods on Events/Processes (e.g., lab experiment, survey, field study, etc.) have dominated, although there has been a decrease during the period of 2003-2008. There is a great increase in the proportion of papers utilizing Conceptual orientation methods (e.g., framework, conceptual model, conceptual overview, theory) during the periods of 1996-2002 and 2003-2008. The proportion of papers utilizing Illustration methods (e.g., opinion, description of a tool or technique) also increased steadily, albeit slightly. The proportion of papers using Applied concept methods (e.g., framework and application) decreased over the three periods.

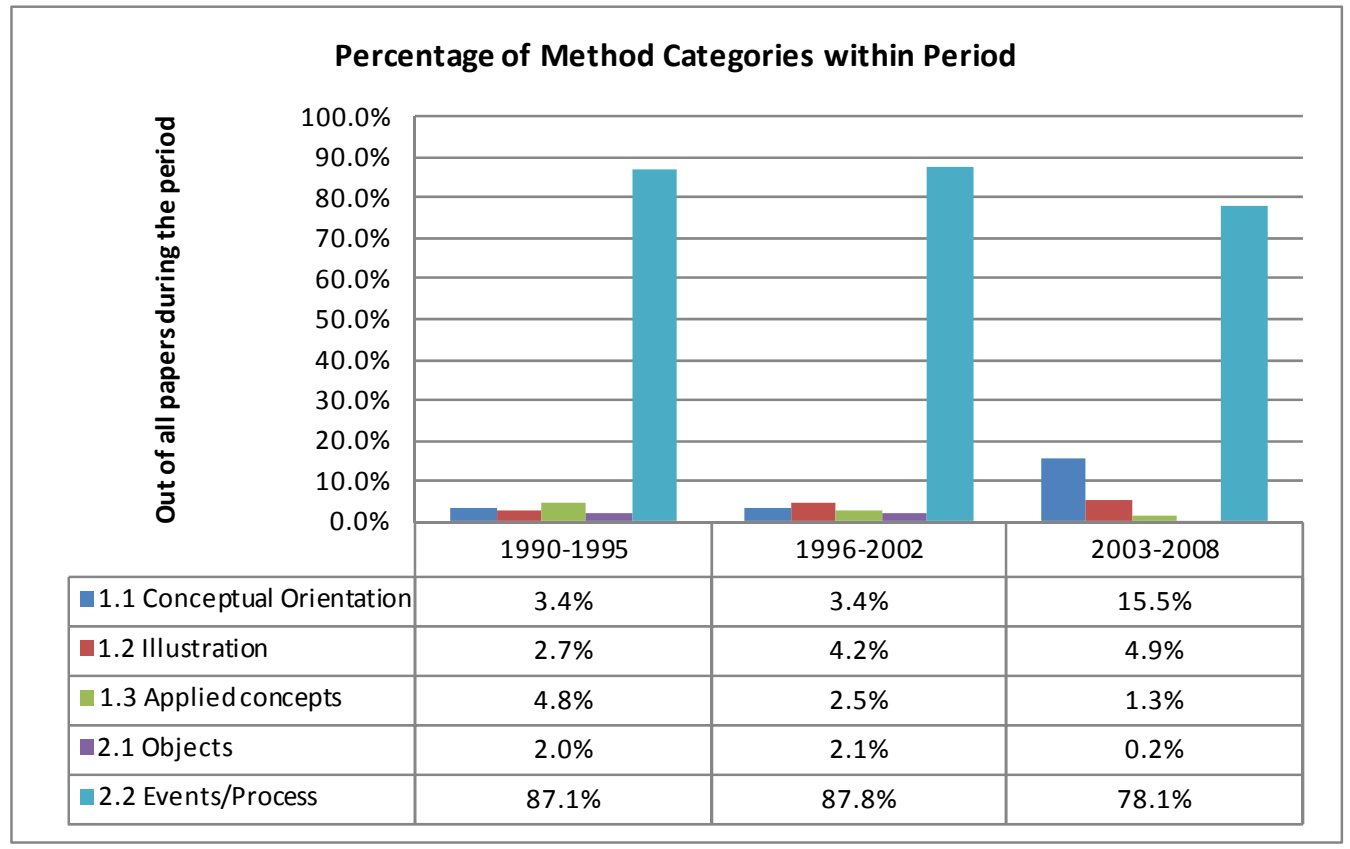

Figure 8: Percentage of Method Categories within each Period 


\section{RQ3.4: What are the changes in the level of analysis over the years?}

Figure 9 shows that over the periods of 1990-1995, 1996-2002, and 2003-2008, the percentage of papers covering individual level of analysis decreased, while the percentage of papers covering group levels and both levels increased slightly. Of note, the percentages in each period do not add up to $100 \%$ due to the small proportion of papers that did not specify any context.

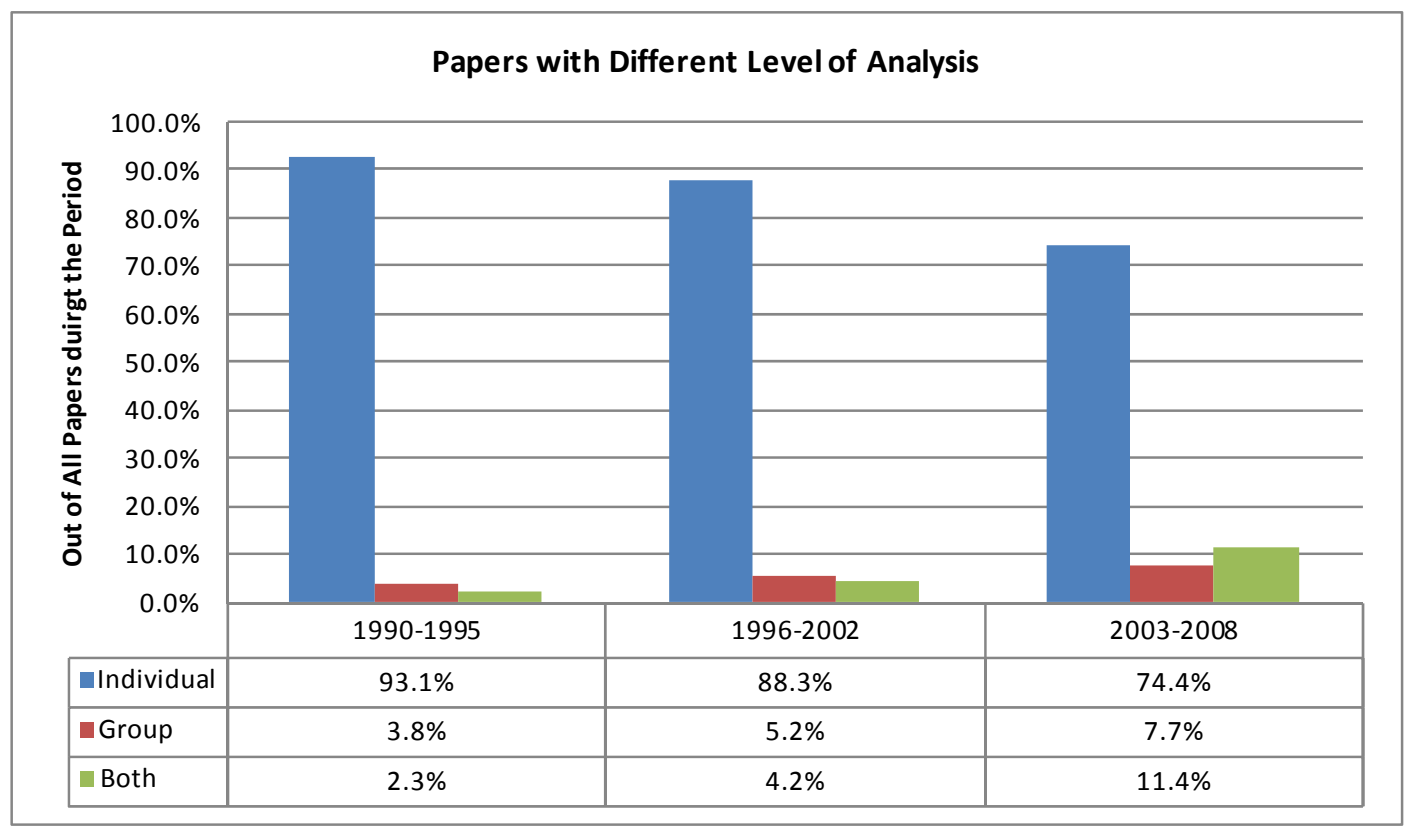

Figure 9: Percentage of Papers with Different Levels of Analysis

RQ3.5: What are the changes in considering IT or service as a research component?

Figure 10 shows the frequencies of coverage among the three categories of technology/service over the three periods of time. Both the Individual Computing and the Organizational/Social Computing categories gained increased coverage over time. The number of studies on the Service category remained about the same, which actually indicates a fall of interest due to the overall increased number of studies in the last two periods.

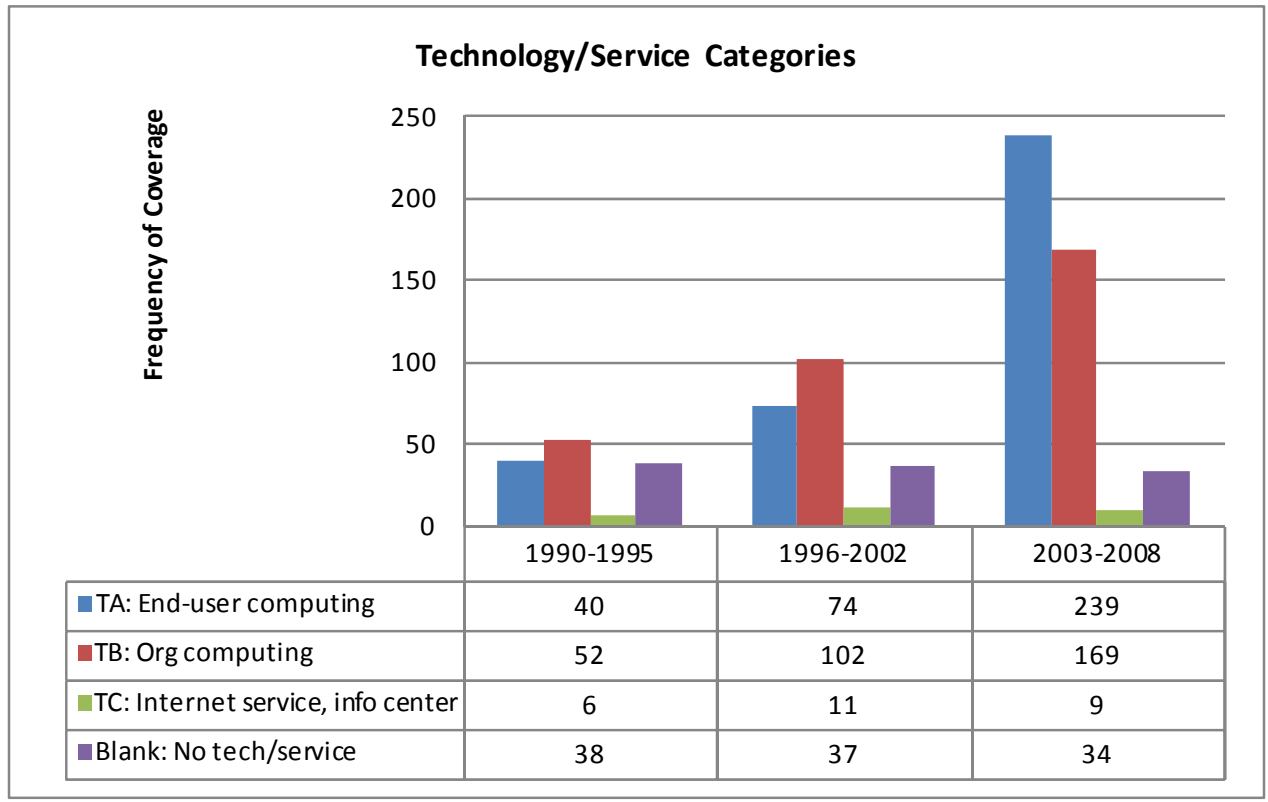

Figure 10: Coverage of Individual Computing Technologies 
Figure 11 shows the frequencies of studies covering individual computing technology over the three periods of time. Apparently, the Web gained tremendous interest in 2003-2008. Other types of technologies also gained more attention in this period. The majority of the Others type is mobile devices and PDAs that may have more than communication or productivity purposes.

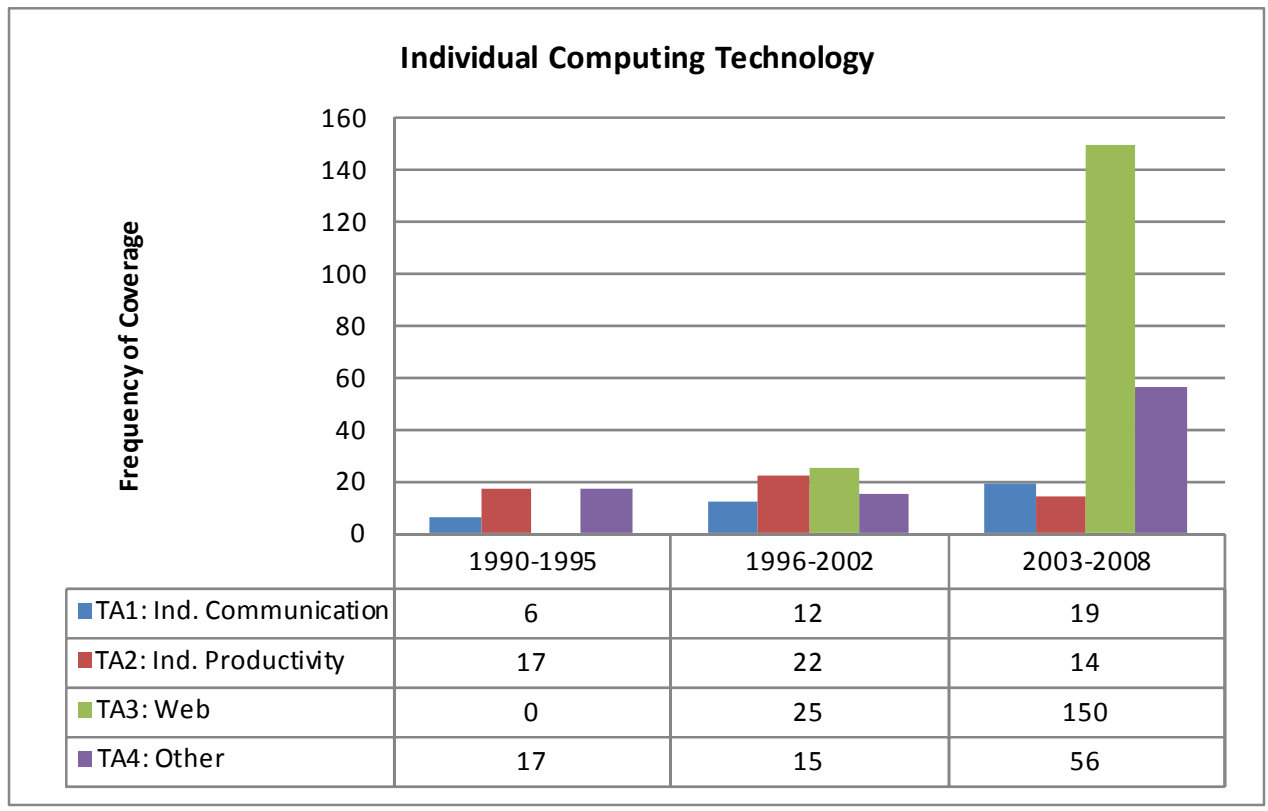

Figure 11: Coverage of Individual Computing Technologies

Figure 12 indicates the frequency of coverage on organizational/social computing technologies over each period. The number of studies covering DSS and MIS/ERP has increased over the years. The sharp increase in number of studies on MIS/ERP can be attributed to increased research interest in ERP systems. Other types of Organizational/Social Computing Technologies have also gained more attention in recent years. Some examples of the Other types are learning management systems and open source software.

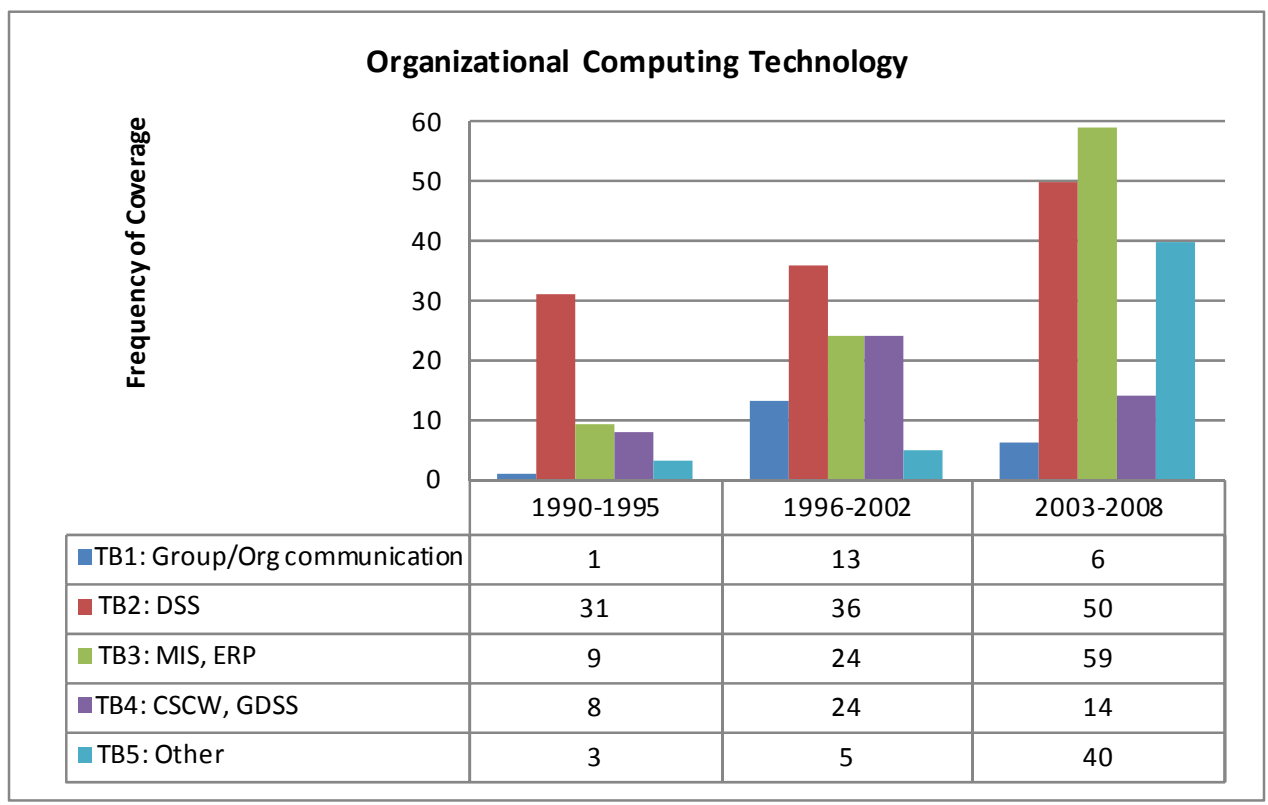

Figure 12: Coverage of Organizational/Social Computing Technologies

RQ3.6: What are the changes in considering individual characteristics as a research component?

Figure 13 shows the trend of change over time on considering individual characteristics in studies. There is a clear 
upward trend showing an increase of such considerations. During the most recent period of 2003-2008, more than $40 \%$ of the papers considered one or both types of individual characteristics. Of note, the percentages in each period do not add up to $100 \%$ due to the proportion of papers that did not consider any individual characteristics.

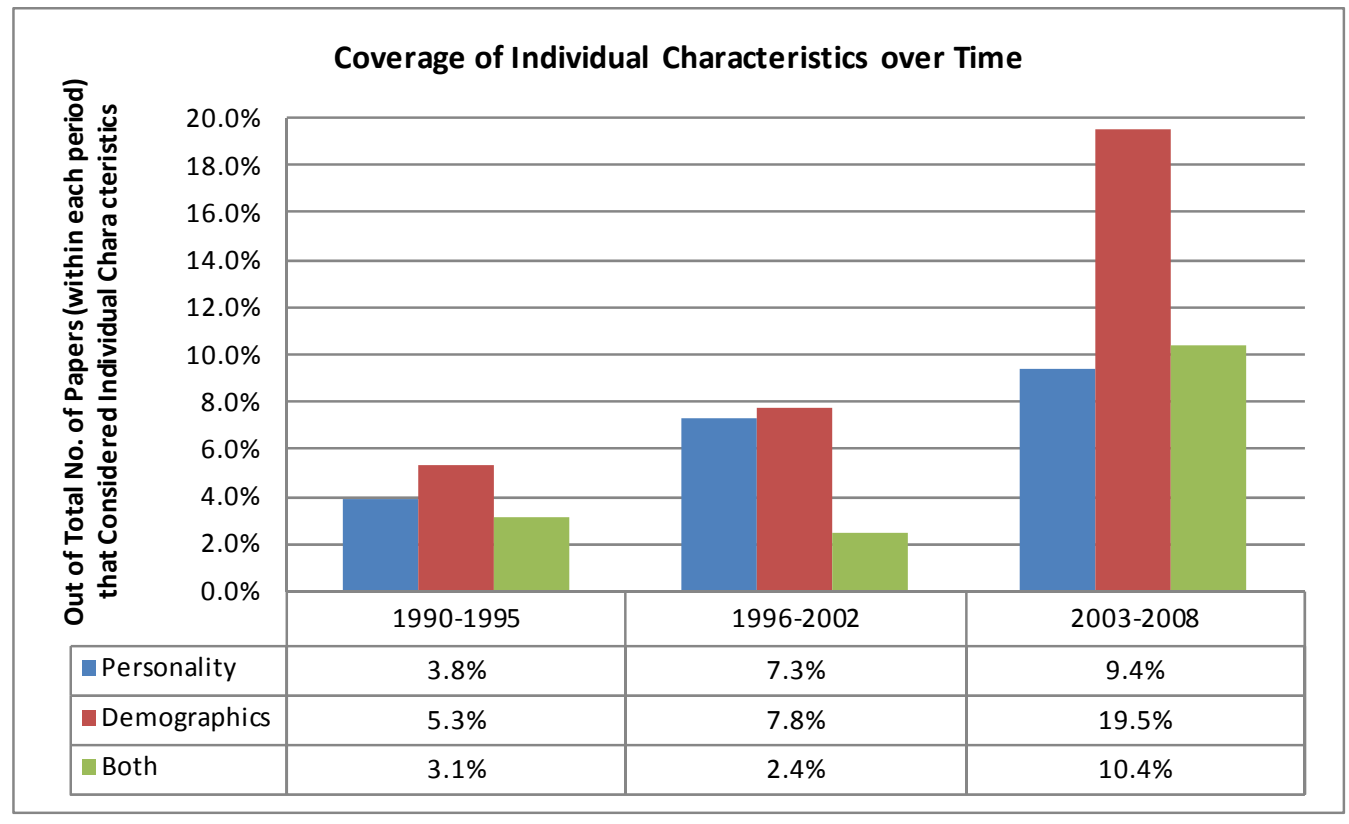

Figure 13: Coverage of Individual Characteristics During the Three Periods

\section{RQ3.7: What are the changes in the contributing disciplines over the years?}

Figure 14 shows the changes in distributions of the fields over the three periods. Note that a field includes multiple disciplines. It indicates that citations to Information, Computing and Communication Sciences (the 2800 fields) as a contributing field decreased over time. Citations to Behavioral and Cognitive Sciences (3800) and Other disciplines increased at a considerable rate over time. Citations to Commerce, Management, Tourism and Services (3500) increased slightly in 1996-2002 but dropped in 2003-2008.

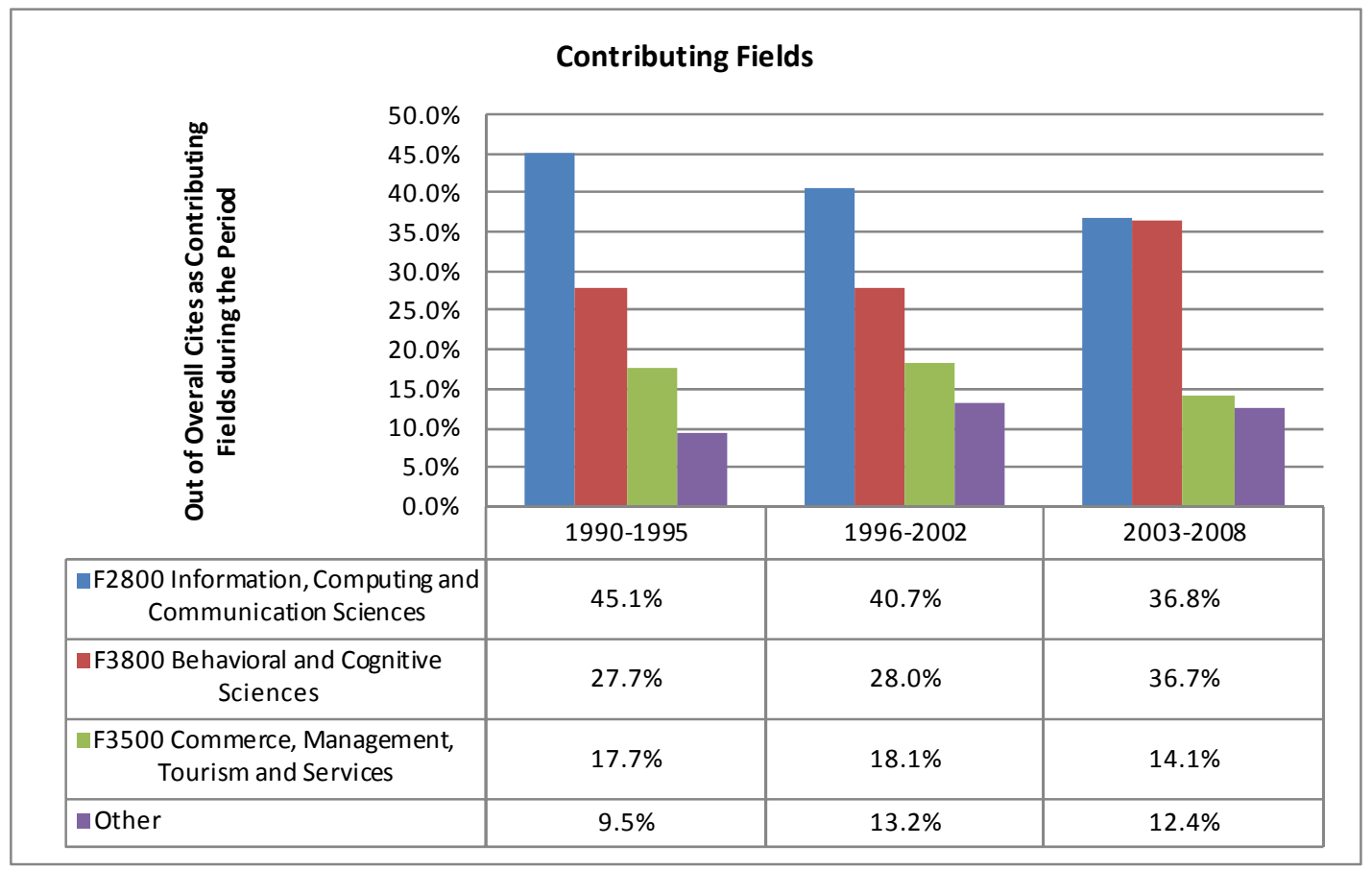

Figure 14: Contributing Fields During the Three Periods 
Figure 15 illustrates the percentage changes of the top 5 contributing disciplines during the three periods. Information Systems was the top contributing discipline across all periods, constituting 39\% of studies during 1990-1995, 35\% during 1996-2002, and 34.5\% during 2003-2008. Business and Management increased slightly in 1996-2002, but dropped in 2003-2008. Slight increases occurred in regard to Psychology and Sociology while Cognitive Science decreased in 1996-2002 but increased in 2003-2008.

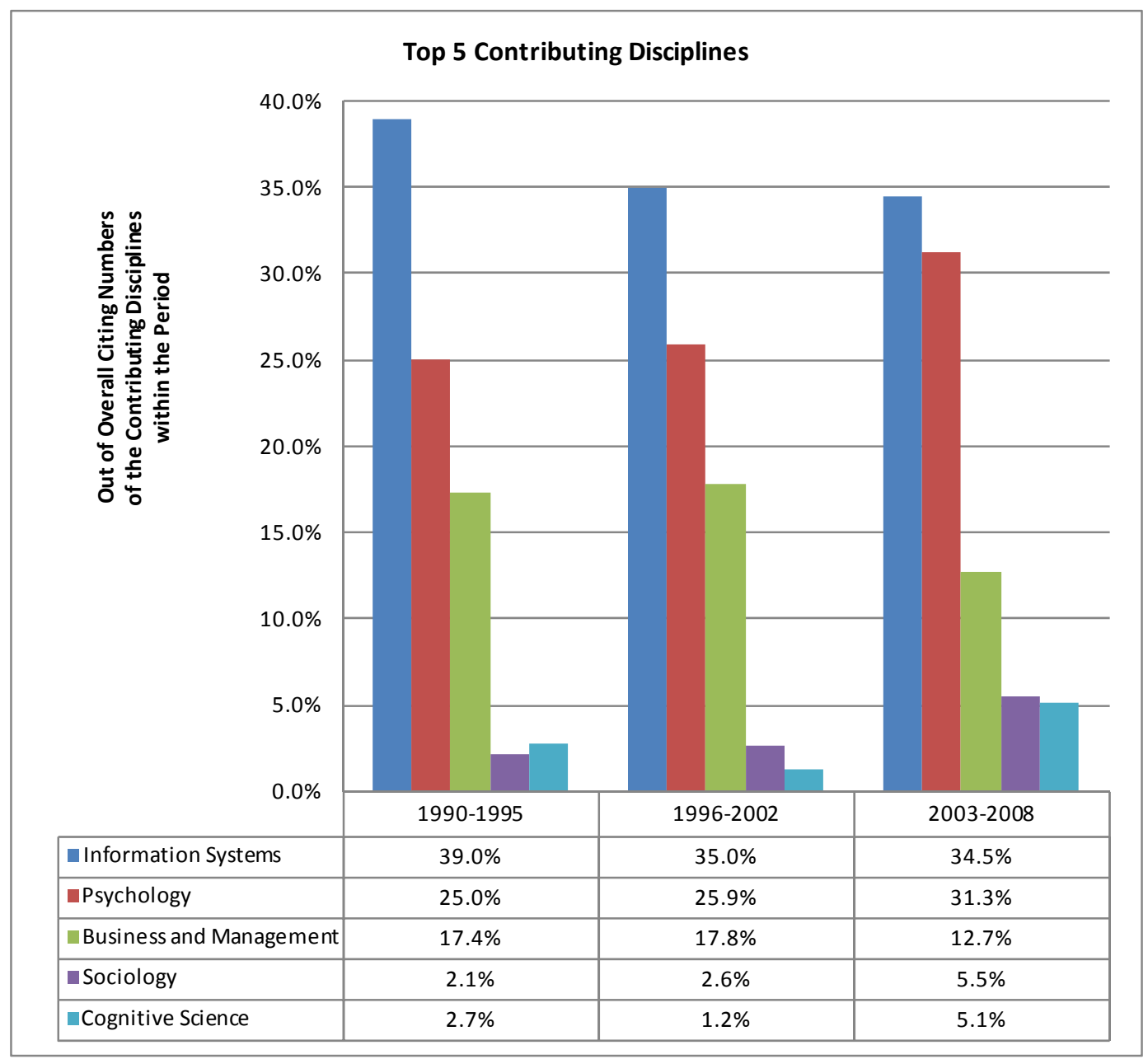

Figure 15: Top 5 Contributing Disciplines During the Three Periods

\section{Summary for RQ3}

The evolution data clearly confirms the prediction Banker and Kauffmann (2004) made about the (re)surge of the $\mathrm{HCl}$ sub-discipline within IS. The total number of studies during 2003-2008 (421) exceeds the total number of those published during 1990-2002 (337). There are changes in almost all of the seven facets. The contexts become broader and more outside organizations and workplaces. There are new or increased interests in certain topics as time progresses. There is an increasing trend of studying multiple topics within one paper. Papers on conceptual orientation have increased in recent years, although the dominating methods are still empirically based. The level of analysis has shifted slightly from the individual level to the group level. IT and service has gained more attention over the years, as both the frequency and percentage of papers specifying IT/service in the studies increased, and the percentage of papers not specifying IT/service decreased. Similarly, the number and percentage of papers covering individual characteristics increased over the years. Finally, there are also some changes among the various contributing disciplines for $\mathrm{HCl}$ studies. The reliance on Information Systems decreased over the years, while the reliance on Psychology and other disciplines increased. 


\section{RQ4: What are the Patterns of Publishing $\mathrm{HCl}$ Studies in the Various Sources?}

\section{RQ4.1: What percentage of published works are $\mathrm{HCl}$ studies? And what is the trend in such percentages?}

Since this question has to do with the general interest in, and track records of, the $\mathrm{HCl}$ studies being published, we will focus on regular IS journals (the eight primary IS journals). These include the three special issues for JAIS, one for JMIS, and one for DB, because being published in these journals as special issues is an indication of the journals' interest in $\mathrm{HCl}$. In addressing this question, we exclude the AMIS books and the six special issues outside the eight journals.

Table 21 summarizes the number of IS articles, the number of $\mathrm{HCl}$ articles, and the percentage of $\mathrm{HCl}$ articles within the IS journals in each journal for each year. Overall, $30 \%$ of the IS articles in the eight journals focused on $\mathrm{HCl}$ issues during the entire 19 years. Generally speaking, the "Total" percentage data at the bottom of the table shows an increase in the collection of the eight journals over the 19 years, as depicted in Figure 16 . The increasing trend of percentage of $\mathrm{HCl}$ studies within the eight journals over the years is additional evidence of the (re)surge of interest in $\mathrm{HCl}$.

Table 21: Number and Percentage of IS and $\mathrm{HCl}$ Articles Published in the Eight Journals

\begin{tabular}{|c|c|c|c|c|c|c|c|c|c|c|c|c|c|c|c|c|c|c|c|c|}
\hline IS Articles & 90 & 91 & 92 & 93 & 94 & 95 & 96 & 97 & 98 & 99 & 00 & 01 & 02 & 03 & 04 & 05 & 06 & 07 & 08 & Total \\
\hline CAIS & & & & & & & & & & 43 & 31 & 60 & 57 & 88 & 67 & 88 & 85 & 98 & 65 & 682 \\
\hline DB & 13 & 11 & 15 & 11 & 13 & 12 & 12 & 12 & 16 & 18 & 14 & 13 & 13 & 12 & 13 & 18 & 25 & 29 & 14 & 284 \\
\hline DS & 7 & 17 & 15 & 15 & 12 & 8 & 7 & 17 & 8 & 17 & 7 & 10 & 6 & 8 & 3 & 3 & 9 & 4 & 14 & 187 \\
\hline ISR & 20 & 12 & 16 & 13 & 20 & 16 & 26 & 21 & 21 & 20 & 24 & 21 & 27 & 15 & 20 & 21 & 21 & 23 & 25 & 382 \\
\hline JAIS & & & & & & & & & & & 10 & 8 & 7 & 23 & 18 & 14 & 33 & 34 & 31 & 178 \\
\hline JMIS & 27 & 27 & 31 & 34 & 33 & 34 & 35 & 35 & 30 & 36 & 35 & 34 & 36 & 35 & 36 & 41 & 43 & 41 & 41 & 664 \\
\hline MISQ & 27 & 30 & 31 & 26 & 23 & 23 & 20 & 17 & 18 & 21 & 23 & 16 & 16 & 18 & 21 & 27 & 41 & 30 & 35 & 463 \\
\hline $\mathrm{MS}$ & 5 & 4 & 4 & 1 & 10 & 15 & 11 & 17 & 12 & 3 & 10 & 4 & 4 & 8 & 8 & 6 & 9 & 8 & 5 & 144 \\
\hline Overall & 99 & 101 & 112 & 100 & 111 & 108 & 111 & 119 & 105 & 115 & 123 & 106 & 109 & 119 & 119 & 130 & 181 & 169 & 165 & 2302 \\
\hline $\mathrm{HCl}$ Articles & 90 & 91 & 92 & 93 & 94 & 95 & 96 & 97 & 98 & 99 & 00 & 01 & 02 & 03 & 04 & 05 & 06 & 07 & 08 & Total \\
\hline CAIS & & & & & & & & & & 2 & 1 & 3 & 1 & 6 & 6 & 11 & 11 & 10 & 10 & 61 \\
\hline $\mathrm{DB}$ & 2 & 2 & 3 & 1 & 3 & 3 & 1 & 7 & 5 & 1 & 2 & 4 & 6 & 1 & 6 & 6 & 10 & 3 & 7 & 73 \\
\hline DS & 2 & 7 & 5 & 2 & 8 & 2 & 3 & 9 & 4 & 7 & 1 & 8 & 2 & 2 & 2 & 3 & 5 & 2 & 2 & 76 \\
\hline ISR & 5 & 4 & 3 & 1 & 5 & 6 & 6 & 3 & 5 & 7 & 7 & 8 & 11 & 6 & 8 & 6 & 10 & 3 & 13 & 117 \\
\hline JAIS & & & & & & & & & & & 3 & 4 & 2 & 7 & 9 & 4 & 7 & 17 & 10 & 63 \\
\hline JMIS & 4 & 3 & 1 & 5 & 3 & 7 & 12 & 4 & 8 & 4 & 4 & 3 & 5 & 10 & 7 & 9 & 10 & 13 & 16 & 128 \\
\hline MISQ & 3 & 4 & 4 & 8 & 6 & 7 & 6 & 8 & 5 & 7 & 6 & 7 & 5 & 8 & 8 & 7 & 16 & 13 & 14 & 142 \\
\hline MS & 3 & 1 & & 1 & 1 & 6 & 2 & 1 & 1 & & 1 & & 1 & 2 & 1 & 3 & 5 & 1 & 3 & 33 \\
\hline Overall & 19 & 21 & 16 & 18 & 26 & 31 & 30 & 32 & 28 & 28 & 25 & 37 & 33 & 42 & 47 & 49 & 74 & 62 & 75 & 693 \\
\hline $\begin{array}{l}\mathrm{HCl} \\
\text { Percentage }\end{array}$ & 90 & 91 & 92 & 93 & 94 & 95 & 96 & 97 & 98 & 99 & 00 & 01 & 02 & 03 & 04 & 05 & 06 & 07 & 08 & Total \\
\hline CAIS & & & & & & & & & & $5 \%$ & $3 \%$ & $5 \%$ & $2 \%$ & $7 \%$ & $9 \%$ & $13 \%$ & $13 \%$ & $10 \%$ & $15 \%$ & $9 \%$ \\
\hline $\mathrm{DB}$ & $15 \%$ & $18 \%$ & $20 \%$ & $9 \%$ & $23 \%$ & $25 \%$ & $8 \%$ & $58 \%$ & $31 \%$ & $6 \%$ & $14 \%$ & $31 \%$ & $46 \%$ & $8 \%$ & $46 \%$ & $33 \%$ & $40 \%$ & $10 \%$ & $50 \%$ & $26 \%$ \\
\hline DS & $29 \%$ & $41 \%$ & $33 \%$ & $13 \%$ & $67 \%$ & $25 \%$ & $43 \%$ & $53 \%$ & $50 \%$ & $41 \%$ & $14 \%$ & $80 \%$ & $33 \%$ & $25 \%$ & $67 \%$ & $100 \%$ & $56 \%$ & $50 \%$ & $14 \%$ & $41 \%$ \\
\hline ISR & $25 \%$ & $33 \%$ & $19 \%$ & $8 \%$ & $25 \%$ & $38 \%$ & $23 \%$ & $14 \%$ & $24 \%$ & $35 \%$ & $29 \%$ & $38 \%$ & $41 \%$ & $40 \%$ & $40 \%$ & $29 \%$ & $48 \%$ & $13 \%$ & $52 \%$ & $31 \%$ \\
\hline JAIS & & & & & & & & & & & $30 \%$ & $50 \%$ & $29 \%$ & $30 \%$ & $50 \%$ & $29 \%$ & $21 \%$ & $50 \%$ & $32 \%$ & $35 \%$ \\
\hline JMIS & $15 \%$ & $11 \%$ & $3 \%$ & $15 \%$ & $9 \%$ & $21 \%$ & $34 \%$ & $11 \%$ & $27 \%$ & $11 \%$ & $11 \%$ & $9 \%$ & $14 \%$ & $29 \%$ & $19 \%$ & $22 \%$ & $23 \%$ & $32 \%$ & $39 \%$ & $19 \%$ \\
\hline MISQ & $11 \%$ & $13 \%$ & $13 \%$ & $31 \%$ & $26 \%$ & $30 \%$ & $30 \%$ & $47 \%$ & $28 \%$ & $33 \%$ & $26 \%$ & $44 \%$ & $31 \%$ & $44 \%$ & $38 \%$ & $26 \%$ & $39 \%$ & $43 \%$ & $40 \%$ & $31 \%$ \\
\hline MS & $60 \%$ & $25 \%$ & $0 \%$ & $100 \%$ & $10 \%$ & $40 \%$ & $18 \%$ & $6 \%$ & $8 \%$ & $0 \%$ & $10 \%$ & $0 \%$ & $25 \%$ & $25 \%$ & $13 \%$ & $50 \%$ & $56 \%$ & $13 \%$ & $60 \%$ & $23 \%$ \\
\hline Overall & $19 \%$ & $21 \%$ & $14 \%$ & $18 \%$ & $23 \%$ & $29 \%$ & $27 \%$ & $27 \%$ & $27 \%$ & $24 \%$ & $20 \%$ & $35 \%$ & $30 \%$ & $35 \%$ & $39 \%$ & $38 \%$ & $41 \%$ & $37 \%$ & $45 \%$ & $30 \%$ \\
\hline
\end{tabular}




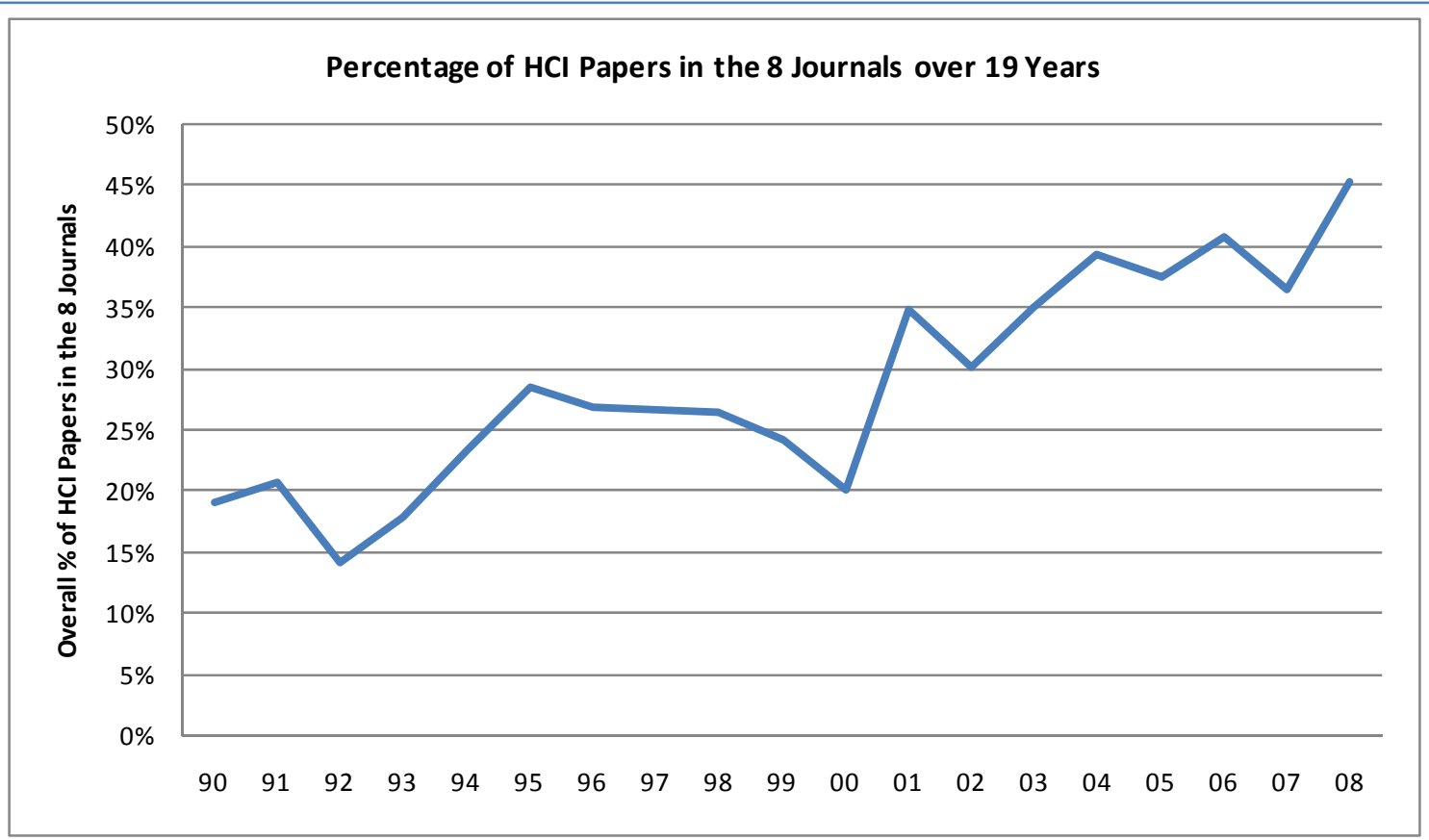

Figure 16: Total Percentage of $\mathrm{HCl}$ Articles in 8 Journals Over 19 Years

Figure 17 depicts the percentages of $\mathrm{HCl}$ articles published in each journal over the three periods (CAIS and JAIS, which were founded in 1999 and 2000, respectively, have only two periods). These percentages range from 4\% to $47 \%$. Within each journal, there seems to be an overall increasing trend in the percentage of $\mathrm{HCl}$ articles among the published IS studies, except for JAIS which started with a strong $\mathrm{HCl}$ focus and has maintained that, and MS, which publishes a small and irregular number of IS articles.

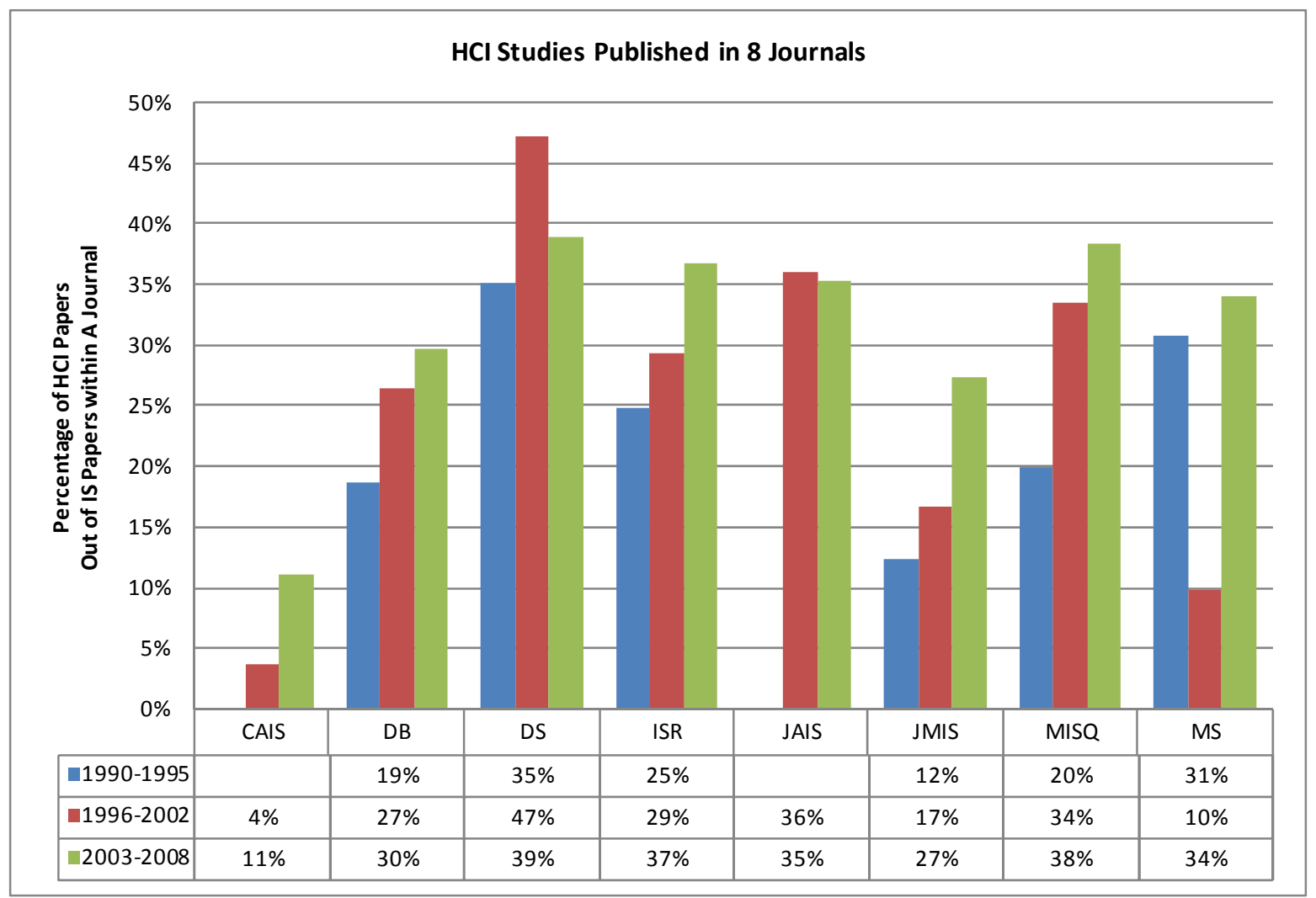

Figure 17: Percentage of the $\mathrm{HCl}$ Articles in Each Journal Over Three Periods of Time 


\section{RQ4.2: What topics are "preferred" by which sources?}

By sources, we refer to the eight regular journals, six special issues in four other journals, and the two AMIS books. Table 22 shows the percentage of topics published within each of the sources (8 journals, AMS books, special issues outside the 8 journals). In each source, the percentages of IT Development (A), IT Use and Impact (B), and Research and Education (C) topical categories add up to 100\%. Table 22 also demonstrates the total $\mathrm{HCl}$ topics and the average number of topics per $\mathrm{HCl}$ article in a source. We derive the following observations from the table:

- $\quad$ Cognitive belief and behavior (B01) was the predominant topic, with Attitude (B02), and Performance (B06) following as the second and third in all sources.

- $\quad$ Cognitive belief and behavior (B01), Attitude (B02), and Emotion (B05) were covered by all sources.

- Among the eight journals, Data Base has the highest ratio on IT Development (A topics) coverage, while JAIS has the highest ratio on IT Use and Impact (B topics) coverage.

- The AMIS books have the highest ratio on general research and education issues (C topics), which is consistent with the goals of the books.

- $\quad$ The average number of topics per paper varies greatly among the sources. The special issues and the AMIS books have fewer topics per paper, as compared to the papers in the eight regular journals. Among the eight journals, the newest ones, CAIS and JAIS, have the highest average number of topics per paper: 3.4 and 3.0 , respectively. JMIS has an average of 2.8 topics per paper, which is higher than the average number of 2.4 .

Table 22: Percentage of Topics within Sources

\begin{tabular}{|c|c|c|c|c|c|c|c|c|c|c|c|c|c|c|c|}
\hline \multicolumn{2}{|r|}{ Topic } & \multirow{2}{*}{$\begin{array}{c}\text { AMIS } \\
1 \%\end{array}$} & \multirow[t]{2}{*}{ BIT } & \multirow[t]{2}{*}{$\mathrm{IJHCl}$} & \multirow[t]{2}{*}{ IJHCS } & \multirow[t]{2}{*}{ ISJ } & \multirow{2}{*}{$\begin{array}{c}\text { CAIS } \\
1 \%\end{array}$} & \multirow{2}{*}{$\begin{array}{l}\text { DB } \\
1 \%\end{array}$} & \multirow[t]{2}{*}{ DS } & \multirow{2}{*}{$\frac{\text { ISR }}{1 \%}$} & \multirow{2}{*}{$\begin{array}{c}\text { JAIS } \\
1 \%\end{array}$} & \multirow{2}{*}{$\begin{array}{c}\text { JMIS } \\
1 \%\end{array}$} & \multirow[t]{2}{*}{ MISQ } & \multirow[t]{2}{*}{ MS } & \multirow{2}{*}{$\begin{array}{c}\text { Total } \\
0.7 \%\end{array}$} \\
\hline $\mathrm{A} 01$ & Deve. methods \& tools & & & & & & & & & & & & & & \\
\hline $\mathrm{A} 02$ & User analyst involvement & $3 \%$ & & & & & $1 \%$ & $4 \%$ & $2 \%$ & $2 \%$ & $1 \%$ & $1 \%$ & $3 \%$ & $5 \%$ & $2.1 \%$ \\
\hline $\mathrm{A} 03$ & SW/HW development & & & & & & $0 \%$ & $4 \%$ & $1 \%$ & $3 \%$ & & $3 \%$ & $2 \%$ & $8 \%$ & $2.2 \%$ \\
\hline $\mathrm{A} 04$ & SW/HW evaluation & & & & $12 \%$ & & $1 \%$ & $2 \%$ & & & & & & & $0.4 \%$ \\
\hline A05 & User interface design \& dev. & $1 \%$ & & $5 \%$ & & $11 \%$ & $5 \%$ & $2 \%$ & $3 \%$ & $3 \%$ & $2 \%$ & $2 \%$ & $4 \%$ & $2 \%$ & $3.0 \%$ \\
\hline $\mathrm{A} 06$ & User interface evaluation & $3 \%$ & & $15 \%$ & $6 \%$ & & $3 \%$ & $5 \%$ & $10 \%$ & $2 \%$ & $1 \%$ & $2 \%$ & $2 \%$ & & $2.8 \%$ \\
\hline \multirow[t]{2}{*}{$\mathrm{A} 07$} & User training & & & & & & $3 \%$ & & & & $1 \%$ & $1 \%$ & $1 \%$ & & $0.8 \%$ \\
\hline & Subtotal of $A$ & $8 \%$ & $0 \%$ & $20 \%$ & $18 \%$ & $11 \%$ & $15 \%$ & $19 \%$ & $16 \%$ & $12 \%$ & $6 \%$ & $10 \%$ & $12 \%$ & $15 \%$ & $12 \%$ \\
\hline B01 & Cognitive beliefs and behavior & $24 \%$ & $43 \%$ & $40 \%$ & $35 \%$ & $33 \%$ & $16 \%$ & $31 \%$ & $28 \%$ & $31 \%$ & $21 \%$ & $23 \%$ & $29 \%$ & $34 \%$ & $26.1 \%$ \\
\hline B02 & Attitude & $1 \%$ & $14 \%$ & $10 \%$ & $12 \%$ & $22 \%$ & $16 \%$ & $14 \%$ & $16 \%$ & $12 \%$ & $18 \%$ & $20 \%$ & $13 \%$ & $18 \%$ & $15.2 \%$ \\
\hline B03 & Learning & $1 \%$ & & & & & $1 \%$ & $6 \%$ & $5 \%$ & $6 \%$ & $3 \%$ & $3 \%$ & $4 \%$ & & $3.5 \%$ \\
\hline B04 & Motivation & $3 \%$ & & $10 \%$ & $6 \%$ & & $16 \%$ & $1 \%$ & $1 \%$ & $4 \%$ & $14 \%$ & $13 \%$ & $7 \%$ & & $8.2 \%$ \\
\hline B05 & Emotion & $7 \%$ & $14 \%$ & $10 \%$ & $18 \%$ & $11 \%$ & $2 \%$ & $4 \%$ & $1 \%$ & $5 \%$ & $5 \%$ & $2 \%$ & $5 \%$ & $6 \%$ & $3.9 \%$ \\
\hline B06 & Performance & $14 \%$ & $29 \%$ & $5 \%$ & & $11 \%$ & $17 \%$ & $9 \%$ & $17 \%$ & $15 \%$ & $17 \%$ & $17 \%$ & $12 \%$ & $15 \%$ & $14.8 \%$ \\
\hline B07 & Trust & $7 \%$ & & $5 \%$ & $6 \%$ & $11 \%$ & $7 \%$ & $6 \%$ & $1 \%$ & $5 \%$ & $6 \%$ & $7 \%$ & $7 \%$ & $3 \%$ & $6.1 \%$ \\
\hline B08 & Ethics & $1 \%$ & & & & & & & & & $2 \%$ & & $2 \%$ & & $0.6 \%$ \\
\hline B09 & Interpersonal relationship & & & & & & $1 \%$ & $7 \%$ & $3 \%$ & $7 \%$ & $4 \%$ & $2 \%$ & $5 \%$ & $10 \%$ & $4.1 \%$ \\
\hline B10 & User support & & & & & & $0 \%$ & $1 \%$ & $3 \%$ & & & $1 \%$ & $1 \%$ & & $0.7 \%$ \\
\hline \multirow[t]{2}{*}{ B11 } & Others & & & & & & & & & & & & $0 \%$ & & $0.1 \%$ \\
\hline & Subtotal of $B$ & $58 \%$ & $100 \%$ & $80 \%$ & $76 \%$ & $89 \%$ & $78 \%$ & $79 \%$ & $77 \%$ & $85 \%$ & $90 \%$ & $89 \%$ & $85 \%$ & $85 \%$ & $83 \%$ \\
\hline $\mathrm{C} 01$ & Research & $32 \%$ & & & & & $5 \%$ & $3 \%$ & $7 \%$ & $3 \%$ & $4 \%$ & $1 \%$ & $3 \%$ & & $4.2 \%$ \\
\hline \multirow[t]{6}{*}{$\mathrm{CO2}$} & Education & $1 \%$ & & & $6 \%$ & & $1 \%$ & & & & & $1 \%$ & & & $0.4 \%$ \\
\hline & Subtotal of $C$ & $33 \%$ & $0 \%$ & $0 \%$ & $6 \%$ & $0 \%$ & $7 \%$ & $3 \%$ & $7 \%$ & $3 \%$ & $4 \%$ & $1 \%$ & $3 \%$ & $0 \%$ & $5 \%$ \\
\hline & Total $\%$ of Topics & $100 \%$ & $100 \%$ & $100 \%$ & $100 \%$ & $100 \%$ & $100 \%$ & $100 \%$ & $100 \%$ & $100 \%$ & $100 \%$ & $100 \%$ & $100 \%$ & $100 \%$ & $100 \%$ \\
\hline & Total \# of Topics & 72 & 7 & 20 & 17 & 9 & 207 & 140 & 134 & 260 & 187 & 354 & 325 & 62 & 1794 \\
\hline & Total \# of $\mathrm{HCl}$ papers & 37 & 3 & 12 & 8 & 5 & 61 & 73 & 76 & 117 & 63 & 128 & 142 & 33 & 758 \\
\hline & rage \# of topics per paper & 1.9 & 2.3 & 1.7 & 2.1 & 1.8 & 3.4 & 1.9 & 1.8 & 2.2 & 3.0 & 2.8 & 2.3 & 1.9 & 2.4 \\
\hline
\end{tabular}




\section{RQ4.3: What methods are "preferred" by which sources?}

Table 23 summarizes the percentage of the various methods used within each source, with the percentages of all methods used in $\mathrm{HCl}$ papers adding up to $100 \%$. The table also demonstrates the total number of methods and the average number of methods per $\mathrm{HCl}$ article in the source.

Table 23 shows that among this collection, the various sources demonstrated slightly different emphases on research methods. The AMIS books and the special issues show some distinctive preferences on methods. For example, AMIS book chapters utilized a great deal of non-empirical methods, in particular, frameworks, opinions, and models. Such emphasis reflects the nature of these books to be collections of work that synthesize existing work and provide directions for future research. Due to small numbers of $\mathrm{HCl}$ articles in the other four special issue sources, the distribution of methods used is even more condensed than that of the eight journals.

Table 23: Percentage of Methods within Sources

\begin{tabular}{|c|c|c|c|c|c|c|c|c|c|c|c|c|c|c|}
\hline Method & AMIS & BIT & $\mathrm{IJHCl}$ & IJHCS & ISJ & CAIS & DB & DS & ISR & JAIS & JMIS & MISQ & MS & Total \\
\hline 1.1.1 Framework & $18 \%$ & & & & & $23 \%$ & & & & & $1 \%$ & $1 \%$ & & $3 \%$ \\
\hline 1.1.2 Conceptual model & $10 \%$ & & & $13 \%$ & & $12 \%$ & $2 \%$ & & $2 \%$ & $16 \%$ & $3 \%$ & $8 \%$ & & $5 \%$ \\
\hline 1.1.3 Conceptual overview & $5 \%$ & & & & & $2 \%$ & & & & $1 \%$ & $1 \%$ & $1 \%$ & $2 \%$ & $1 \%$ \\
\hline 1.1.4 Theory & & & & & & & & & & $7 \%$ & & & & $1 \%$ \\
\hline 1.2.1 Opinion (pure) & $15 \%$ & & & $13 \%$ & & $3 \%$ & $1 \%$ & $3 \%$ & $1 \%$ & $1 \%$ & & $4 \%$ & & $3 \%$ \\
\hline 1.2.2 Opinion (personal exp) & $10 \%$ & & & & & & & & & & & & & $0.5 \%$ \\
\hline 1.2.3 Desc. a tool, technique & $8 \%$ & & $8 \%$ & & & $6 \%$ & & & $1 \%$ & & & $1 \%$ & & $1 \%$ \\
\hline 1.3.1 Frameworks \& appl. & $8 \%$ & & & & $20 \%$ & & $1 \%$ & $2 \%$ & $4 \%$ & & $2 \%$ & $3 \%$ & & $2 \%$ \\
\hline Conceptual Methods Subtotal & $74 \%$ & & $8 \%$ & $25 \%$ & $20 \%$ & $46 \%$ & $5 \%$ & $6 \%$ & $8 \%$ & $27 \%$ & $8 \%$ & $16 \%$ & $2 \%$ & $16 \%$ \\
\hline 2.1.2 Desc. of a specific appl. & & & & & & & $4 \%$ & & & & $3 \%$ & $1 \%$ & $2 \%$ & $1 \%$ \\
\hline 2.2.1 Lab experiment & $13 \%$ & $100 \%$ & $46 \%$ & $38 \%$ & $20 \%$ & $6 \%$ & $16 \%$ & $38 \%$ & $35 \%$ & $19 \%$ & $41 \%$ & $14 \%$ & $24 \%$ & $26 \%$ \\
\hline 2.2.2 Field experiment & & & $8 \%$ & & $20 \%$ & $2 \%$ & $6 \%$ & $7 \%$ & $2 \%$ & $3 \%$ & $3 \%$ & $10 \%$ & $2 \%$ & $5 \%$ \\
\hline 2.2.3 Field study & $3 \%$ & & & $13 \%$ & & $3 \%$ & $17 \%$ & $6 \%$ & $13 \%$ & $1 \%$ & $14 \%$ & $7 \%$ & $19 \%$ & $9 \%$ \\
\hline 2.2.4 Positivist case study & & & & $13 \%$ & & $3 \%$ & $5 \%$ & $1 \%$ & & $3 \%$ & $1 \%$ & $6 \%$ & $2 \%$ & $3 \%$ \\
\hline 2.2.5 Interpretive case study & & & & & & $3 \%$ & $5 \%$ & & $1 \%$ & $1 \%$ & $1 \%$ & $5 \%$ & & $2 \%$ \\
\hline 2.2.6 Action research & & & & & & $2 \%$ & $1 \%$ & & & & & & & $0.2 \%$ \\
\hline 2.2.7 Survey & $8 \%$ & & $31 \%$ & $13 \%$ & $20 \%$ & $26 \%$ & $29 \%$ & $28 \%$ & $22 \%$ & $33 \%$ & $23 \%$ & $34 \%$ & $21 \%$ & $26 \%$ \\
\hline 2.2.8 Instrument develop. & & & & & $20 \%$ & & $6 \%$ & $10 \%$ & $9 \%$ & $1 \%$ & $1 \%$ & $2 \%$ & $5 \%$ & $4 \%$ \\
\hline 2.2.10 Secondary data & & & & & & & $5 \%$ & $2 \%$ & $5 \%$ & $1 \%$ & $1 \%$ & $1 \%$ & $14 \%$ & $3 \%$ \\
\hline 2.2.11 Interview & $3 \%$ & & $8 \%$ & & & $5 \%$ & & $2 \%$ & $4 \%$ & $6 \%$ & $4 \%$ & $3 \%$ & $5 \%$ & $3 \%$ \\
\hline 2.2.12 Delphi & & & & & & & $1 \%$ & & & & $1 \%$ & $1 \%$ & & $0.4 \%$ \\
\hline 2.2.13 Focus group & & & & & & $5 \%$ & & & & $3 \%$ & & & $2 \%$ & $1 \%$ \\
\hline 2.2.14 Other & & & & & & & & & $1 \%$ & & & $1 \%$ & & $0.4 \%$ \\
\hline Empirical Methods Subtotal & $26 \%$ & $100 \%$ & $92 \%$ & $75 \%$ & $80 \%$ & $54 \%$ & $95 \%$ & $94 \%$ & $92 \%$ & $73 \%$ & $92 \%$ & $84 \%$ & $98 \%$ & $84 \%$ \\
\hline Total \% & $100 \%$ & $100 \%$ & $100 \%$ & $100 \%$ & $100 \%$ & $100 \%$ & $100 \%$ & $100 \%$ & $100 \%$ & $100 \%$ & $100 \%$ & $100 \%$ & $100 \%$ & $100 \%$ \\
\hline Total \# of methods used & 39 & 3 & 13 & 8 & 5 & 65 & 82 & 88 & 136 & 67 & 138 & 152 & 42 & 838 \\
\hline Total \# of $\mathrm{HCl}$ papers & 37 & 3 & 12 & 8 & 5 & 61 & 73 & 76 & 117 & 63 & 128 & 142 & 33 & 758 \\
\hline Average \# of methods per paper & 1.1 & 1.0 & 1.1 & 1.0 & 1.0 & 1.1 & 1.1 & 1.2 & 1.2 & 1.1 & 1.1 & 1.1 & 1.3 & 1.1 \\
\hline
\end{tabular}

There are some differences among the eight journals as well. For example, CAIS is different from all other journals in that almost half of the methods used are non-empirical. The other journal that has a slightly higher use of nonempirical methods is JAIS, as about $27 \%$ of the methods used are non-empirical. HCI papers in DS, ISR, and JMIS used more Lab experiments (2.2.1) than Surveys (2.2.6); while the $\mathrm{HCl}$ papers in DB, JAIS, and MISQ employed more Surveys than Lab experiments. In general, four empirical methods, Lab experiment (2.2.1), Survey (2.2.6), Field study (2.2.3), and Field experiment (2.2.2) were popular in $\mathrm{HCl}$ studies in all eight journals. Instrument development- 
related studies have found homes in all journals but CAIS, as have Secondary data-based studies.

Readers are cautioned against over-generalizing these results due to the limited number of studies within some journals and the journal policy changes from time to time.

\section{RQ4.4: Which contributing disciplines are cited more frequently in which sources?}

Table 24 shows the distribution of contributing disciplines cited within each source. For example, among all 403 citations to contributing disciplines by the 142 papers in MISQ, 33\% of citations were within Information Systems (D2801). This table is consistent with the analysis for RQ2.1, where we consider only the 14 core contributing disciplines that have been cited by more than 10 of the 758 papers in the collection. Therefore, the total percentage of each source may not be $100 \%$. A very small portion is constituted by other less-cited disciplines in each source. Table 24 indicates the following:

- $\quad$ During 1990-2008, Information Systems (2801) was the most cited discipline (35\%), followed by Psychology (3801, 29\%) and Business and Management (3502, 15\%).

- $\quad$ Other disciplines that were cited by $\mathrm{HCl}$ studies in all eight journals include Computer Software (D2803) and Sociology (D3701).

- Finally, articles in all eight journals were built on at least two disciplines on average, with articles in MS, MISQ, and ISR slightly more multi-disciplinary than those in the other four journals.

Table 24: Distribution of Top Cited Contributing Disciplines within Each Source

\begin{tabular}{|c|c|c|c|c|c|c|c|c|c|c|c|c|c|c|c|c|c|}
\hline Discipline & AMIS & BIT & $\mathrm{IJHCl}$ & IJHCS & ISJ & CAIS & $\mathrm{DB}$ & DS & ISR & JAIS & JMIS & MISQ & MS & Total & $\begin{array}{c}1990- \\
1995\end{array}$ & $\begin{array}{l}1996- \\
2002\end{array}$ & $\begin{array}{l}2003- \\
2008\end{array}$ \\
\hline D2302 Statistics & & & & & & & $1 \%$ & $3 \%$ & $1 \%$ & & & & & & $2 \%$ & & \\
\hline D2801 Information Systems & $39 \%$ & $75 \%$ & $35 \%$ & $47 \%$ & $42 \%$ & $37 \%$ & $42 \%$ & $37 \%$ & $33 \%$ & $34 \%$ & $36 \%$ & $33 \%$ & $30 \%$ & $35 \%$ & $39 \%$ & $35 \%$ & $35 \%$ \\
\hline $\begin{array}{l}\text { D2802 Al and Signal and } \\
\text { Image Processing }\end{array}$ & & & & & & & $1 \%$ & $3 \%$ & $1 \%$ & & $1 \%$ & $2 \%$ & $1 \%$ & $1 \%$ & $3 \%$ & $1 \%$ & $1 \%$ \\
\hline D2803 Computer Software & & & & & & $5 \%$ & $2 \%$ & $3 \%$ & $2 \%$ & $1 \%$ & $5 \%$ & $1 \%$ & $2 \%$ & $2 \%$ & $3 \%$ & $4 \%$ & $1 \%$ \\
\hline D3301 Education Studies & $3 \%$ & & & & & $4 \%$ & $1 \%$ & $2 \%$ & $2 \%$ & $1 \%$ & $1 \%$ & $2 \%$ & & $2 \%$ & $2 \%$ & $2 \%$ & $2 \%$ \\
\hline D3402 Applied Economics & & & & & & $1 \%$ & $20 \%$ & & $2 \%$ & & & $1 \%$ & $3 \%$ & $1 \%$ & & $1 \%$ & $1 \%$ \\
\hline D3502 Business and Mgt. & $24 \%$ & & $26 \%$ & $18 \%$ & $33 \%$ & $1 \%$ & & $21 \%$ & $20 \%$ & $5 \%$ & $6 \%$ & $17 \%$ & $25 \%$ & $15 \%$ & $17 \%$ & $18 \%$ & $13 \%$ \\
\hline $\begin{array}{l}\text { Other Commerce, Mgt, } \\
\text { Tour, \& Service }\end{array}$ & & & & & & & & & & $1 \%$ & & $2 \%$ & & $1 \%$ & & & $1 \%$ \\
\hline D3701 Sociology & $1 \%$ & & & $6 \%$ & & $4 \%$ & $2 \%$ & $1 \%$ & $5 \%$ & $9 \%$ & $5 \%$ & $4 \%$ & $5 \%$ & $4 \%$ & $2 \%$ & $3 \%$ & $5 \%$ \\
\hline D3801 Psychology & $21 \%$ & $25 \%$ & $29 \%$ & $18 \%$ & $25 \%$ & $35 \%$ & $28 \%$ & $26 \%$ & $26 \%$ & $37 \%$ & $30 \%$ & $30 \%$ & $24 \%$ & $29 \%$ & $25 \%$ & $26 \%$ & $31 \%$ \\
\hline D3803 Cognitive Science & $2 \%$ & & & & & $8 \%$ & $1 \%$ & $1 \%$ & $3 \%$ & $5 \%$ & $9 \%$ & $2 \%$ & & $4 \%$ & $3 \%$ & $1 \%$ & $5 \%$ \\
\hline $\begin{array}{l}\text { Journalism, Com, and } \\
\text { Media }\end{array}$ & $4 \%$ & & $6 \%$ & & & $1 \%$ & $1 \%$ & $2 \%$ & $3 \%$ & & $3 \%$ & $1 \%$ & $5 \%$ & $2 \%$ & $2 \%$ & $4 \%$ & $1 \%$ \\
\hline D4203 Cultural Studies & & & & & & $2 \%$ & $1 \%$ & & & $1 \%$ & $1 \%$ & $1 \%$ & & $1 \%$ & & $1 \%$ & $1 \%$ \\
\hline D4401 Philosophy & $1 \%$ & & & & & & & & $1 \%$ & $3 \%$ & & $1 \%$ & $1 \%$ & $1 \%$ & & $1 \%$ & $1 \%$ \\
\hline Total \% & $95 \%$ & $100 \%$ & $97 \%$ & $88 \%$ & $100 \%$ & $98 \%$ & $98 \%$ & $96 \%$ & $98 \%$ & $97 \%$ & $96 \%$ & $98 \%$ & $98 \%$ & $97 \%$ & $98 \%$ & $96 \%$ & $97 \%$ \\
\hline Total cites & 96 & 4 & 31 & 17 & 12 & 163 & 166 & 199 & 332 & 150 & 344 & 403 & 91 & 2008 & 328 & 568 & 1112 \\
\hline Avg \# of disciplines per paper & 2.6 & 1.3 & 2.6 & 2.1 & 2.4 & 2.7 & 2.3 & 2.6 & 2.8 & 2.4 & 2.7 & 2.8 & 2.8 & 2.6 & 2.5 & 2.7 & 2.7 \\
\hline
\end{tabular}

Table 25 shows within each source, the percentage of papers that cited each particular contributing discipline. For example, in the $142 \mathrm{HCl}$ papers published in MISQ, 94\% cited Information Systems (D2801) as a contributing discipline. Since a large number of papers have cited a non-core discipline as a contributing discipline (that is, outside the 14 core disciplines), we decided to show all 38 supporting disciplines in this table so that it can depict an accurate picture. This table shows information that is not evident in Table 24. 
Table 25: Percentage of Papers within Each Source Citing a Contributing Discipline

\begin{tabular}{|c|c|c|c|c|c|c|c|c|c|c|c|c|c|c|c|c|c|c|}
\hline & & AMIS & BIT & $\mathrm{IJHCl}$ & IJHCS & ISJ & CAIS & DB & DS & ISR & JAIS & JMIS & MISQ & MS & Total & \begin{tabular}{|c|}
$1990-$ \\
1995 \\
\end{tabular} & $\begin{array}{l}1996- \\
2002 \\
\end{array}$ & $\begin{array}{l}2003- \\
2008 \\
\end{array}$ \\
\hline D2302 & Statistics & & & & & & & $1 \%$ & $7 \%$ & $3 \%$ & & & $1 \%$ & & $1 \%$ & $5 \%$ & $1 \%$ & \\
\hline D2801 & Info Systems & $100 \%$ & $100 \%$ & $92 \%$ & $100 \%$ & $100 \%$ & $100 \%$ & $96 \%$ & $97 \%$ & $92 \%$ & $81 \%$ & $96 \%$ & $94 \%$ & $82 \%$ & $94 \%$ & $98 \%$ & $93 \%$ & $93 \%$ \\
\hline D2802 & $\begin{array}{l}\text { Al \& Signal and } \\
\text { Image Processing }\end{array}$ & & & & & & & $1 \%$ & $7 \%$ & $2 \%$ & & $4 \%$ & $7 \%$ & $3 \%$ & $3 \%$ & $7 \%$ & $4 \%$ & $2 \%$ \\
\hline D2803 & Computer Software & & & & & & $13 \%$ & $4 \%$ & $7 \%$ & $7 \%$ & $2 \%$ & $13 \%$ & $2 \%$ & $6 \%$ & $6 \%$ & $8 \%$ & $10 \%$ & $3 \%$ \\
\hline D2804 & $\begin{array}{l}\text { Computation } \\
\text { Theory \& Math }\end{array}$ & & & & & & & & & $1 \%$ & & & & & & & & \\
\hline D2805 & Data Format & & & & & & & & & & & $2 \%$ & & & & & $1 \%$ & \\
\hline D2899 & $\begin{array}{l}\text { Other Info, Comp, } \\
\& \text { Com Sciences }\end{array}$ & & & & $25 \%$ & & & & & & $3 \%$ & & & & $1 \%$ & & & $1 \%$ \\
\hline D2900 & $\begin{array}{l}\text { Engineering and } \\
\text { Technology }\end{array}$ & & & & & & & & & & & & & $3 \%$ & & $1 \%$ & & \\
\hline D2903 & $\begin{array}{l}\text { Manufacturing } \\
\text { Engineering }\end{array}$ & $3 \%$ & & & & & & & & & & & & & & & & \\
\hline D2912 & $\begin{array}{l}\text { Maritime } \\
\text { Engineering }\end{array}$ & & & & & & & & $1 \%$ & & & & & & & & & \\
\hline D3201 & Medicine - General & & & & & & & & $1 \%$ & & & $2 \%$ & & & & & $1 \%$ & \\
\hline D3212 & $\begin{array}{l}\text { Public Health \& } \\
\text { Health Services }\end{array}$ & & & & & & & & & & & $1 \%$ & & & & & & \\
\hline D3301 & Education Studies & $8 \%$ & & & & & $10 \%$ & $3 \%$ & $5 \%$ & $5 \%$ & $2 \%$ & $4 \%$ & $5 \%$ & & $4 \%$ & $5 \%$ & $5 \%$ & $4 \%$ \\
\hline D3401 & Economic Theory & & & & & & & $1 \%$ & $1 \%$ & $1 \%$ & $2 \%$ & $2 \%$ & $1 \%$ & & $1 \%$ & & $1 \%$ & $1 \%$ \\
\hline D3402 & Applied Economics & & & & & & $3 \%$ & $45 \%$ & & $6 \%$ & & & $2 \%$ & $9 \%$ & $2 \%$ & & $2 \%$ & $2 \%$ \\
\hline D3501 & $\begin{array}{l}\text { Accounting, } \\
\text { Auditing }\end{array}$ & & & & & & & & $1 \%$ & & & $1 \%$ & & & & $1 \%$ & & \\
\hline D3502 & Business and Mgt. & $62 \%$ & & $67 \%$ & $38 \%$ & $80 \%$ & $3 \%$ & & $54 \%$ & $56 \%$ & $11 \%$ & $16 \%$ & $48 \%$ & $70 \%$ & $39 \%$ & $44 \%$ & $47 \%$ & $34 \%$ \\
\hline D3503 & $\begin{array}{l}\text { Banking, Finance, } \\
\text { and Investment }\end{array}$ & & & & & & & & $1 \%$ & & & & & & & & & \\
\hline D3504 & Transportation & & & & & & & & $1 \%$ & & & & $1 \%$ & & & & & \\
\hline D3505 & Tourism & & & & & & & & & & & & $1 \%$ & & & & & \\
\hline D3599 & $\begin{array}{l}\text { Other Commerce, } \\
\text { Mgt, Tour, \& Serv }\end{array}$ & & & & & & & & & & $3 \%$ & $1 \%$ & $7 \%$ & & $2 \%$ & & & $3 \%$ \\
\hline D3601 & Political Science & & & & & & & & & $1 \%$ & & & & & & & & \\
\hline D3602 & $\begin{array}{l}\text { Policy and } \\
\text { Administration }\end{array}$ & & & & & & $2 \%$ & & & & $3 \%$ & & & & & & & $1 \%$ \\
\hline D3701 & Sociology & $3 \%$ & & & $13 \%$ & & $11 \%$ & $4 \%$ & $3 \%$ & $15 \%$ & $22 \%$ & $13 \%$ & $11 \%$ & $15 \%$ & $11 \%$ & $5 \%$ & $7 \%$ & $15 \%$ \\
\hline D3703 & Anthropology & & & & & & $2 \%$ & & & & & & & & & & & \\
\hline D3704 & Human Geography & $3 \%$ & & & & & & & & & & & & & & & & \\
\hline D3799 & $\begin{array}{l}\text { Other Studies in } \\
\text { Human Society }\end{array}$ & & & & & & & $1 \%$ & & & & & & & & & & \\
\hline D3801 & Psychology & $54 \%$ & $33 \%$ & $75 \%$ & $38 \%$ & $60 \%$ & $93 \%$ & $63 \%$ & $67 \%$ & $74 \%$ & $89 \%$ & $80 \%$ & $85 \%$ & $67 \%$ & $76 \%$ & $63 \%$ & $69 \%$ & $84 \%$ \\
\hline D3802 & Linguistics & $3 \%$ & & & & & & $1 \%$ & & $2 \%$ & & $2 \%$ & $1 \%$ & & $1 \%$ & & $2 \%$ & \\
\hline D3803 & Cognitive Science & $5 \%$ & & & & & $21 \%$ & $1 \%$ & $1 \%$ & $8 \%$ & $11 \%$ & $23 \%$ & $7 \%$ & & $10 \%$ & $7 \%$ & $3 \%$ & $14 \%$ \\
\hline D3899 & $\begin{array}{l}\text { Other Behavioral \& } \\
\text { Cognitive Sci }\end{array}$ & $3 \%$ & & & & & & & & & & & & & & & & \\
\hline D3901 & Law & & & & & & & & & & & $1 \%$ & $3 \%$ & & $1 \%$ & $1 \%$ & $1 \%$ & \\
\hline D4001 & $\begin{array}{l}\text { Journalism, Comm, } \\
\text { and Media }\end{array}$ & $11 \%$ & & $17 \%$ & & & $2 \%$ & $1 \%$ & $5 \%$ & $9 \%$ & & $8 \%$ & $2 \%$ & $15 \%$ & $5 \%$ & $5 \%$ & $10 \%$ & $3 \%$ \\
\hline D4102 & Visual Arts \& Crafts & $3 \%$ & & & & & $2 \%$ & & & & & $1 \%$ & & & & & & $1 \%$ \\
\hline D4104 & Design Studies & & & $8 \%$ & & & & & & & & & & & & & & \\
\hline D4203 & Cultural Studies & & & & & & $5 \%$ & $3 \%$ & & & $2 \%$ & $2 \%$ & $4 \%$ & & $2 \%$ & & $2 \%$ & $2 \%$ \\
\hline D4401 & Philosophy & $3 \%$ & & & & & & & & $3 \%$ & $8 \%$ & & $3 \%$ & $3 \%$ & $2 \%$ & $1 \%$ & $3 \%$ & $2 \%$ \\
\hline
\end{tabular}

\section{Summary for RQ4}

It is obvious that publication numbers and percentages of $\mathrm{HCl}$ studies among IS studies have been steadily increasing over the years. This is a sure sign that $\mathrm{HCl}$ studies are attracting more interest from MIS scholars and becoming more important to MIS over the years. The eight journals are all encouraging multi-disciplinary work, although they exhibit some differences in topics, methods, and contributing disciplines.

\section{RQ5: Who are the Contributing Members?}

\section{RQ5.1: Who are the most prolific authors?}

Three methods have been used to identify prolific authors and institutions in the literature: normal rank, adjusted rank, 
and straight rank (Chua et al. 2003; Romano and Fjermestad 2001). Normal rank is based on the assumption that all authors perform equal-value work, thus every co-author of an article receives one point. Adjusted rank assumes that the marginal contribution of an author is greater for works with fewer authors, thus each co-author of an article receives only a fraction of a point determined by the number of co-authors. For example, each of the two co-authors of a paper receives half a point, and each of the three co-authors of a paper receives one third point. Finally, straight rank is based on the belief that the first author is solely responsible for idea creation, thus being the only person receiving credit. We consider the straight rank method to be limited in recognizing the contributions of all other authors, and in representing the fact that many co-authors agree to be listed alphabetically in their publications. In addition, it discourages recognitions in collaborations, which is not healthy for the advancement of the sub-discipline. Thus, in this paper, we only use the first two methods.

Figure 18 shows the total numbers of different authors and institutes during the three periods of time. Over the 19year period, a total of 1,107 different authors contributed to the 758 articles. These authors came from 406 different institutions. Since not all authors can be displayed within the limited space in this paper, we only present the most prolific authors. Table 26, Table 27, and Table 28 list the two ranks for the most prolific authors during the three periods of times, respectively. Table 29 lists the most prolific authors during the entire 19 years. Of note, rankings denoted with a star $(*)$ indicate a tie, in which case authors are listed alphabetically.

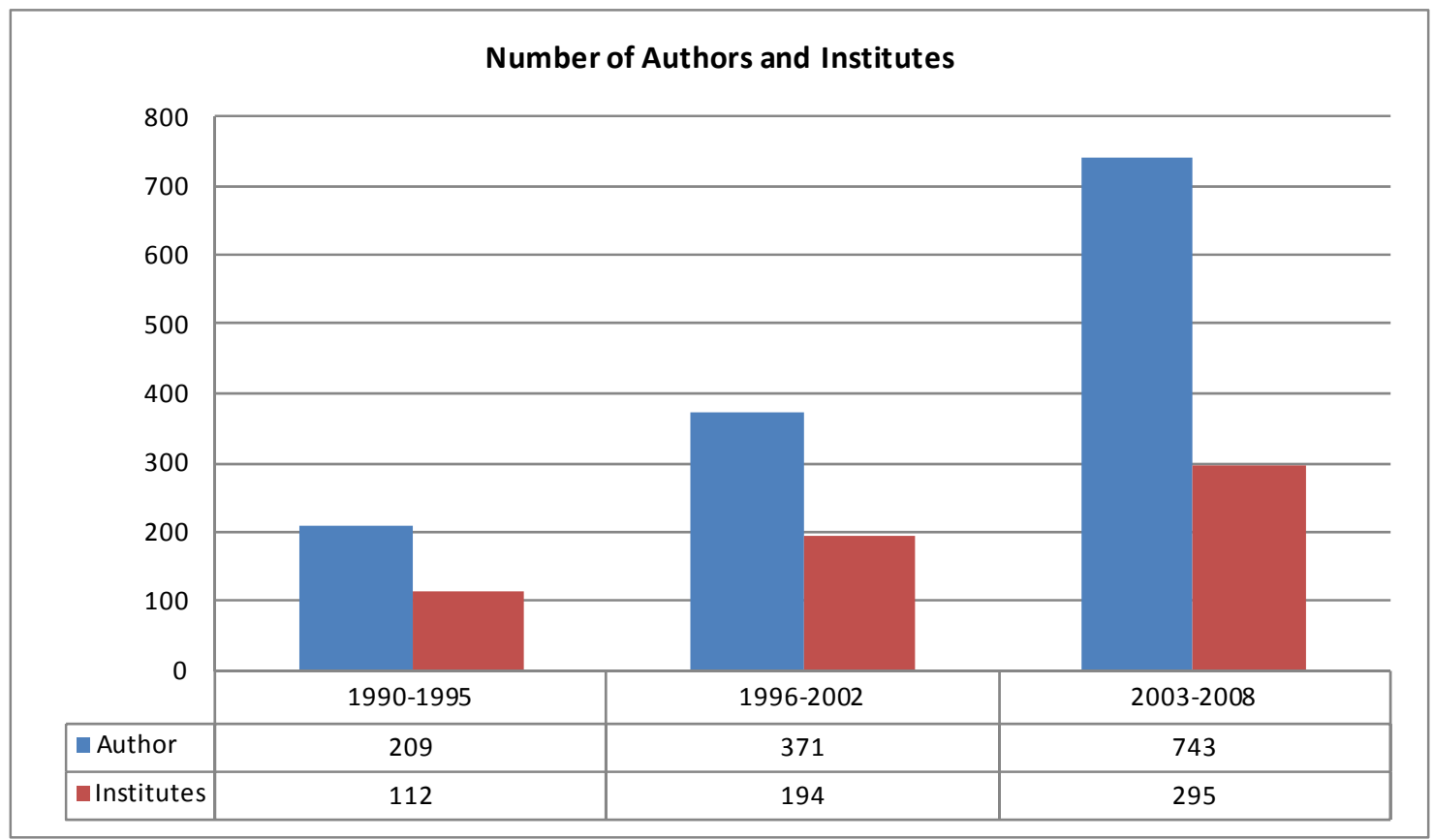

Figure 18: Numbers of Authors and Institutes during Different Periods of Time

Table 26: The Most Prolific Authors during 1990-1995

Top Normal Ranks

\begin{tabular}{c|l|c}
\hline Rank & \multicolumn{1}{|c}{ Author } & Score \\
\hline 1 & Todd, Peter & 6 \\
\hline $2^{*}$ & Benbasat, Izak & 5 \\
\hline $2^{*}$ & Guimaraes, Tor & 5 \\
\hline $3^{*}$ & Chin, Wynne & 4 \\
\hline $3^{*}$ & Doll, William & 4 \\
\hline $3^{*}$ & Higgins, Christopher & 4 \\
\hline $3^{*}$ & Vessey, Iris & 4 \\
\hline $4^{*}$ & Barki, Henri & 3 \\
\hline $4^{*}$ & Cronan, Timothy & 3 \\
\hline $4^{*}$ & Galletta, Dennis & 3 \\
\hline $4^{*}$ & Hartwick, Jon & 3 \\
\hline $4^{*}$ & King, William & 3 \\
\hline $4^{*}$ & Straub, Detmar & 3 \\
\hline $4^{*}$ & Thompson, Ronald & 3 \\
\hline $4^{*}$ & Torkzadeh, Gholamreza & 3 \\
\hline
\end{tabular}

Top Adjusted Ranks

\begin{tabular}{c|l|c}
\hline Rank & \multicolumn{1}{|c}{ Author } & Score \\
\hline 1 & Todd, Peter & 2.83 \\
\hline $2^{*}$ & Benbasat, Izak & 2.50 \\
\hline $2^{*}$ & Vessey, Iris & 2.50 \\
\hline $3^{*}$ & Alavi, Maryam & 2.00 \\
\hline $3^{*}$ & Chin, Wynne & 2.00 \\
\hline $4^{*}$ & Higgins, Christopher & 1.83 \\
\hline $4^{*}$ & Guimaraes, Tor & 1.83 \\
\hline $5^{*}$ & Doll, William & 1.58 \\
\hline $5^{*}$ & Straub, Detmar & 1.58 \\
\hline $6^{*}$ & Barki, Henri & 1.50 \\
\hline $6^{*}$ & Goodhue, Dale & 1.50 \\
\hline $6^{*}$ & Hartwick, Jon & 1.50 \\
\hline $6^{*}$ & Mathieson, Kieran & 1.50 \\
\hline $6^{*}$ & Shaft, Teresa & 1.50 \\
\hline $6^{*}$ & Szajna, Bernadette & 1.50 \\
\hline
\end{tabular}


Table 27: The Most Prolific Authors during 1996-2002

Top Normal Ranks

\begin{tabular}{|c|c|c|}
\hline Rank & Author & Score \\
\hline $1^{*}$ & Agarwal, Ritu & 8 \\
\hline $1^{*}$ & Benbasat, Izak & 8 \\
\hline $1^{*}$ & Venkatesh, Viswanath & 8 \\
\hline $2^{*}$ & Dennis, Alan & 5 \\
\hline $2^{*}$ & Gefen, David & 5 \\
\hline $3^{*}$ & Bhattacherjee, Anol & 4 \\
\hline $3^{*}$ & Chau, Patrick & 4 \\
\hline $3^{*}$ & Davis, Fred & 4 \\
\hline $3 *$ & Igbaria, Magid & 4 \\
\hline $3^{*}$ & Lerch, Javier & 4 \\
\hline $3^{*}$ & Satzinger, John & 4 \\
\hline $3^{*}$ & Speier, Cheri & 4 \\
\hline $3^{*}$ & Watson, Richard & 4 \\
\hline $3 *$ & Wei, Kwok-Kee & 4 \\
\hline $4^{*}$ & Alavi, Maryam & 3 \\
\hline $4^{*}$ & Cronan, Timothy & 3 \\
\hline $4^{*}$ & Galletta, Dennis & 3 \\
\hline $4^{*}$ & $\mathrm{Hu}$, Paul & 3 \\
\hline $4^{*}$ & Huff, Sid & 3 \\
\hline $4^{*}$ & Hunton, James & 3 \\
\hline $4^{*}$ & Kappelman, Leon & 3 \\
\hline $4^{*}$ & Kettinger, William & 3 \\
\hline $4^{*}$ & Lim, Kai & 3 \\
\hline $4^{*}$ & Marakas, George & 3 \\
\hline $4^{*}$ & Morris, Michael & 3 \\
\hline $4^{*}$ & Prasad, Jayesh & 3 \\
\hline $4^{*}$ & Prybutok, Victor & 3 \\
\hline $4^{*}$ & Straub, Detmar & 3 \\
\hline
\end{tabular}

Top Adjusted Ranks

\begin{tabular}{|c|c|c|}
\hline Rank & Author & Score \\
\hline 1 & Venkatesh, Viswanath & 4.83 \\
\hline $2^{*}$ & Agarwal, Ritu & 3.50 \\
\hline $2^{*}$ & Gefen, David & 3.50 \\
\hline 3 & Benbasat, Izak & 3.17 \\
\hline 4 & Bhattacherjee, Anol & 3.00 \\
\hline 5 & Chau, Patrick & 2.25 \\
\hline 6 & Dennis, Alan & 2.08 \\
\hline $7 *$ & Hunton, James & 2.00 \\
\hline $7^{*}$ & Lerch, Javier & 2.00 \\
\hline 8 & Davis, Fred & 1.67 \\
\hline $9 *$ & Kasper, George & 1.50 \\
\hline $9 *$ & Kettinger, William & 1.50 \\
\hline $9 *$ & Panko, Raymond & 1.50 \\
\hline 9* & Prasad, Jayesh & 1.50 \\
\hline 9* & Te'eni, Dov & 1.50 \\
\hline $9 *$ & Webster, Jane & 1.50 \\
\hline $9 *$ & Speier, Cheri & 1.50 \\
\hline $10^{*}$ & Igbaria, Magid & 1.42 \\
\hline $10^{*}$ & Satzinger, John & 1.42 \\
\hline $10^{*}$ & Watson, Richard & 1.42 \\
\hline $10^{*}$ & Wei, Kwok-Kee & 1.42 \\
\hline $11^{*}$ & Alavi, Maryam & 1.33 \\
\hline $11^{*}$ & Cronan, Timothy & 1.33 \\
\hline $11^{*}$ & Goodhue, Dale & 1.33 \\
\hline $11^{*}$ & Straub, Detmar & 1.33 \\
\hline $12^{*}$ & $\mathrm{Hu}, \mathrm{Paul}$ & 1.25 \\
\hline $12^{*}$ & Simon, Steven & 1.25 \\
\hline 13 & Tegarden, David & 1.20 \\
\hline
\end{tabular}

Table 28: The Most Prolific Authors during 2003-2008

Top Normal Ranks

\begin{tabular}{|c|c|c|}
\hline Rank & Author & Score \\
\hline 1 & Benbasat, Izak & 24 \\
\hline 2 & Galletta, Dennis & 14 \\
\hline 3 & Zhang, Ping & 12 \\
\hline $4^{*}$ & Gefen, David & 9 \\
\hline $4^{*}$ & Tam, Kar-Yan & 9 \\
\hline $5^{*}$ & Pavlou, Paul & 8 \\
\hline $5^{*}$ & Venkatesh, Viswanath & 8 \\
\hline 6 & McCoy, Scott & 7 \\
\hline $7^{*}$ & Agarwal, Ritu & 6 \\
\hline $7^{*}$ & Dennis, Alan & 6 \\
\hline $7^{*}$ & Kim, Sung & 6 \\
\hline $7^{*}$ & Straub, Detmar & 6 \\
\hline $7^{*}$ & Valacich, Joseph & 6 \\
\hline $8^{*}$ & Burton-Jones, Andrew & 5 \\
\hline $8^{*}$ & Davis, Fred & 5 \\
\hline $8 *$ & Fuller, Mark & 5 \\
\hline $8^{*}$ & Te'eni, Dov & 5 \\
\hline 9* & Browne, Glenn & 4 \\
\hline $9 *$ & Butler, Brian & 4 \\
\hline 9* & Cenfetelli, Ronald & 4 \\
\hline $9 *$ & Chin, Wynne & 4 \\
\hline $9 *$ & Henry, Raymond & 4 \\
\hline $9 *$ & Ho, Shuk Ying & 4 \\
\hline $9 *$ & Karahanna, Elena & 4 \\
\hline $9 *$ & Kim, Jinwoo & 4 \\
\hline $9 *$ & Malhotra, Naresh & 4 \\
\hline 9* & Nah, Fui-Hoon & 4 \\
\hline 9* & Polak, Peter & 4 \\
\hline $9^{*}$ & Sun, Heshan & 4 \\
\hline 9* & Thong, James & 4 \\
\hline $9 *$ & Vessey, Iris & 4 \\
\hline
\end{tabular}

Top Adjusted Ranks

\begin{tabular}{|c|c|c|}
\hline Rank & Author & Score \\
\hline 1 & Benbasat, Izak & 11.58 \\
\hline 2 & Zhang, Ping & 5.58 \\
\hline 3 & Galletta, Dennis & 5.00 \\
\hline 4 & Gefen, David & 4.17 \\
\hline 5 & Venkatesh, Viswanath & 3.83 \\
\hline 6 & Tam, Kar-Yan & 3.50 \\
\hline 7 & Pavlou, Paul & 3.17 \\
\hline $8^{*}$ & Burton-Jones, Andrew & 2.50 \\
\hline $8^{*}$ & Kim, Sung & 2.50 \\
\hline $9 *$ & Te'eni, Dov & 2.42 \\
\hline 9* & Davis, Fred & 2.42 \\
\hline 10 & Agarwal, Ritu & 2.37 \\
\hline 11 & Nah, Fui-Hoon & 2.33 \\
\hline 12 & Dennis, Alan & 2.25 \\
\hline $13^{*}$ & Browne, Glenn & 2.17 \\
\hline $13^{*}$ & McCoy, Scott & 2.17 \\
\hline 14 & Straub, Detmar & 2.08 \\
\hline 15 & Vessey, Iris & 2.03 \\
\hline $16^{*}$ & Sen, Ravi & 2.00 \\
\hline $16^{*}$ & Cenfetelli, Ronald & 2.00 \\
\hline $17^{*}$ & Gallivan, Michael & 1.83 \\
\hline $17^{*}$ & Ho, Shuk Ying & 1.83 \\
\hline $17^{*}$ & Limayem, Moez & 1.83 \\
\hline $17^{*}$ & Valacich, Joseph & 1.83 \\
\hline $18^{*}$ & Fuller, Mark & 1.67 \\
\hline $18^{*}$ & Karahanna, Elena & 1.67 \\
\hline $18^{*}$ & Malhotra, Naresh & 1.67 \\
\hline $18^{*}$ & Stewart, Katherine & 1.67 \\
\hline $18^{*}$ & Sun, Heshan & 1.67 \\
\hline $19^{*}$ & Carroll, John & 1.50 \\
\hline $19 *$ & Jiang, Zhenhui & 1.50 \\
\hline
\end{tabular}


Table 29: The Most Prolific Authors during 1990-2008

Top Normal Ranks

\begin{tabular}{|c|c|c|}
\hline Rank & Author & Score \\
\hline 1 & Benbasat, Izak & 37 \\
\hline 2 & Galletta, Dennis & 20 \\
\hline 3 & Venkatesh, Viswanath & 16 \\
\hline $4^{*}$ & Agarwal, Ritu & 14 \\
\hline $4^{*}$ & Gefen, David & 14 \\
\hline $4^{*}$ & Zhang, Ping & 14 \\
\hline $5^{*}$ & Dennis, Alan & 12 \\
\hline $5^{\star}$ & Straub, Detmar & 12 \\
\hline $6^{*}$ & Davis, Fred & 11 \\
\hline $6^{*}$ & Tam, Kar-Yan & 11 \\
\hline $7 *$ & Todd, Peter & 10 \\
\hline $7 *$ & Vessey, Iris & 10 \\
\hline $8^{*}$ & Chin, Wynne & 9 \\
\hline $8^{*}$ & Pavlou, Paul & 9 \\
\hline $8^{*}$ & Valacich, Joseph & 9 \\
\hline 9 & Te'eni, Dov & 8 \\
\hline $10^{*}$ & Guimaraes, Tor & 7 \\
\hline $10^{*}$ & Higgins, Christopher & 7 \\
\hline $10^{*}$ & Karahanna, Elena & 7 \\
\hline $10^{*}$ & McCoy, Scott & 7 \\
\hline $10^{*}$ & Olfman, Lorne & 7 \\
\hline $10^{*}$ & Wei, Kwok-Kee & 7 \\
\hline $11^{*}$ & Alavi, Maryam & 6 \\
\hline $11^{*}$ & Barki, Henri & 6 \\
\hline $11^{*}$ & Bhattacherjee, Anol & 6 \\
\hline $11^{*}$ & Chau, Patrick & 6 \\
\hline $11^{*}$ & Compeau, Deborah & 6 \\
\hline $11^{*}$ & Cronan, Timothy & 6 \\
\hline $11^{*}$ & Doll, William & 6 \\
\hline $11^{*}$ & Igbaria, Magid & 6 \\
\hline $11^{*}$ & Kim, Jinwoo & 6 \\
\hline $11^{*}$ & Kim, Sung & 6 \\
\hline $11^{*}$ & King, William & 6 \\
\hline $11^{*}$ & Morris, Michael & 6 \\
\hline $11^{*}$ & Speier, Cheri & 6 \\
\hline $11^{*}$ & Watson, Richard & 6 \\
\hline $11^{*}$ & Webster, Jane & 6 \\
\hline $12^{*}$ & Burton-Jones, Andrew & 5 \\
\hline $12^{*}$ & Butler, Brian & 5 \\
\hline $12^{*}$ & Cheney, Paul & 5 \\
\hline $12^{*}$ & Fuller, Mark & 5 \\
\hline $12^{*}$ & Goodhue, Dale & 5 \\
\hline $12^{*}$ & Grover, Varun & 5 \\
\hline $12^{*}$ & Johnson, Richard & 5 \\
\hline $12^{*}$ & Limayem, Moez & 5 \\
\hline $12^{*}$ & Massey, Anne & 5 \\
\hline $12^{*}$ & Santhanam, Radhika & 5 \\
\hline $12^{*}$ & Satzinger, John & 5 \\
\hline $12^{*}$ & Thong, James & 5 \\
\hline $12^{*}$ & Yi, Mun & 5 \\
\hline
\end{tabular}

Top Adjusted Ranks

\begin{tabular}{|c|c|c|}
\hline Rank & Author & Score \\
\hline 1 & Benbasat, Izak & 17.25 \\
\hline 2 & Venkatesh, Viswanath & 8.67 \\
\hline 3 & Gefen, David & 7.67 \\
\hline 4 & Galletta, Dennis & 7.03 \\
\hline 5 & Zhang, Ping & 6.75 \\
\hline 6 & Agarwal, Ritu & 5.87 \\
\hline 7 & Vessey, Iris & 5.37 \\
\hline 8 & Davis, Fred & 5.08 \\
\hline 9 & Straub, Detmar & 5.00 \\
\hline 10 & Dennis, Alan & 4.58 \\
\hline $11^{*}$ & Te'eni, Dov & 4.42 \\
\hline $11^{*}$ & Todd, Peter & 4.42 \\
\hline $12^{*}$ & Bhattacherjee, Anol & 4.00 \\
\hline $12^{*}$ & Tam, Kar-Yan & 4.00 \\
\hline $13^{*}$ & Goodhue, Dale & 3.83 \\
\hline $13^{*}$ & Alavi, Maryam & 3.83 \\
\hline 14 & Chin, Wynne & 3.75 \\
\hline 15 & Pavlou, Paul & 3.67 \\
\hline 16 & Webster, Jane & 3.33 \\
\hline $17^{*}$ & Higgins, Christopher & 3.00 \\
\hline $17^{*}$ & Valacich, Joseph & 3.00 \\
\hline $18^{*}$ & Chau, Patrick & 2.92 \\
\hline $18^{*}$ & Olfman, Lorne & 2.92 \\
\hline $19 *$ & Guimaraes, Tor & 2.83 \\
\hline $19^{*}$ & Karahanna, Elena & 2.83 \\
\hline $19 *$ & Barki, Henri & 2.83 \\
\hline 20 & Limayem, Moez & 2.67 \\
\hline $21^{*}$ & Burton-Jones, Andrew & 2.50 \\
\hline $21^{*}$ & Cronan, Timothy & 2.50 \\
\hline $21^{*}$ & Kim, Sung & 2.50 \\
\hline $21^{*}$ & King, William & 2.50 \\
\hline $21^{*}$ & Shaft, Teresa & 2.50 \\
\hline $21^{*}$ & Szajna, Bernadette & 2.50 \\
\hline 22 & Wei, Kwok-Kee & 2.42 \\
\hline $23^{*}$ & Nah, Fui-Hoon & 2.33 \\
\hline $23^{*}$ & George, Joey & 2.33 \\
\hline $23^{*}$ & Kasper, George & 2.33 \\
\hline $23^{*}$ & Speier, Cheri & 2.33 \\
\hline 24 & Butler, Brian & 2.27 \\
\hline $25^{*}$ & Browne, Glenn & 2.17 \\
\hline $25^{*}$ & Compeau, Deborah & 2.17 \\
\hline $25^{*}$ & Koufaris, Marios & 2.17 \\
\hline $25^{*}$ & McCoy, Scott & 2.17 \\
\hline $25^{*}$ & Morris, Michael & 2.17 \\
\hline $25^{*}$ & Santhanam, Radhika & 2.17 \\
\hline $25^{*}$ & Stewart, Katherine & 2.17 \\
\hline 26 & Doll, William & 2.12 \\
\hline 27 & Igbaria, Magid & 2.08 \\
\hline
\end{tabular}

Figure 19 and Figure 20 show the top 10 most prolific authors' ranking scores over the entire 19 years, with the three periods' data stacked to the whole. 


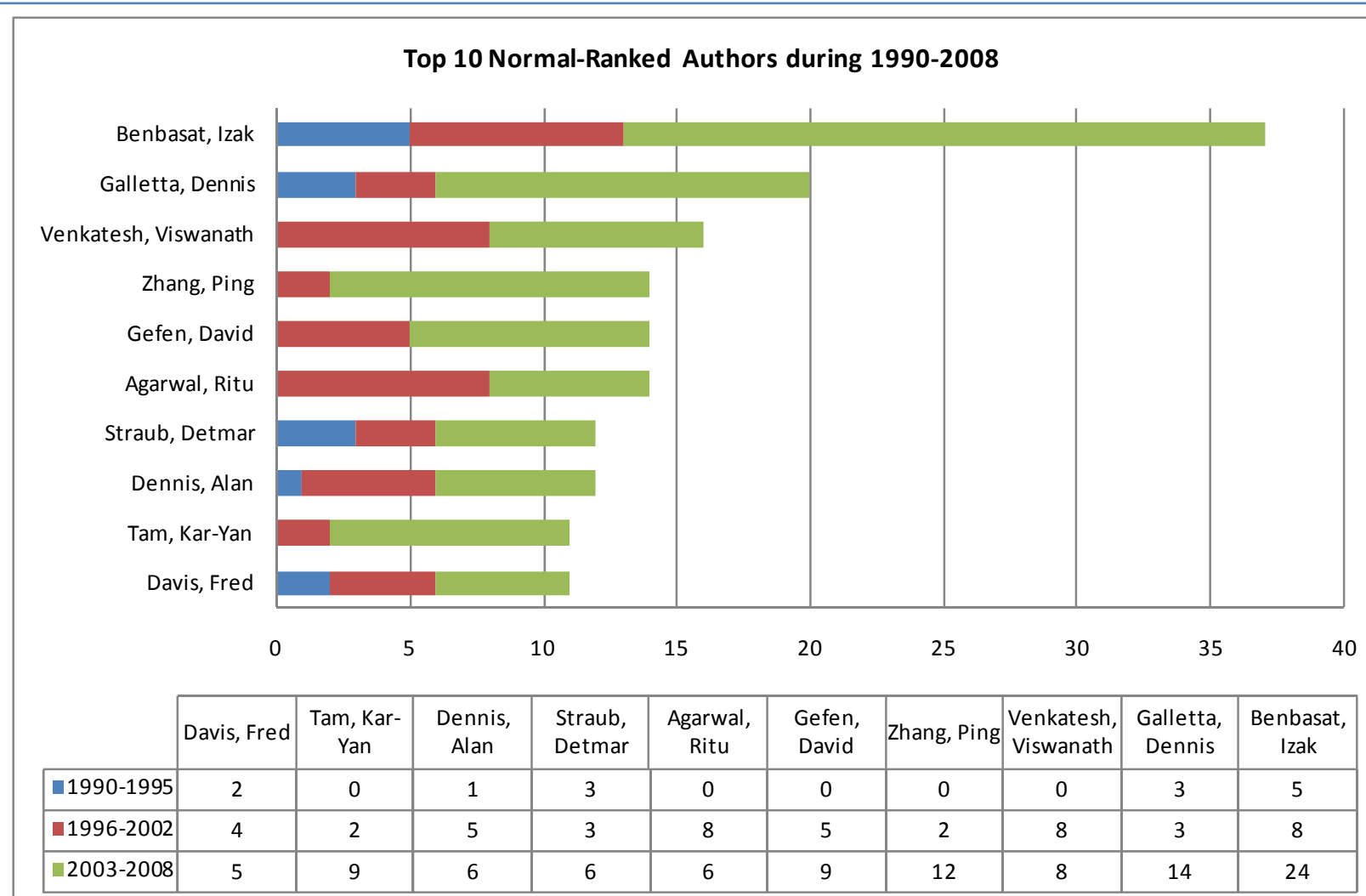

Figure 19: Top 10 Normal-Ranked Authors during 1990-2008

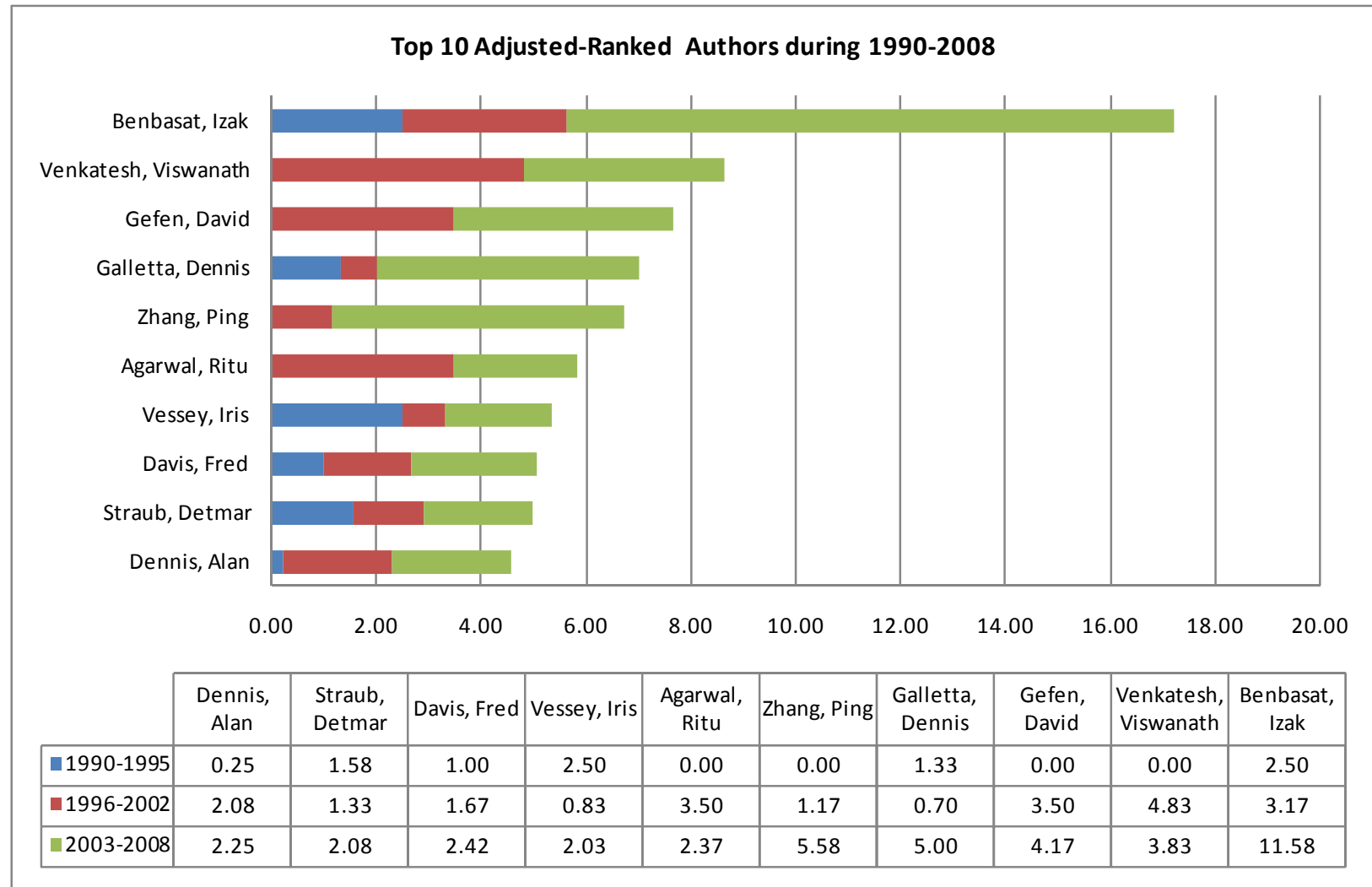

Figure 20: Top 10 Adjusted-Ranked Authors during 1990-2008 


\section{RQ5.2: What are the most prolific institutions housing $\mathrm{HCl}$ researchers?}

We applied the same formulas used for authors to institutions. Table 30 presents the normal and adjusted ranks among the most prolific institutions during the entire 19 years. As per above in the author rankings, ties are starred $\left({ }^{*}\right)$.

\section{Table 30: The Most Prolific Institutions during 19 Years (1990-2008)}

Top Normal Ranks

\begin{tabular}{|c|c|c|}
\hline Rank & Institute & Score \\
\hline 1 & University of British Columbia & 65 \\
\hline 2 & University of Pittsburgh & 43 \\
\hline $3^{\star}$ & Indiana University & 42 \\
\hline $3^{*}$ & University of Maryland & 42 \\
\hline 4 & Georgia State University & 38 \\
\hline 5 & City University of Hong Kong & 37 \\
\hline 6 & University of Arkansas & 35 \\
\hline 7 & Syracuse University & 32 \\
\hline 8 & National Univ. of Singapore & 29 \\
\hline 9 & Carnegie Mellon University & 28 \\
\hline 10 & University of Georgia & 27 \\
\hline 11 & Queen's University & 24 \\
\hline 12 & Hong Kong UST & 23 \\
\hline $13^{*}$ & University of Houston & 22 \\
\hline $13^{*}$ & University of Minnesota & 22 \\
\hline $13^{*}$ & Washington State University & 22 \\
\hline $14^{*}$ & Florida State University & 21 \\
\hline $14^{*}$ & University of Arizona & 21 \\
\hline $14^{*}$ & University of South Carolina & 21 \\
\hline $14^{*}$ & University of Toledo & 21 \\
\hline $15^{\star}$ & Drexel University & 20 \\
\hline $16^{*}$ & Michigan State University & 19 \\
\hline $16^{*}$ & Yonsei University & 19 \\
\hline $17^{*}$ & University of South Florida & 18 \\
\hline $17^{*}$ & University of Western Ontario & 18 \\
\hline $18^{\star}$ & Pennsylvania State University & 17 \\
\hline $18^{*}$ & University of Michigan & 17 \\
\hline 19 & NJIT & 16 \\
\hline $20^{*}$ & Case Western Reserve Univ. & 15 \\
\hline $20^{*}$ & Claremont Graduate University & 15 \\
\hline $20^{*}$ & University of Calgary & 15 \\
\hline 21 & University of Central Florida & 14 \\
\hline $22^{*}$ & Tel Aviv University & 13 \\
\hline $22^{*}$ & University of North Texas & 13 \\
\hline $22^{*}$ & University of Notre Dame & 13 \\
\hline $23^{*}$ & Oklahoma State University & 12 \\
\hline $23^{*}$ & Texas Tech University & 12 \\
\hline $23^{*}$ & University of Melbourne & 12 \\
\hline $23^{*}$ & University of Memphis & 12 \\
\hline $23^{*}$ & University of Virginia & 12 \\
\hline $24^{*}$ & Florida Atlantic University & 11 \\
\hline $24^{*}$ & UIUC & 11 \\
\hline $24^{*}$ & Worcester Polytechnic Institute & 11 \\
\hline
\end{tabular}

Top Adjusted Ranks

\begin{tabular}{|c|c|c|}
\hline Rank & Institute & Score \\
\hline 1 & University of British Columbia & 29.92 \\
\hline 2 & University of Maryland & 20.90 \\
\hline 3 & Indiana University & 16.80 \\
\hline 4 & University of Pittsburgh & 16.30 \\
\hline 5 & Georgia State University & 15.34 \\
\hline 6 & University of Arkansas & 15.25 \\
\hline 7 & Syracuse University & 14.25 \\
\hline 8 & City Univ. of Hong Kong & 13.83 \\
\hline 9 & National Univ. of Singapore & 11.50 \\
\hline 10 & University of Georgia & 11.42 \\
\hline 11 & Carnegie Mellon University & 10.75 \\
\hline 12 & Queen's University & 10.17 \\
\hline 13 & Drexel University & 10.00 \\
\hline 14 & University of Houston & 9.58 \\
\hline 15 & Hong Kong UST & 8.53 \\
\hline $16^{*}$ & University of South Florida & 8.42 \\
\hline $16^{*}$ & Florida State University & 8.42 \\
\hline 17 & University of Minnesota & 8.23 \\
\hline 18 & University of South Carolina & 8.08 \\
\hline 19 & Michigan State University & 7.92 \\
\hline 20 & Washington State University & 7.42 \\
\hline 21 & University of Michigan & 7.19 \\
\hline 22 & Pennsylvania State Univ. & 7.11 \\
\hline 23 & University of Western Ontario & 7.08 \\
\hline 24 & University of Toledo & 6.82 \\
\hline 25 & Yonsei University & 6.58 \\
\hline 26 & University of Calgary & 6.25 \\
\hline $27^{*}$ & Tel Aviv University & 6.08 \\
\hline $27^{*}$ & University of Arizona & 6.08 \\
\hline 28 & Texas Tech University & 6.00 \\
\hline $29^{*}$ & Claremont Graduate Univ. & 5.58 \\
\hline $29 *$ & NJIT & 5.58 \\
\hline 30 & UIUC & 5.08 \\
\hline 31 & University of North Texas & 5.00 \\
\hline 32 & University of Nebraska-Lincoln & 4.83 \\
\hline 33 & McGill University & 4.75 \\
\hline 34 & University of Notre Dame & 4.67 \\
\hline 35 & Florida Atlantic University & 4.67 \\
\hline 36 & Case Western Reserve Univ. & 4.63 \\
\hline 37 & University of Melbourne & 4.55 \\
\hline 38 & University of Texas at Austin & 4.45 \\
\hline $39 *$ & University of Virginia & 4.33 \\
\hline $39 *$ & Boston University & 4.33 \\
\hline $39 *$ & Texas Christian University & 4.33 \\
\hline
\end{tabular}

\section{Summary for RQ5}

Over the past 19 years, $\mathrm{HCl}$ research has attracted a great number of researchers from a great number of institutions. The total number of authors has increased steadily over the years. This indicates the broad interests IS scholars have had in $\mathrm{HCl}$ research, and good opportunities for collaboration and employment. 


\section{DISCUSSION}

The five mega-research questions and their corresponding detailed questions have been addressed with quantitative descriptions from the 19-year literature review. It is important to point out the limitations of this study before we further discuss the potential directions for the $\mathrm{HCl}$ sub-discipline as a whole, and the significance and implications of this study.

\section{Limitations}

This paper is among the few to draw a multifaceted overview of $\mathrm{HCl}$ studies in the IS discipline based on the evidence of published articles. It is limited due to the time-consuming nature of such studies. First, it has the limitation of using a journal "basket" (Chua et al. 2003; Lowry et al. 2004) that is constrained by the selected journals and other sources, as well as the time period. We considered the recent 19 years of the eight prime MIS journals and several other highly relevant sources in this study. While this is very reasonable, and much broader in coverage than other studies of a similar nature (Romano and Fjermestad 2001; Vessey et al. 2002), the 19-year time period and various sources may have had a strong influence on the assessment results. This includes the potential biases of the sources' emphases on publishable works, and the characteristics of the research that may be salient only for this period of time.

Second, we continue to realize that some classifications are not detailed enough, as previously noted (Zhang and Li 2005). For example, the RFCD classification scheme for disciplines does not distinguish different types of Information Systems in the 2801 discipline, and treats several areas normally regarded as different disciplines as several subjects within 2801. Psychology (3801) represents a similar example. It would be interesting to see what type of psychology, such as cognitive psychology, organizational psychology, social psychology, or consumer psychology, is most influential for some of the studies. Despite this limitation, we still consider RFCD to be superior to some other classifications for disciplines due to its comprehensive coverage.

\section{Potential Future Directions for the $\mathrm{HCl}$ sub-discipline}

\section{Research Topics and the Evolution of ICT Artifacts and Use Contexts}

The literature reviewed here supports the suggestion that the $\mathrm{MIS} / \mathrm{HCl}$ discipline must be closely linked to practice and consulting (Banville and Landry 1989), and hence, research on cutting-edge technology. For example, studies focusing on the Web have increased tremendously (see Figure 10), while the contexts of studies have gradually shifted from organizational and work place (see Figure 2) to broader contexts. With more focus on social and interpersonal issues, research efforts on topics such as trust, emotion, and interpersonal relationship have increased over the years (Figure 4); as have studies at the group level of analysis (Figure 9). On the other hand, researchers in the $\mathrm{HCl}$ sub-discipline might also focus on long-term theoretical works that examine more fundamental issues as $\mathrm{HCl}$ research is inherently inclined toward human characteristics and human cognitive, affective, motivational, and behavioral factors that do not change as frequently or quickly as technology or contexts. This gives $\mathrm{HCl}$ researchers the advantage of emphasizing the fundamental theoretical understandings of humans and their interaction with IT, and the advantage of applying or testing such understandings in new IT development and IT use contexts to further enhance or enrich such understandings.

For example, we have seen more research that examines the fundamental issues of humans that are beyond performance, such as cognitive beliefs and behavior, attitude, emotion, and motivation (Figure 4). We have also seen that more studies examine multiple topics (Figure 3) because inherently many $\mathrm{HCl}$ issues intertwine with each other. All of these are exciting and promising. Such interests prompt for additional investigations that will reveal the true phenomenon of $\mathrm{HCl}$ in various contexts.

\section{Theoretical Frameworks and Models}

Related to the need for long-term work is the development of conceptual frameworks (and empirical validations) to understand the $\mathrm{HCl}$ sub-discipline as a whole, including both IT design/development and IT use/impact issues. With the increased importance of $\mathrm{HCl}$ in IT development and use, and increased understanding required to guide practice, comes the need for more informative and parsimonious frameworks and models. Compared to relatively low efforts during the first two periods, which was reported previously (Zhang and Li 2005), there have been more studies focusing on providing frameworks and high-level overviews in recent years (see Table 12 and Figure 8). This is very promising because good frameworks and models enhance our understanding at a higher level, and thus, can substantially advance the sub-discipline. In particular, we hope to see additional theoretical perspectives that are beyond some of the dominating ones in the IS discipline that are either for individual IT use, or omit other important factors such as emotions (Benbasat and Barki 2007). 


\section{More Focus on IT Design/Development}

The majority of the efforts so far have been on IT use and impact (see Table 9). Research should also emphasize IT design/development because it is part of the $\mathrm{HCl}$ research area. Designing new and better technologies with informed practice should be one of the ultimate goals of $\mathrm{HCl}$ research. Theoretical understandings that do not feed design can eventually lose their relevance. There have been strong calls to focus more on the IT artifacts (Benbasat and Zmud 2003; Orlikowski and Iacono 2001), and to inform IT design by focusing on the specific antecedents of cognitive beliefs so that IT design can be guided (Benbasat and Barki 2007). We echo our colleagues on such calls. In particular, IT design or design research (Hevner et al., 2004) can be significantly enhanced by a consciousness of studying $\mathrm{HCl}$ issues with the IT design in mind, by linking our understanding of human reactions to IT back to guiding IT design/development, and by focusing on IT design and development for its own sake. This should be done both within the IS discipline and between IS and other design-oriented disciplines such as Computer Science, Engineering, and General Design Studies. While IS researchers have begun to rejuvenate interest in this important area, additional effort needs to be put into more design-oriented research, and into making $\mathrm{HCl}$ research in IS known to other design disciplines. Likewise, the work of other disciplines needs to be known to IS researchers, as each side has a great deal to ultimately contribute to IT products and services. Only a strong collaborative spirit and environment can enable informed IT designs that consider human, organizational, and societal needs. AIS SIGHCI has engaged in a number of activities to make this happen. We call for more efforts toward design-oriented research and making IT Use and Impact research more design relevant.

\section{Research Methods}

RQ1.4 ("What are the research methods?") and RQ1.5 ("What methods are often used to study what topics?") show that many methods are accepted in the $\mathrm{HCl}$ sub-discipline and different methods can address the same research topics. Yet, the current literature shows a continued need to utilize more interpretive and qualitative research methods in $\mathrm{HCl}$ studies. The advantage of such an approach is obvious. Due to the dynamic nature of $\mathrm{HCl}$ for supporting tasks within contexts, and the need for technology to be more socially aware and more supportive of communication, research methods such as action research, case study, interview, etc., are better suited for addressing the complexity and dynamics of $\mathrm{HCl}$ phenomena in everyday settings.

\section{Implications for Research, Education, and Practice}

Besides some of the directions pointed out earlier, this study has several additional research implications. This study continues to outline the ingredients of a typical research study. In addition to being used to assess literature, the seven facets may be used by a scholar to design a research study, including dissertation research. Results from this literature assessment may trigger some interesting explorations. For instance, Table 13 shows the co-occurrence pattern of research topics and methods. This may give scholars suggestions on which methods have been proven to be effective (or ineffective) in examining a certain phenomenon, and which methods might lead to a fresh viewpoint and, thus, be worth exploring. Finally, this study strongly suggests that a number of very useful classification schemes can be used for similar future studies. For example, the classification of $\mathrm{HCl}$ research topics is very comprehensive and allows dialogues with other related disciplines such as design-oriented disciplines. Each of the topics in the scheme can be further examined in terms of its current status and future direction. An existing classification framework for methods (Alavi and Carlson 1992) is expanded to reflect the current research methods. The classification of contexts depicts the rich environments where MIS-oriented $\mathrm{HCl}$ studies are conducted.

This literature assessment has teaching and educational implications, especially in preparing doctoral students. Students might want to familiarize themselves with knowledge and issues from several other disciplines in addition to the IS discipline, especially psychology and business, and be able to conduct research with a variety of methods. The recent trend toward multiple topics within a study challenges our future scholars to prepare themselves for designing research studies. Frequently used methods may be taken into consideration when doctoral program directors or curricula committees decide which methodological courses should be offered. Ph.D. students may benefit from the concise collection of the major scholars and their work in the $\mathrm{HCl}$ field. Part of a good foundation for scholarly activity is to be able to recognize and cite major scholars and their contributions to the intellectual body of the field. In most Ph.D. programs, the building of this knowledge occurs in a rather random fashion as students take seminars and write papers. This paper provides a good base of scholarly knowledge. In addition, professors in Ph.D. programs may use this article to provide ideas for questions to be asked in preliminary and qualification exams.

This study has practical implications as well. While designing IT, practitioners are strongly encouraged to examine what happens after previous or similar products have been released and put into use in real contexts. Such an examination should provide abundant insight for the design of new products. As demonstrated by this study, the majority of $\mathrm{HCl}$ studies in the IS discipline are particularly interested in issues that occur in the use and impact stage, thus, such research results are worth referencing by practitioners. The topic classification scheme (Table 4) lists a variety of issues and concerns that can provide an $\mathrm{HCl}$ designer with broad perspectives pertinent to human interaction with technologies in various contexts. IT practitioners may be concerned with issues that occur at all 
stages of the IT lifecycle. This article lists various issues involved in the IT lifecycle that may or may not have been studied (see Table 4).

\section{CONCLUSION}

The importance of $\mathrm{HCl}$ research is elevated by the continued expansion of IT capabilities, yet limited by the realization of IT values because of human users' cognitive qualities, information processing capabilities, and use of IT (Banker and Kauffman 2004). Although $\mathrm{HCl}$ research in MIS has a history as long as the MIS discipline, understanding its intellectual substances, its current state, evolutions, and possible future directions is of significant importance to the $\mathrm{HCl}$ sub-discipline, to MIS as a whole, and to other closely-related disciplines.

This study builds on earlier efforts (Zhang and Li 2005) to systematically assess the IS literature, and to depict the status of research considering humans and their interaction with technologies over a period of 19 years, which has involved a large number of scholars. Using a classification approach with seven facets, this study allows multiple categories of a particular facet to be assigned to a paper. This multiplicity captures a more accurate picture of the nature of $\mathrm{HCl}$ research and allows us to reveal more realistic and interesting patterns by conducting co-occurrence and cross-facet analyses. Overall, this study is informative in that it provides state-of-the-art research issues and concerns, research emphases and gaps, potential research directions, and publication and employment opportunities. Thus, it can play an important role in the identification and promotion of this sub-discipline, and suggest directions for guiding future efforts in research, collaboration, publication, practice, and education. It can also help guide doctoral students in identifying potential research topics for dissertation research, and even suggest academic institutions for future employment.

$\mathrm{HCl}$ research occupies a gratifying percentage of space in primary MIS journals, showing an increase in both number and percentage. This indicates that $\mathrm{HCl}$ studies have gained more importance over the years. $\mathrm{HCl}$ research is attractive to a great number of MIS scholars. Equally encouraging is the existence of a large number of institutions where such scholars are employed and appreciated, thus forming centers of excellence in $\mathrm{HCl}$ research.

The $\mathrm{HCl}$ sub-discipline has evolved over the last 19 years. Since 1990, there have been some very obvious changes. Evolving from its current state, there are a number of potential future directions for this sub-discipline. Understanding that a field cannot be created and cannot evolve according to precisely pre-defined plans (Banville and Landry 1989), we hope that our efforts will inspire additional discussions, initiatives, and actions within the community so that we can advance our understanding of humans interactions with technologies in various contexts for various purposes. Together with other MIS sub-disciplines and related disciplines, the community can make human experiences with technologies more pleasant, interesting, rewarding, and fulfilling, thus generating greater personal value for individuals, more profitable business value for organizations, and additional social value for large communities and societies. 


\section{REFERENCES}

Agarwal, R. and J. Prasad (1998) "A Conceptual and Operational Definition of Personal Innovativeness in the Domain of Information Technology," Information Systems Research (9) 2, pp. 204-215.

Alavi, M. and P. Carlson (1992) "A Review of MIS Research and Disciplinary Development," Journal of Management Information Systems (8) 4, pp. 45-62.

Banker, R. D. and R. J. Kauffman (2004) "The Evolution of Research on Information Systems: A Fiftieth-Year Survey of the Literature in Management Science," Management Science (50) 3, pp. 281-298.

Banville, C. and M. Landry (1989) "Can the Field of MIS Be Disciplined?" Communications of the ACM (32) 1, pp. 4860.

Barki, H. and J. Hartwick (1994) "User Participation, Conflict, and Conflict Resolution: The Mediating Roles of Influence," Information Systems Research (5) 4, pp. 422-438.

Beath, C. M. and W. J. Orlikowski (1994) "The Contradictory Structure of Systems Development Methodologies: Deconstructing the IS-User Relationship in Information Engineering," Information Systems Research (5) 4, pp. 350-377.

Benbasat, I. and H. Barki (2007) "Quo Vadis Tam?" Journal of the Association for Information Systems (8) 4, pp. 211218.

Benbasat, I. and R. W. Zmud (2003) "The Identity Crisis within the IS Discipline: Defining and Communicating the Discipline's Core Properties," MIS Quarterly (27) 2, pp. 183-194.

Boudreau, M., D. Gefen and D. Straub (2001) "Validation in IS Research: A State-of-the-Art Assessment," MIS Quarterly (25) 1, pp. 1-24.

Carey, J., D. Galletta, J. Kim, D. Te'eni, B. Wildermuth and P. Zhang (2004) "The Role of HCl in IS Curricula: A Call to Action," Communication of the AIS (13) 23, pp. 357-379.

Carr, C. L. (2002) "A Psychometric Evaluation of the Expectations, Perceptions, and Difference-Scores Generated by the IS-Adapted Servqual Instrument," Decision Sciences (33) 2, pp. 281-296.

Chen, M. (1995) "A Model-Driven Approach to Accessing Managerial Information: The Development of a RepositoryBased Executive Information System," Journal of Management Information Systems (11) 4, pp. 33-63.

Chua, C., L. Cao, K. Cousins and D. W. Straub (2003) "Measuring Researcher-Production in Information Systems," Journal of Association for Information Systems (3) 6, pp. 145-215.

Compeau, D. R., C. A. Higgins and S. Huff (1999) "Social Cognitive Theory and Individual Reactions to Computing Technology: A Longitudinal Study," MIS Quarterly (23) 2, pp. 145-158.

Conrath, D. W. and R. S. Sharma (1992) "Toward a Diagnostic Instrument for Assessing the Quality of Expert Systems," The Data Base for Advances in Information Systems (23) 1, pp. 37-43.

Culnan, M. J. (1986) "The Intellectual Development of Management Information Systems, 1972-1982: A Co-Citation Analysis," Management Science (32) 2, pp. 156-172.

Culnan, M. J. (1987) "Mapping the Intellectual Structure of MIS 1980-1985: A Co-Citation Analysis," MIS Quarterly, (11) 3, pp. 341-353.

Davidson, E. J. (2002) "Technology Frames and Framing: A Socio-Cognitive Investigation of Requirements Determination," MIS Quarterly (26) 4, pp. 329-358.

Dennis, A. R., B. H. Wixom and R. J. Vandenberg (2001) "Understanding Fit and Appropriation Effects in Group Support Systems via Meta-Analysis," MIS Quarterly (25) 2, pp. 167-193.

Galletta, D. and P. Zhang (eds.) (2006) Human-Computer Interaction and Management Information Systems Applications. Armonk, NY: M. E. Sharpe, Inc.

Gefen, D. (2002) "Reflections on the Dimensions of Trust and Trustworthiness among Online Consumers," The Data Base for Advances in Information Systems (33) 3, pp. 38-53.

Geissler, G., G. Zinkhan and R. T. Watson (2001) "Web Home Page Complexity and Communication Effectiveness," Journal of Association for Information Systems (2) 2, pp. 1-47.

Gerlach, J. and F.-Y. Kuo (1991) "Understanding Human Computer Interaction for Information Systems Design," MIS Quarterly (15) 4, pp. 257-274.

Gordon, M. D. and S. A. Moore (1999) "Depicting the Use and Purpose of Documents to Improve Information Retrieval," Information Systems Research (10) 1, pp. 23-37.

Gorgone, J. T., P. Gray, E. A. Stohr, J. S. Valacich and R. T. Wigand (2005) "MSIS 2006 Curriculum Review," Communications of the Association for Information Systems (15), pp. 544-554.

Hawk, S. R. and N. S. Raju (1991) "Test-Retest Reliability of User Information Satisfaction: A Comment on Galletta and Lederer's Paper," Decision Sciences (22) 5, pp. 1165-1170.

Hevner, A.R., S. T. March, J. Park, and S. Ram (2004) "Design Science in Information Systems Research," Management Information System Quarterly (28) 1, pp. 75-105. 
Hitt, L. M. and F. X. Frei (2002) "Do Better Customers Utilize Electronic Distribution Channels? The Case of PC Banking," Management Science (48) 6, pp. 732-749.

Hunton, J. E. (1996) "Involving Information System Users in Defining System Requirements: The Influence of Procedural Justice Perceptions on User Attitudes and Performance," Decision Sciences (27) 4, pp. 647-671.

Kawalek, P. and T. Wood-Harper (2002) "The Finding of Thorns: User Participation in Enterprise System Implementation," The Data Base for Advances in Information Systems (33) 1, pp. 13-22.

Kekre, S., M. S. Krishnan and K. Srinivasan (1995) "Drivers of Customer Satisfaction for Software Products: Implications for Design and Service Support," Management Science (41) 9, pp. 1456-1470.

Kutzschan, A. O. and J. Webster (2006) "HCl as MIS" in P. Zhang and D. Galletta (ed.) Human-Computer Interaction and Management Information Systems: Foundations. Armonk, NY: M.E. Sharpe, Inc., pp. 32-47.

Lawrence, M. and G. Low (1993) "Exploring Individual User Satisfaction within User-Led Development," MIS Quarterly (17) 2, pp. 195-208.

Lee, S. M., Y. R. Kim and J. Lee (1995) "An Empirical Study of the Relationships among End-User Information Systems Acceptance, Training, and Effectiveness," Journal of Management Information Systems (12) 2, pp. 189-202.

Lowry, P. B., D. Romans and A. Curtis (2004) "Global Journal Prestige and Supporting Disciplines: A Scientometric Study of Information Systems Journals," Journal of Association for Information Systems (5) 2, pp. 29-77.

McKinney, V., K. Yoon and F. Zahedi (2002) "The Measurement of Web-Customer Satisfaction: An Expectation and Disconfirmation Approach," Information Systems Research (13) 3, pp. 296-315.

Melone, N. P. (1990) "A Theoretical Assessment of the User-Satisfaction Construct in Information Systems Research," Management Science (36) 1, pp. 76-91.

Miles, M. B. and A. M. Huberman (1994) Qualitative Data Analysis: An Expanded Sourcebook. Thousand Oaks, CA: Sage Publications.

Morris, M. G., C. Speier and J. A. Hoffer (1999) "An Examination of Procedural and Object-Oriented Systems Analysis Methods: Does Prior Experience Help or Hinder Performance?" Decision Sciences (30) 1, pp. 107136.

Mylonopoulos, N. and V. Theoharakis (2001) "On-Site: Global Perceptions of IS Journals," Communications of the ACM (44) 9, pp. 29-33.

Nambisan, S., R. Agarwal and M. Tanniru (1999) "Organizational Mechanisms for Enhancing User Innovation in Information Technology," MIS Quarterly (23) 3, pp. 365-395.

Orlikowski, W. J. and C. S. Iacono (2001) "Desperately Seeking The "IT" In IT Research - a Call to Theorizing the IT Artifact," Information Systems Research (12) 2, pp. 121-134.

Peffers, K. and Y. Tang (2003) "Identifying and Evaluating the Universe of Outlets for Information Systems Research: Ranking the Journals," The Journal of Information Technology Theory and Application (5) 1, pp. 63-84.

Rainer, K. and M. Miller (2005) "Examining Differences across Journal Rankings," Communications of the ACM (48) 2, pp. 91-94.

Romano, N. C. and J. Fjermestad (2001) "Electronic Commerce Customer Relationship Management: An Assessment of Research," International Journal of Electronic Commerce (6) 2, pp. 61-113.

Shibata, Y., M. Fukuda and M. Katsumoto (1997) "A Hypermedia-Based Design Image Database System Using a Perceptional Link Method," Journal of Management Information Systems (13) 3, pp. 25-44.

Sidorova, A., N. Evangelopoulos, J. S. Valacich and T. Ramakrishnan (2008) "Uncovering the Intellectual Core of the Information Systems Discipline," MIS Quarterly (32) 3, pp. 467-482.

Silver, M. S. (1991) "Decisional Guidance for Computer-Based Decision Support," MIS Quarterly (15) 1, pp. $105-122$.

Srinivasan, A. and D. Te'eni (1995) "Modeling as Constrained Problem Solving: An Empirical Study of the Data Modeling Process," Management Science (41) 3, pp. 419-434.

Tan, F. B. and G. M. Hunter (2002) "The Repertory Grid Technique: A Method for the Study of Cognition in Information Systems," MIS Quarterly (26) 1, pp. 39-57.

Te'eni, D. (2001) "Review: A Cognitive-Affective Model of Organizational Communication for Designing IT," MIS Quarterly (25) 2, pp. 251-312.

Te'eni, D., J. Carey and P. Zhang (2007) Human-Computer Interaction: Developing Effective Organizational Information Systems. New York: John Wiley \& Sons, Inc.

Vessey, I. (1991) "Cognitive Fit: A Theory-Based Analysis of the Graphs Versus Tables Literature," Decision Sciences (22) 2, pp. 219-240.

Vessey, I., V. Ramesh and R. L. Glass (2002) "Research in Information Systems: An Empirical Study of Diversity in the Discipline and Its Journals," Journal of Management Information Systems (19) 2, pp. 129-174.

Weber, R. (2003) "Still Desperately Seeking the IT Artifact," MIS Quarterly (27) 2, pp. iii-xi.

Webster, J. and H. Ho (1997) "Audience Engagement in Multimedia Presentations," The Data Base Advances in Information Systems (28) 2, pp. 63 - 77. 
Webster, J. and J. J. Martocchio (1992) "Microcomputer Playfulness: Development of a Measure with Workplace Implications," MIS Quarterly, (16) 1, pp. 201-226.

Whitten, J., L. Bentley and K. Dittman (2004) Systems Analysis and Design Methods. Boston: McGraw-Hill Irwin.

Zhang, P. (2000) "The Effect of Animation on Information Seeking Performance on the World Wide Web: Securing Attention or Interfering with Primary Tasks," Journal of Association for Information Systems (1) 1, pp. 1-28.

Zhang, P., I. Benbasat, J. Carey, F. Davis, D. Galletta and D. Strong (2002) "Human-Computer Interaction Research in the MIS Discipline," Communications of the AIS (9) 20, pp. 334-355.

Zhang, P. and D. Galletta (eds.) (2006) Human-Computer Interaction and Management Information Systems Foundations. Armonk, NY: M. E. Sharpe, Inc.

Zhang, P. and N. Li (2004) "An Assessment of Human-Computer Interaction Research in Management Information Systems: Topics and Methods," Computers in Human Behavior (20) 2, pp. 125-147.

Zhang, P. and N. Li (2005) "The Intellectual Development of Human-Computer Interaction Research: A Critical Assessment of the MIS Literature (1990-2002)," Journal of Association for Information Systems (6) 11, pp. 227-292.

Zigurs, I. and B. K. Buckland (1998) "A Theory of Task/Technology Fit and Group Support Systems Effectiveness," MIS Quarterly (22) 3, pp. 313-334. 


\section{Appendix A: List of 758 Articles Assessed in This Study}

\section{AMIS Books Chapters}

\begin{tabular}{|c|c|}
\hline ID & Article \\
\hline 1. & Agarwal \& Angst, 2006 \\
\hline 2. & Benbasat, 2006 \\
\hline 3. & Browne, 2006 \\
\hline 4. & Carroll \& Rosson, 2006 \\
\hline 5. & Carroll, 2006 \\
\hline 6. & Compeau, et al., 2006 \\
\hline 7. & Crowston, et al., 2006 \\
\hline 8. & Davis, 2006 \\
\hline 9. & Dennis, et al., 2006 \\
\hline 10. & DeSanctis, 2006 \\
\hline 11. & Dhillon \& May, 2006 \\
\hline 12. & Dillon, 2006 \\
\hline 13. & Friedman, et al., 2006 \\
\hline 14. & Galletta \& Zhang, 2006 \\
\hline 15. & Galletta, et al., 2006 \\
\hline 16. & Goodhue, 2006 \\
\hline 17. & Grudin, 2006 \\
\hline 18. & Hiltz, et al., 2006 \\
\hline 19. & Hubona, et al., 2006 \\
\hline 20. & Kasper \& Andoh-Baidoo, 2006 \\
\hline 21. & Kim, et al., 2006 \\
\hline 22. & Kutzschan \& Webster, 2006 \\
\hline 23. & Nass, et al., 2006 \\
\hline 24. & Olfman, et al., 2006 \\
\hline 25. & Olson \& Olson, 2006 \\
\hline 26. & Randolph \& Hubona, 2006 \\
\hline 27. & Sasidharan \& Santhanam, 2006 \\
\hline 28. & Shayo \& Olfman, 2006 \\
\hline 29. & Silver, 2006 \\
\hline 30. & Stanton, et al., 2006 \\
\hline 31. & Sun \& Zhang, 2006 \\
\hline 32. & Te'eni, 2006 \\
\hline 33. & Tractinsky, 2006 \\
\hline 34. & Vessey, 2006 \\
\hline 35. & Zhang \& Galletta, 2006 \\
\hline 36. & Zhang, 2006 \\
\hline 37. & Zigurs \& Munkvold, 2006 \\
\hline
\end{tabular}

\section{BIT Special Issue}

\begin{tabular}{|l|l|}
\hline ID & Article \\
\hline 38. & Chae \& Kim, 2004 \\
\hline 39. & Hall \& Hanna, 2004 \\
\hline 40. & Nah, 2004 \\
\hline
\end{tabular}

\section{Communications of AIS}

\begin{tabular}{|l|l|}
\hline ID & Article \\
\hline 41. & Seddon, et al., 1999 \\
\hline 42. & Tegarden, 1999 \\
\hline 43. & Berg \& Spiegler, 2000 \\
\hline 44. & Kock, 2001 \\
\hline 45. & Urbaczewski \& Wheeler, 2001 \\
\hline 46. & Vogel, et al., 2001 \\
\hline 47. & Zhang, et al., 2002 \\
\hline 48. & Hitchman, 2003 \\
\hline 49. & Lee, et al., 2003 \\
\hline 50. & Nadkarni \& Nah, 2003 \\
\hline 51. & Shaw, 2003 \\
\hline 52. & Whitworth \& Zaic, 2003 \\
\hline 53. & Zviran \& Erlich, 2003 \\
\hline 54. & Carey, et al., 2004 \\
\hline
\end{tabular}

\begin{tabular}{|c|c|}
\hline 55. & Chen, et al., 2004 \\
\hline 56. & Kavanagh, 2004 \\
\hline 57. & Loiacono \& McCoy, 2004 \\
\hline 58. & Lyytinen, et al., 2004 \\
\hline 59. & Te'eni \& Schwarz, 2004 \\
\hline 60. & Anandarajan \& Simmers, 2005 \\
\hline 61. & Finneran \& Zhang, 2005 \\
\hline 62. & Lankton \& Louis, 2005 \\
\hline 63. & Liang, et al., 2005 \\
\hline 64. & Liao, et al., 2005 \\
\hline 65. & Looi, 2005 \\
\hline 66. & Lorenzo, et al., 2005 \\
\hline 67. & McCoy, et al., 2005 \\
\hline 68. & McKeen, etal., 2005 \\
\hline 69. & Musa, et al., 2005 \\
\hline 70. & Zhang, et al., 2005 \\
\hline 71. & Avital, et al., 2006 \\
\hline 72. & Balijepally, et al., 2006 \\
\hline 73. & Beaudry \& Carillo, 2006 \\
\hline 74. & Faja \& Trimi, 2006 \\
\hline 75. & Gefen, et al., 2006 \\
\hline 76. & Jawadi \& Akremi, 2006 \\
\hline 77. & Lafky, et al., 2006 \\
\hline 78. & Pan \& Pan, 2006 \\
\hline 79. & Ridings, et al., 2006 \\
\hline 80. & Sen, 2006 \\
\hline 81. & Tulu, et al., 2006 \\
\hline 82. & Bandyopadhyay \& Fraccastoro, 2007 \\
\hline 83. & Civan \& Pratt, 2007 \\
\hline 84. & Dong, et al., 2007 \\
\hline 85. & Harrison \& Datta, 2007 \\
\hline 86. & Hennington \& Janz, 2007 \\
\hline 87. & Kim, et al., 2007 \\
\hline 88. & Parameswaran \& Whinston, 2007 \\
\hline 89. & Sen, 2007 \\
\hline 90. & Shroff, et al., 2007 \\
\hline 91. & Treiblmaier, 2007 \\
\hline 92. & Chatterjee \& Datta, 2008 \\
\hline 93. & Crazier, et al., 2008 \\
\hline 94. & Djamasbi, et al., 2008 \\
\hline 95. & Jones, et al., 2008 \\
\hline 96. & Miaskiewicz \& Monarchi, 2008 \\
\hline 97. & Nguyen, et al., 2008 \\
\hline 98. & Smith \& McKeen, 2008 \\
\hline 99. & Urbaczewski \& Koivisto, 2008 \\
\hline 100. & Wilson \& Sheetz, 2008 \\
\hline 101. & Zhang \& Bhattacharyya, 2008 \\
\hline
\end{tabular}

\section{Data Base (Incl. Special Issue)}

\begin{tabular}{|l|l|}
\hline ID & Article \\
\hline 102. & Alavi, 1990 \\
\hline 103. & Hwang \& Wu, 1990 \\
\hline 104. & Ein-Dor \& Segev, 1991 \\
\hline 105. & George, 1991 \\
\hline 106. & Amoroso \& Cheney, 1992 \\
\hline 107. & Conrath \& Sharma, 1992 \\
\hline 108. & Napier, et al., 1992 \\
\hline 109. & Galletta, et al., 1993 \\
\hline 110. & Dekleva, 1994 \\
\hline 111. & Mathieson \& Ryan, 1994 \\
\hline 112. & Shirani, et al., 1994 \\
\hline 113. & Chin \& Gopal, 1995 \\
\hline 114. & Kappelman, 1995 \\
\hline 115. & Shaft, 1995 \\
\hline 116. & Jiang \& Klein, 1996 \\
\hline
\end{tabular}




\begin{tabular}{|c|c|}
\hline 117. & Atkinson \& Kydd, 1997 \\
\hline 118. & Ju \& Wagner, 1997 \\
\hline 119. & Kendall, 1997 \\
\hline 120. & Perry \& Ballou, 1997 \\
\hline 121. & Rivard, et al., 1997 \\
\hline 122. & Webster \& Ho, 1997 \\
\hline 123. & Yager, et al., 1997 \\
\hline 124. & Chan, et al., 1998 \\
\hline 125. & Curl, et al., 1998 \\
\hline 126. & Gefen \& Keil, 1998 \\
\hline 127. & Khalifa, 1998 \\
\hline 128. & Louadi, et al., 1998 \\
\hline 129. & Zigurs, et al., 1999 \\
\hline 130. & Higa \& Wijayanayake, 2000 \\
\hline 131. & Ryan, et al., 2000 \\
\hline 132. & Chiasson \& Lovato, 2001 \\
\hline 133. & Cooper \& Bhattacherjee, 2001 \\
\hline 134. & Mathieson, et al., 2001 \\
\hline 135. & Simon, 2001 \\
\hline 136. & Antony \& Batra, 2002 \\
\hline 137. & Gefen, 2002 \\
\hline 138. & Henfridsson \& Holmstrom, 2002 \\
\hline 139. & Hong \& Lerch, 2002 \\
\hline 140. & Kawalek \& Wood-Harper, 2002 \\
\hline 141. & Shaw, et al., 2002 \\
\hline 142. & Gefen \& Ridings, 2003 \\
\hline 143. & Cash, et al., 2004 \\
\hline 144. & Chen, et al., 2004 \\
\hline 145. & Gallivan, 2004 \\
\hline 146. & Kim \& Prabhakar, 2004 \\
\hline 147. & Powell, et al., 2004 \\
\hline 148. & Slyke, et al., 2004 \\
\hline 149. & Burton-Jones \& Hubona, 2005 \\
\hline 150. & Fox \& Spence, 2005 \\
\hline 151. & Gefen \& Ridings, 2005 \\
\hline 152. & livari, 2005 \\
\hline 153. & Sauter \& Free, 2005 \\
\hline 154. & Serva, et al., 2005 \\
\hline 155. & Fang \& Neufeld, 2006 \\
\hline 156. & Gao \& Koufaris, 2006 \\
\hline 157. & Glassberg, et al., 2006 \\
\hline 158. & Lee, et al., 2006 \\
\hline 159. & Li, et al., 2006 \\
\hline 160. & Limayem, 2006 \\
\hline 161. & Liu \& Ma, 2006 \\
\hline 162. & Mao \& Palvia, 2006 \\
\hline 163. & Moores, et al., 2006 \\
\hline 164. & Strong, et al., 2006 \\
\hline 165. & Leclercq, 2007 \\
\hline 166. & Schultze \& Carte, 2007 \\
\hline 167. & Turetken \& Sharda, 2007 \\
\hline 168. & Cao, et al., 2008 \\
\hline 169. & Ho, et al., 2008 \\
\hline 170. & Ocker \& Fjermestad, 2008 \\
\hline 171. & Plummer, et al., 2008 \\
\hline 172. & Slyke, et al., 2008 \\
\hline 173. & Truemper, et al., 2008 \\
\hline 174. & Wu \& Kuo, 2008 \\
\hline
\end{tabular}

\section{Decision Sciences}

\begin{tabular}{|l|l|}
\hline ID & Article \\
\hline 175. & King, et al., 1990 \\
\hline 176. & Umanath, et al., 1990 \\
\hline 177. & Doll \& Torkzadeh, 1991 \\
\hline 178. & Hawk \& Raju, 1991 \\
\hline 179. & Howard \& Mendelow, 1991 \\
\hline 180. & Kottemann \& Davis, 1991 \\
\hline 181. & Loy, 1991 \\
\hline
\end{tabular}

\begin{tabular}{|c|c|}
\hline 182. & Torkzadeh \& Doll, 1991 \\
\hline 183. & Vessey, 1991 \\
\hline 184. & Fedorowicz, et al., 1992 \\
\hline 185. & Gal \& Steinbart, 1992 \\
\hline 186. & Guimaraes, et al., 1992 \\
\hline 187. & Mackay, et al., 1992 \\
\hline 188. & Sulek \& Marucheck, 1992 \\
\hline 189. & Cook, 1993 \\
\hline 190. & Tan \& Benbasat, 1993 \\
\hline 191. & Davis \& Kottemann, 1994 \\
\hline 192. & Hendrickson, et al., 1994 \\
\hline 193. & Kettinger \& Lee, 1994 \\
\hline 194. & Mirani \& King, 1994 \\
\hline 195. & Moffitt, 1994 \\
\hline 196. & Sambamurthy \& Chin, 1994 \\
\hline 197. & Snead \& Harrell, 1994 \\
\hline 198. & Subramanian, 1994 \\
\hline 199. & Swink, 1995 \\
\hline 200. & Valacich \& Schwenk, 1995 \\
\hline 201. & Hunton, 1996 \\
\hline 202. & Teng \& Calhoun, 1996 \\
\hline 203. & Venkatesh \& Davis, 1996 \\
\hline 204. & Agarwal \& Prasad, 1997 \\
\hline 205. & Gonzalez \& Kasper, 1997 \\
\hline 206. & Guimaraes \& Igbaria, 1997 \\
\hline 207. & Jackson, et al., 1997 \\
\hline 208. & Kettinger \& Grover, 1997 \\
\hline 209. & King \& Xia, 1997 \\
\hline 210. & Ramarapu, et al., 1997 \\
\hline 211. & Smelcer \& Carmel, 1997 \\
\hline 212. & Warkentin, et al., 1997 \\
\hline 213. & Bhattacherjee, 1998 \\
\hline 214. & Doll, et al., 1998 \\
\hline 215. & Goodhue, 1998 \\
\hline 216. & McHaney \& Cronan, 1998 \\
\hline 217. & Agarwal \& Prasad, 1999 \\
\hline 218. & Kettinger \& Lee, 1999 \\
\hline 219. & Lucas \& Spitler, 1999 \\
\hline 220. & Morris, et al., 1999 \\
\hline 221. & Speier, et al., 1999 \\
\hline 222. & Swink \& Speier, 1999 \\
\hline 223. & Van Dyke, et al., 1999 \\
\hline 224. & Chu \& Spires, 2000 \\
\hline 225. & Bolt, et al., 2001 \\
\hline 226. & Chau \& Hu, 2001 \\
\hline 227. & Dunn \& Grabski, 2001 \\
\hline 228. & Grabowski \& Sanborn, 2001 \\
\hline 229. & Parikh, et al., 2001 \\
\hline 230. & Reneau \& Blanthorne, 2001 \\
\hline 231. & Schmidt, et al., 2001 \\
\hline 232. & Yi \& Davis, 2001 \\
\hline 233. & Carr, 2002 \\
\hline 234. & Venkatesh, et al., 2002 \\
\hline 235. & Somers, et al., 2003 \\
\hline 236. & Speier, et al., 2003 \\
\hline 237. & Piccoli, et al., 2004 \\
\hline 238. & Stafford, et al., 2004 \\
\hline 239. & Abdinnour-Helm, et al., 2005 \\
\hline 240. & Boyer \& Hult, 2005 \\
\hline 241. & Kim \& Malhotra, 2005 \\
\hline 242. & Froehle, 2006 \\
\hline 243. & Li, et al., 2006 \\
\hline 244. & Looney, et al., 2006 \\
\hline 245. & Venkatesh, 2006 \\
\hline 246. & Yi, et al., 2006 \\
\hline 247. & Fuller, et al., 2007 \\
\hline 248. & Massey, et al., 2007 \\
\hline 249. & Looney, et al., 2008 \\
\hline 250. & Venkatesh \& Bala, 2008 \\
\hline
\end{tabular}




ISJ Special Issue
\begin{tabular}{|l|l|}
\hline ID & Article \\
\hline 251. & Avital \& Te'eni, 2008 \\
\hline 252. & Dinev, et al., 2008 \\
\hline 253. & Guo \& Poole, 2008 \\
\hline 254. & McCoy, et al., 2008 \\
\hline 255. & Tomiuk \& Pinsonneault, 2008 \\
\hline
\end{tabular}

\section{ISR}

\begin{tabular}{|c|c|}
\hline ID & Article \\
\hline 256. & Brancheau \& Wetherbe, 1990 \\
\hline 257. & Elam \& Mead, 1990 \\
\hline 258. & Galletta \& Heckman, 1990 \\
\hline 259. & Newman \& Noble, 1990 \\
\hline 260. & Tan \& Benbasat, 1990 \\
\hline 261. & Mathieson, 1991 \\
\hline 262. & Moore \& Benbasat, 1991 \\
\hline 263. & Todd \& Benbasat, 1991 \\
\hline 264. & Vessey \& Galletta, 1991 \\
\hline 265. & Mackay \& Elam, 1992 \\
\hline 266. & Morris, et al., 1992 \\
\hline 267. & Suh \& Jenkins, 1992 \\
\hline 268. & Ang, et al., 1993 \\
\hline 269. & Barki \& Hartwick, 1994 \\
\hline 270. & Beath \& Orlikowski, 1994 \\
\hline 271. & Constant, et al., 1994 \\
\hline 272. & Santhanam \& Sein, 1994 \\
\hline 273. & Straub, 1994 \\
\hline 274. & Asahi, et al., 1995 \\
\hline 275. & Chin \& Newsted, 1995 \\
\hline 276. & Compear \& Higgins, 1995 \\
\hline 277. & Doll, et al., 1995 \\
\hline 278. & Shaft \& Vessey, 1995 \\
\hline 279. & Taylor \& Todd, 1995 \\
\hline 280. & Kasper, 1996 \\
\hline 281. & Roy \& Lerch, 1996 \\
\hline 282. & Sharda \& Steriger, 1996 \\
\hline 283. & Simon, et al., 1996 \\
\hline 284. & Vandenbosch \& Higgins, 1996 \\
\hline 285. & Weber, 1996 \\
\hline 286. & Harrison, et al., 1997 \\
\hline 287. & Kim \& Lerch, 1997 \\
\hline 288. & Lim, et al., 1997 \\
\hline 289. & Agarwal \& Prasad, 1998 \\
\hline 290. & Dennis \& Carte, 1998 \\
\hline 291. & Dennis \& Kinney, 1998 \\
\hline 292. & Marakas, et al., 1998 \\
\hline 293. & Parthasarathy \& Bhattacherjee, 1998 \\
\hline 294. & Gattiker \& Kelley, 1999 \\
\hline 295. & Gordon \& Moore, 1999 \\
\hline 296. & Kraut, et al., 1999 \\
\hline 297. & Sein \& Santhanam, 1999 \\
\hline 298. & Sethi \& King, 1999 \\
\hline 299. & Sussman \& Sproull, 1999 \\
\hline 300. & Todd \& Benbasat, 1999 \\
\hline 301. & Agarwal, et al., 2000 \\
\hline 302. & Johnson \& Marakas, 2000 \\
\hline 303. & Kim, et al., 2000 \\
\hline 304. & Lim, et al., 2000 \\
\hline 305. & Limayem \& DeSanctis, 2000 \\
\hline 306. & Marcolin, et al., 2000 \\
\hline 307. & Venkatesh, 2000 \\
\hline 308. & Alavi \& Leidner, 2001 \\
\hline 309. & Belanger, et al., 2001 \\
\hline 310. & Butler, 2001 \\
\hline 311. & Chwelos, et al., 2001 \\
\hline 312. & Garfield, et al., 2001 \\
\hline
\end{tabular}

\begin{tabular}{|c|c|}
\hline 313. & Lerch \& Harter, 2001 \\
\hline 314. & Orlikowski \& Iacono, 2001 \\
\hline 315. & Plouffe, et al., 2001 \\
\hline 316. & Agarwal \& Venkatesh, 2002 \\
\hline 317. & Alavi, et al., 2002 \\
\hline 318. & Chen \& Hitt, 2002 \\
\hline 319. & Devaraj, et al., 2002 \\
\hline 320. & Koufaris, 2002 \\
\hline 321. & McKinney, et al., 2002 \\
\hline 322. & McKnight, et al., 2002 \\
\hline 323. & Palmer, 2002 \\
\hline 324. & Rai, et al., 2002 \\
\hline 325. & Sia, et al., 2002 \\
\hline 326. & Stewart \& Segars, 2002 \\
\hline 327. & Chin, et al., 2003 \\
\hline 328. & Fisher, et al., 2003 \\
\hline 329. & Miranda \& Saunders, 2003 \\
\hline 330. & Purao, et al., 2003 \\
\hline 331. & Sussman \& Siegal, 2003 \\
\hline 332. & Yi \& Davis, 2003 \\
\hline 333. & Hong, et al., 2004 \\
\hline 334. & Jarvenpaa, et al., 2004 \\
\hline 335. & Jones, et al., 2004 \\
\hline 336. & Karimi, et al., 2004 \\
\hline 337. & Lilien, et al., 2004 \\
\hline 338. & Malhotra, et al., 2004 \\
\hline 339. & Pavlou \& Gefen, 2004 \\
\hline 340. & Schultze \& Orlikowski, 2004 \\
\hline 341. & Chidambaram \& Tung, 2005 \\
\hline 342. & Kim, et al., 2005 \\
\hline 343. & Majchrzak, et al., 2005 \\
\hline 344. & Pavlou \& Gefen, 2005 \\
\hline 345. & Tam \& Ho, 2005 \\
\hline 346. & Wixom \& Todd, 2005 \\
\hline 347. & Burton-Jones \& Straub, 2006 \\
\hline 348. & Dinev \& Hart, 2006 \\
\hline 349. & Galletta, et al., 2006 \\
\hline 350. & Heninger, et al., 2006 \\
\hline 351. & Hong \& Tam, 2006 \\
\hline 352. & Khatri, et al., 2006 \\
\hline 353. & Kim \& Benbasat, 2006 \\
\hline 354. & Kumar \& Benbasat, 2006 \\
\hline 355. & Nicolaou \& McKnight, 2006 \\
\hline 356. & Pavlou \& Dimoka, 2006 \\
\hline 357. & Barki, et al., 2007 \\
\hline 358. & Jiang \& Benbasat, 2007 \\
\hline 359. & Ma \& Agarwal, 2007 \\
\hline 360. & Cenfetelli, et al., 2008 \\
\hline 361. & Dabbish \& Kraut, 2008 \\
\hline 362. & Dawande, et al., 2008 \\
\hline 363. & Devaraj, et al., 2008 \\
\hline 364. & Forman, et al., 2008 \\
\hline 365. & Hahn, et al., 2008 \\
\hline 366. & Kane \& Alavi, 2008 \\
\hline 367. & Kuruzovich, et al., 2008 \\
\hline 368. & Moon \& Sproull, 2008 \\
\hline 369. & Ragu-Nathan, et al., 2008 \\
\hline 370. & Robert, et al., 2008 \\
\hline 371. & Santhanam, et al., 2008 \\
\hline 372. & Wakefield, et al., 2008 \\
\hline
\end{tabular}

\section{IJHCI Special Issues}

\begin{tabular}{|l|l|}
\hline ID & Article \\
\hline 373. & Ho \& Tam, 2005 \\
\hline 374. & Jain \& Kanungo, 2005 \\
\hline 375. & Park, et al., 2005 \\
\hline 376. & Qiu \& Benbasat, 2005 \\
\hline 377. & Rajeswari \& Anantharaman, 2005 \\
\hline
\end{tabular}




\begin{tabular}{|l|l|}
\hline 378. & Rao, et al., 2005 \\
\hline 379. & Tarasewich, et al., 2005 \\
\hline 380. & Cai \& Xu, 2008 \\
\hline 381. & McCoy, et al., 2008 \\
\hline 382. & Shen \& Khalifa, 2008 \\
\hline 383. & Tan \& Chou, 2008 \\
\hline 384. & Zhang, et al., 2008 \\
\hline
\end{tabular}

\section{IJHCS Special Issues}

\begin{tabular}{|l|l|}
\hline ID & Article \\
\hline 385. & Chan, et al., 2003 \\
\hline 386. & Featherman \& Pavlou, 2003 \\
\hline 387. & Finneran \& Zhang, 2003 \\
\hline 388. & Ryan, et al., 2003 \\
\hline 389. & Yi \& Hwang, 2003 \\
\hline 390. & Chung, 2006 \\
\hline 391. & Du \& Wagner, 2006 \\
\hline 392. & Thong, et al., 2006 \\
\hline
\end{tabular}

\section{JAIS (Incl. Special Issues)}

\begin{tabular}{|l|l|}
\hline ID & Article \\
\hline 393. & Gefen \& Straub, 2000 \\
\hline 394. & Tan \& Teo, 2000 \\
\hline 395. & Zhang, 2000 \\
\hline 396. & Geissler, et al., 2001 \\
\hline 397. & Leonard \& Cronan, 2001 \\
\hline 398. & Panko \& Halverson, 2001 \\
\hline 399. & Te'eni \& Feldman, 2001 \\
\hline 400. & Gefen, 2002 \\
\hline 401. & Shim, et al., 2002 \\
\hline 402. & Khalifa \& Liu, 2003 \\
\hline 403. & Lee, et al., 2003 \\
\hline 404. & Li, et al., 2003 \\
\hline 405. & Limayem \& Hirt, 2003 \\
\hline 406. & Rafaeli \& Raban, 2003 \\
\hline 407. & Sarker \& Sahay, 2003 \\
\hline 408. & Shin, 2003 \\
\hline 409. & Brown, et al., 2004 \\
\hline 410. & Carte \& Chidambaram, 2004 \\
\hline 411. & Cenfetelli, 2004 \\
\hline 412. & Fichman, 2004 \\
\hline 413. & Galletta, et al., 2004 \\
\hline 414. & Kim, et al., 2004 \\
\hline 415. & Markus \& Mao, 2004 \\
\hline 416. & Nah \& Benbasat, 2004 \\
\hline 417. & Wasko, et al., 2004 \\
\hline 418. & Li, et al., 2005 \\
\hline 419. & Sarker, et al., 2005 \\
\hline 420. & Wang \& Benbasat, 2005 \\
\hline 421. & Zhang and Li, 2005 \\
\hline 422. & Al-Natour, et al., 2006 \\
\hline 423. & Bowen, et al., 2006 \\
\hline 424. & Hargittai, 2006 \\
\hline 425. & Rensel, et al., 2006 \\
\hline 426. & Son, et al., 2006 \\
\hline 427. & Sun \& Zhang, 2006 \\
\hline 428. & Van Slyke, et al., 2006 \\
\hline 429. & Bagozzi, 2007 \\
\hline 430. & Benbasat \& Barki, 2007 \\
\hline 431. & Choi, et al., 2007 \\
\hline 432. & Compeau, et al., 2007 \\
\hline 433. & Dickey, et al., 2007 \\
\hline 434. & Dinev \& Hu, 2007 \\
\hline 435. & Germonprez, et al., 2007 \\
\hline 436. & Marakas, et al., 2007 \\
\hline 437. & Olphert \& Damodaran, 2007 \\
\hline 438. & Parameswaran \& Whinston, 2007 \\
\hline
\end{tabular}

\begin{tabular}{|l|l|}
\hline 439. & Porra \& Hirschheim, 2007 \\
\hline 440. & Schwarz \& Chin, 2007 \\
\hline 441. & Silva, 2007 \\
\hline 442. & Stahl, 2007 \\
\hline 443. & Straub \& Burton-Jones, 2007 \\
\hline 444. & Venkatesh, et al., 2007 \\
\hline 445. & Wagner \& Newell, 2007 \\
\hline 446. & Briggs, et al., 2008 \\
\hline 447. & Burton-Jones \& Meso, 2008 \\
\hline 448. & Gable, et al., 2008 \\
\hline 449. & George, et al., 2008 \\
\hline 450. & Goswami, et al., 2008 \\
\hline 451. & Hardin, et al., 2008 \\
\hline 452. & Komiak \& Benbasat, 2008 \\
\hline 453. & Kudaravalli \& Faraj, 2008 \\
\hline 454. & Sheng, et al., 2008 \\
\hline 455. & Zhang \& Watts, 2008 \\
\hline
\end{tabular}

\section{JMIS (Incl. Special Issue)}

\begin{tabular}{|l|l|}
\hline ID & Article \\
\hline 456. & Cronan \& Douglas, 1990 \\
\hline 457. & Davis \& Davis, 1990 \\
\hline 458. & Minch, 1990 \\
\hline 459. & Smith \& Vanecek, 1990 \\
\hline 460. & Amoroso \& Cheney, 1991 \\
\hline 461. & Gogan, 1991 \\
\hline 462. & Magal, 1991 \\
\hline 463. & Harrison \& Rainer, 1992 \\
\hline 464. & Briggs, et al., 1993 \\
\hline 465. & Burton, et al., 1993 \\
\hline 466. & Levine \& Rossmoore, 1993 \\
\hline 467. & Vessey \& Conger, 1993 \\
\hline 468. & Zmud, et al., 1993 \\
\hline 469. & Mirani \& King, 1994 \\
\hline 470. & Tan, 1994 \\
\hline 471. & Thompson \& Higgins, 1994 \\
\hline 472. & Chen, 1995 \\
\hline 473. & Igbaria, et al., 1995 \\
\hline 474. & Lee, et al., 1995 \\
\hline 475. & Massey \& Clapper, 1995 \\
\hline 476. & Satzinger \& Olfman, 1995 \\
\hline 477. & Steiger, 1995 \\
\hline 478. & Yoon \& Guimaraes, 1995 \\
\hline 479. & Agarwal, et al., 1996 \\
\hline 480. & Chau, 1996 \\
\hline 481. & Choe, 1996 \\
\hline 482. & Edberg \& Bowman, 1996 \\
\hline 483. & Igbaria, et al., 1996 \\
\hline 484. & Leitheiser \& March, 1996 \\
\hline 485. & Money, 1996 \\
\hline 486. & Montazemi, et al., 1996 \\
\hline 487. & Reinig, et al., 1996 \\
\hline 488. & Saleem, 1996 \\
\hline 489. & Tillquist, 1996 \\
\hline 490. & Wang \& Strong, 1996 \\
\hline 491. & Galletta, et al., 1997 \\
\hline 492. & McKeen \& Guimaraes, 1997 \\
\hline 493. & Sheetz, et al., 1997 \\
\hline 494. & Shibata, et al., 1997 \\
\hline 495. & Ahituv, et al., 1998 \\
\hline 496. & Essex, et al., 1998 \\
\hline 497. & Jarvenpaa, et al., 1998 \\
\hline 498. & Moody, et al., 1998 \\
\hline 499. & Satzinger \& Olfman, 1998 \\
\hline 500. & Schenk, et al., 1998 \\
\hline 501. & Shaft \& Vessey, 1998 \\
\hline 502. & Tan, et al., 1998 \\
\hline 503. & Hu, et al., 1999 \\
\hline & \\
\hline
\end{tabular}




\begin{tabular}{|c|c|}
\hline 504. & Panko, 1999 \\
\hline 505. & Satzinger, et al., 1999 \\
\hline 506. & Zviran \& Haga, 1999 \\
\hline 507. & Burgoon, et al., 2000 \\
\hline 508. & Grise \& Gallupe, 2000 \\
\hline 509. & Huang \& Wei, 2000 \\
\hline 510. & Mao \& Benbasat, 2000 \\
\hline 511. & Hillmer \& Dennis, 2001 \\
\hline 512. & Markus, 2001 \\
\hline 513. & Sack, 2001 \\
\hline 514. & Bargeron, et al., 2002 \\
\hline 515. & Chau \& Hu, 2002 \\
\hline 516. & Coppola, et al., 2002 \\
\hline 517. & Hong, et al., 2002 \\
\hline 518. & Sniezek, et al., 2002 \\
\hline 519. & DeLone \& McLean, 2003 \\
\hline 520. & Easley, et al., 2003 \\
\hline 521. & Hardgrave, et al., 2003 \\
\hline 522. & Hayne, et al., 2003 \\
\hline 523. & Kahai \& Cooper, 2003 \\
\hline 524. & Kang \& Santhanam, 2003 \\
\hline 525. & Massey, et al., 2003 \\
\hline 526. & Peace, et al., 2003 \\
\hline 527. & Pennington, et al., 2003 \\
\hline 528. & Reinig, 2003 \\
\hline 529. & Brown, et al., 2004 \\
\hline 530. & Doll, et al., 2004 \\
\hline 531. & Gefen, 2004 \\
\hline 532. & Kohli \& Mahmood, 2004 \\
\hline 533. & Pitts \& Browne, 2004 \\
\hline 534. & Santanen, et al., 2004 \\
\hline 535. & Sharda, et al., 2004 \\
\hline 536. & Gallivan, et al., 2005 \\
\hline 537. & Hong, et al., 2005 \\
\hline 538. & Jiang \& Benbasat, 2005 \\
\hline 539. & Leimeister, et al., 2005 \\
\hline 540. & Malhotra \& Galletta, 2005 \\
\hline 541. & Nelson, et al., 2005 \\
\hline 542. & Paul, et al., 2005 \\
\hline 543. & Roberts, et al., 2005 \\
\hline 544. & Tiwana \& McLean, 2005 \\
\hline 545. & Everard, et al., 2006 \\
\hline 546. & Fang, et al., 2006 \\
\hline 547. & Gemino, et al., 2006 \\
\hline 548. & Hess, et al., 2006 \\
\hline 549. & Lam \& Lee, 2006 \\
\hline 550. & Lim, et al., 2006 \\
\hline 551. & Lopes \& Galletta, 2006 \\
\hline 552. & Stewart, 2006 \\
\hline 553. & Wei, et al., 2006 \\
\hline 554. & Zhou, et al., 2006 \\
\hline 555. & Biocca, et al., 2007 \\
\hline 556. & Espinosa, et al., 2007 \\
\hline 557. & Fuller, et al., 2007 \\
\hline 558. & Hann, et al., 2007 \\
\hline 559. & $\mathrm{He}$, et al., 2007 \\
\hline 560. & Kankanhalli, et al., 2007 \\
\hline 561. & Liang, et al., 2007 \\
\hline 562. & Mithas, et al., 2007 \\
\hline 563. & Santhanam, et al., 2007 \\
\hline 564. & Tarafdar, et al., 2007 \\
\hline 565. & Wang \& Benbasat, 2007 \\
\hline 566. & Zhang, D., et al., 2007 \\
\hline 567. & Zhang, J., et al., 2007 \\
\hline 568. & Awad \& Ragowsky, 2008 \\
\hline 569. & Bolton, et al., 2008 \\
\hline 570. & Charki \& Josserand, 2008 \\
\hline 571. & Cyr, 2008 \\
\hline 572. & Gefen, et al., 2008 \\
\hline
\end{tabular}

\begin{tabular}{|l|l|}
\hline 573. & He \& King, 2008 \\
\hline 574. & Kim, 2008 \\
\hline 575. & Lowry, et al., 2008 \\
\hline 576. & Malhotra, et al., 2008 \\
\hline 577. & Ren, et al., 2008 \\
\hline 578. & Tang, et al., 2008 \\
\hline 579. & Turel, et al., 2008 \\
\hline 580. & Vance, et al., 2008 \\
\hline 581. & Wang \& Benbasat, 2008 \\
\hline 582. & Zahedi \& Song, 2008 \\
\hline 583. & Zimmer, et al., 2008 \\
\hline
\end{tabular}

\section{Management Science}

\begin{tabular}{|l|l|}
\hline ID & Article \\
\hline 584. & Connolly, et al., 1990 \\
\hline 585. & Hiltz \& Johnson, 1990 \\
\hline 586. & Melone, 1990 \\
\hline 587. & Poole, et al., 1991 \\
\hline 588. & Grabowski \& Wallace, 1993 \\
\hline 589. & Hartwick \& Barki, 1994 \\
\hline 590. & Anson, et al., 1995 \\
\hline 591. & Bell \& O'Keefe, 1995 \\
\hline 592. & Goodhue, 1995 \\
\hline 593. & Kekre, et al., 1995 \\
\hline 594. & Srinivasan \& Te'eni, 1995 \\
\hline 595. & Straub, et al., 1995 \\
\hline 596. & Hoch \& Schkade, 1996 \\
\hline 597. & Szajna, 1996 \\
\hline 598. & Hunton \& Price, 1997 \\
\hline 599. & van Bruggen, et al., 1998 \\
\hline 600. & Venkatesh \& Davis, 2000 \\
\hline 601. & Hitt \& Frei, 2002 \\
\hline 602. & Ahuja, et al., 2003 \\
\hline 603. & Balasubramanian, et al., 2003 \\
\hline 604. & Johnson, et al., 2004 \\
\hline 605. & Ding, et al., 2005 \\
\hline 606. & Kim \& Malhotra, 2005 \\
\hline 607. & Song \& Zahedi, 2005 \\
\hline 608. & Bagozzi \& Dholakia, 2006 \\
\hline 609. & Roberts, et al., 2006 \\
\hline 610. & Sabherwal, et al., 2006 \\
\hline 611. & Shah, 2006 \\
\hline 612. & Venkatesh \& Agarwal, 2006 \\
\hline 613. & Boh, et al., 2007 \\
\hline 614. & Ahearne, et al., 2008 \\
\hline 615. & Porter \& Donthu, 2008 \\
\hline 616. & Tucker, 2008 \\
\hline & \\
\hline
\end{tabular}

\section{MIS Quarterly}

\begin{tabular}{|l|l|}
\hline ID & Article \\
\hline 617. & Bergeron, et al., 1990 \\
\hline 618. & Lamberti \& Wallace, 1990 \\
\hline 619. & Nelson, 1990 \\
\hline 620. & Gerlach \& Kuo, 1991 \\
\hline 621. & Joshi, 1991 \\
\hline 622. & Silver, 1991 \\
\hline 623. & Thompson, et al., 1991 \\
\hline 624. & Adams, et al., 1992 \\
\hline 625. & Todd \& Benbasat, 1992 \\
\hline 626. & Trauth \& Cole, 1992 \\
\hline 627. & Webster \& Martocchio, 1992 \\
\hline 628. & Ahrens \& Sankar, 1993 \\
\hline 629. & Chan, et al., 1993 \\
\hline 630. & Culnan, 1993 \\
\hline 631. & Hendrickson, et al., 1993 \\
\hline 632. & Kraemer, et al., 1993 \\
\hline 633. & Lawrence \& Low, 1993 \\
\hline
\end{tabular}




\begin{tabular}{|c|c|}
\hline 634. & Segars \& Grover, 1993 \\
\hline 635. & Szajna \& Scamell, 1993 \\
\hline 636. & Alavi, 1994 \\
\hline 637. & Barki \& Hartwick, 1994 \\
\hline 638. & Doll, et al., 1994 \\
\hline 639. & McKeen, et al., 1994 \\
\hline 640. & Olfman \& Mandviwalla, 1994 \\
\hline 641. & Szajna, 1994 \\
\hline 642. & Chin \& Todd, 1995 \\
\hline 643. & Compeau \& Higgins, 1995 \\
\hline 644. & Goodhue \& Thompson, 1995 \\
\hline 645. & Pitt, et al., 1995 \\
\hline 646. & Taylor \& Todd, 1995 \\
\hline 647. & Ye \& Johnson, 1995 \\
\hline 648. & Yoon, et al., 1995 \\
\hline 649. & George, 1996 \\
\hline 650. & Gill, 1996 \\
\hline 651. & Griffith \& Northcraft, 1996 \\
\hline 652. & Harrington, 1996 \\
\hline 653. & Massetti, 1996 \\
\hline 654. & Smith, et al., 1996 \\
\hline 655. & Gefen \& Straub, 1997 \\
\hline 656. & Hunton \& Beeler, 1997 \\
\hline 657. & Igbaria, et al., 1997 \\
\hline 658. & Kettinger \& Lee, 1997 \\
\hline 659. & Klein, et al., 1997 \\
\hline 660. & Pitt, et al., 1997 \\
\hline 661. & Van Dyke, et al., 1997 \\
\hline 662. & Vandenbosch \& Huff, 1997 \\
\hline 663. & Banerjee, et al., 1998 \\
\hline 664. & Watson \& Pitt, 1998 \\
\hline 665. & Webster, 1998 \\
\hline 666. & Wierenga \& Bruggen, 1998 \\
\hline 667. & Zigurs \& Buckland, 1998 \\
\hline 668. & Compeau, et al., 1999 \\
\hline 669. & Gregor \& Benbasat, 1999 \\
\hline 670. & Karahanna, et al., 1999 \\
\hline 671. & Nambisan, et al., 1999 \\
\hline 672. & Smith \& Hasnas, 1999 \\
\hline 673. & Tractinsky \& Meyer, 1999 \\
\hline 674. & Venkatesh, 1999 \\
\hline 675. & Agarwal \& Karahanna, 2000 \\
\hline 676. & Gopal \& Prasad, 2000 \\
\hline 677. & Lim \& Benbasat, 2000 \\
\hline 678. & Mennecke, et al., 2000 \\
\hline 679. & Trauth \& Jessup, 2000 \\
\hline 680. & Venkatesh \& Morris, 2000 \\
\hline 681. & Barki \& Hartwick, 2001 \\
\hline 682. & Bhattacherjee, 2001 \\
\hline 683. & Dennis, et al., 2001 \\
\hline 684. & Piccoli, et al., 2001 \\
\hline 685. & Te'eni, 2001 \\
\hline 686. & Venkatesh \& Brown, 2001 \\
\hline 687. & Yoo \& Alavi, 2001 \\
\hline 688. & Ba \& Pavlou, 2002 \\
\hline 689. & Davidson, 2002 \\
\hline 690. & Tan \& Hunter, 2002 \\
\hline 691. & Thatcher \& Perrewe, 2002 \\
\hline 692. & Walsham, 2002 \\
\hline 693. & Dennis \& Garfield, 2003 \\
\hline 694. & Gefen, et al., 2003 \\
\hline 695. & Griffith, et al., 2003 \\
\hline 696. & Lamb \& Kling, 2003 \\
\hline 697. & Lewis, et al., 2003 \\
\hline 698. & Piccole \& Ives, 2003 \\
\hline
\end{tabular}

\begin{tabular}{|c|c|}
\hline 699. & Speier \& Morris, 2003 \\
\hline 700. & Venkatesh, et al., 2003 \\
\hline 701. & Albert, et al., 2004 \\
\hline 702. & Bapna, et al., 2004 \\
\hline 703. & Bhattacherjee \& Premkumar, 2004 \\
\hline 704. & Dennis \& Reinicke, 2004 \\
\hline 705. & Heijden, 2004 \\
\hline 706. & Kumar \& Benbasat, 2004 \\
\hline 707. & Paul \& Jr., 2004 \\
\hline 708. & Potter \& Balthazard, 2004 \\
\hline 709. & Ahuja \& Thatcher, 2005 \\
\hline 710. & Beaudry \& Pinsonneault, 2005 \\
\hline 711. & Brown \& Venkatesh, 2005 \\
\hline 712. & Jasperson, et al., 2005 \\
\hline 713. & Lapointe \& Rivard, 2005 \\
\hline 714. & Majchrzak, et al., 2005 \\
\hline 715. & Suh \& Lee, 2005 \\
\hline 716. & Allen \& March, 2006 \\
\hline 717. & Arnold, et al., 2006 \\
\hline 718. & Awad \& Krishnan, 2006 \\
\hline 719. & Bhattacherjee \& Sanford, 2006 \\
\hline 720. & Butler \& Gray, 2006 \\
\hline 721. & Karahanna, et al., 2006 \\
\hline 722. & Komiak \& Benbasat, 2006 \\
\hline 723. & Leidner \& Kayworth, 2006 \\
\hline 724. & Massey \& Montoya-Weiss, 2006 \\
\hline 725. & Pavlou \& Fygenson, 2006 \\
\hline 726. & Shaft \& Vessey, 2006 \\
\hline 727. & Srite \& Karahanna, 2006 \\
\hline 728. & Stewart \& Gosain, 2006 \\
\hline 729. & Tam \& Ho, 2006 \\
\hline 730. & Venkatesh \& Ramesh, 2006 \\
\hline 731. & Webster \& Ahuja, 2006 \\
\hline 732. & Armstrong \& Hardgrave, 2007 \\
\hline 733. & Browne, et al., 2007 \\
\hline 734. & Burton-Jones \& Gallivan, 2007 \\
\hline 735. & Chua, et al., 2007 \\
\hline 736. & Davis \& Hufnagel, 2007 \\
\hline 737. & Hui, et al., 2007 \\
\hline 738. & Jiang \& Benbasat, 2007 \\
\hline 739. & Kanawattanachai \& Yoo, 2007 \\
\hline 740. & Limayem, et al., 2007 \\
\hline 741. & McElroy, et al., 2007 \\
\hline 742. & Nadkarni \& Gupta, 2007 \\
\hline 743. & Pavlou, et al., 2007 \\
\hline 744. & Xiao \& Benbasat, 2007 \\
\hline 745. & Au, et al., 2008 \\
\hline 746. & Chin, et al., 2008 \\
\hline 747. & Choudhury \& Karahanna, 2008 \\
\hline 748. & Dennis, et al., 2008 \\
\hline 749. & Gregg \& Walczak, 2008 \\
\hline 750. & Hsieh, et al., 2008 \\
\hline 751. & Kamis, et al., 2008 \\
\hline 752. & Kappos \& Rivard, 2008 \\
\hline 753. & Mithas, et al., 2008 \\
\hline 754. & Olivera, et al., 2008 \\
\hline 755. & Shanks, et al., 2008 \\
\hline 756. & Son \& Kim, 2008 \\
\hline 757. & Venkatesh, et al., 2008 \\
\hline 758. & Vlaar, et al., 2008 \\
\hline
\end{tabular}




\section{About The Authors}

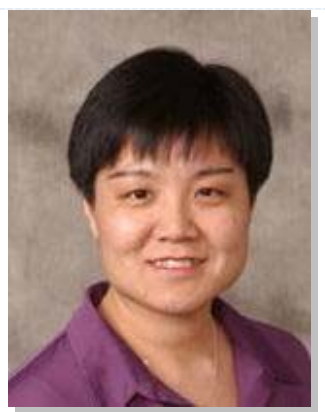

Ping Zhang (http://melody.syr.edu/pzhang/) is Professor in the School of Information Studies at Syracuse University. Her research interests include the intellectual development of information related fields; human-centeredness in ICT development, evaluation and use; affective, cognitive, motivational and behavioral aspects of individual reactions towards ICT; and the impact of ICT design and use on individuals, organizations, societies and cultures. She publishes in information systems, humancomputer interaction and information science journals and conference proceedings. She is co-editor (with Dennis Galletta) of two edited books on $\mathrm{HCl}$ and MIS of the Advances in MIS series (by M.E. Sharpe, 2006), and is co-author (with Dov Te'eni and Jane Carey) of the first $\mathrm{HCl}$ textbook for non-CS students (by John Wiley, 2007). Dr. Zhang has received 4 Best Paper awards, 2 nominations for best paper awards, an excellence in teaching award, and an outstanding service award. She and Dennis Galletta are founding Editors-in-Chief for AIS Transactions on Human-Computer Interaction. In addition, she is Senior Editor for the Journal of Associations for Information Systems (JAIS), former Associate Editor for the International Journal of Human-Computer Studies (IJHCS) and Communications of Association for Information Systems (CAIS), on the editorial board of Journal of Management Information Systems (JMIS) and Journal of Database Management, and a guest senior editor of 7 special issues for Journal of Association for Information Systems (2004 and 2008), Journal of Management Information Systems (2005), International Journal of HumanComputer Studies (2003 and 2006), International Journal of Human Computer Interaction (2005), and Behavior \& Information Technology (2004). Dr. Zhang is co-founder and the first chair (2001-2004) of Association for Information Systems (AIS) Special Interest Group on Human-Computer Interaction (SIGHCI). She received her $\mathrm{PhD}$ in Information Systems from the University of Texas at Austin, and M.Sc. and B.Sc. in Computer Science from Peking University, Beijing, China.

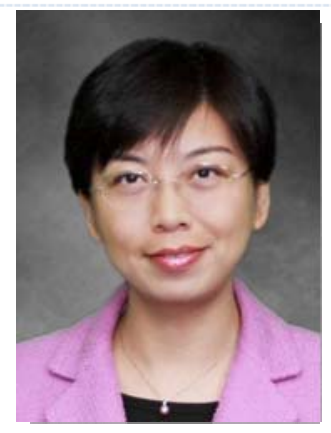

$\mathbf{N a}$ "Lina" Li is an Assistant Professor in Information Systems in the Center for Graduate Studies at Baker College. She received her MPhil and Ph.D. in Information Science and Technology from Syracuse University; Masters degree in Information Science and B.S. in Information Science and Technology from Peking University. Her research interests include human-computer interaction, information system evaluation and adoption, e-commerce websites design and customer behaviors, affect/emotion, and virtual teams. Her work has been published in journals such as Communications of the ACM (CACM), Journal of the Association for Information Systems (JAIS), and Computers in Human Behavior (CHB). She published a few book chapters. She also co-authored and presented a number of papers and received 3 best paper awards at conferences including the International Conference on Information Systems (ICIS), Academy of Management (AOM), Americas Conference on Information Systems (AMCIS), Hawaii International Conference on System Sciences (HICSS), Annual Workshop on $\mathrm{HCl}$ Research in MIS, iConference, and the International Conference on Open Source System . She was the Newsletter Editor of the Association for Information Systems (AIS) Special Interest Group on Human-Computer Interaction (SIGHCI) (2003-2009).

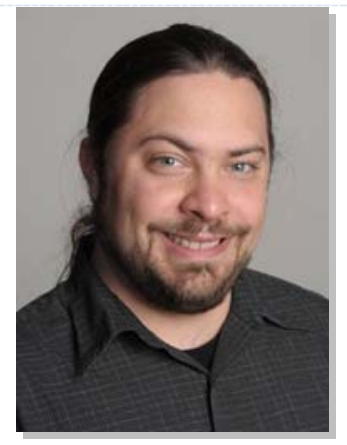

Michael J. Scialdone is a doctoral candidate in Information Science and Technology at Syracuse University. He received his M.S. in Information Design and Technology from State University of New York Institute of Technology in 2006, and his B.A. in Communication Arts from Utica College in 1999. His research has focused on the social aspects of virtual communities, including MMORPGs (Massively Multiplayer Online Role-Playing Games) and FLOSS (Free/Libre Open Source Software) development groups. Currently, Mr. Scialdone is focusing on Web 2.0 technologies in distance-based learning environments, and how these might maximize student engagement and creativity. His work has been published in Journal of the American Society for Information Science and Technology (JASIST), and he has presented at conferences including The Academy of Management Annual Meeting and iConference. He is also the managing editor for AIS Transactions on HumanComputer Interaction ( $\mathrm{THCl}$ ). 


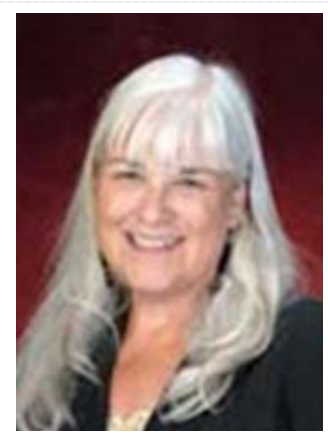

Jane M. Carey is an Associate Professor of Information Systems at the WP Carey School of Business at Arizona State University. Dr. Carey received her PhD in Business Administration from the University of Mississippi and her MBA from Eastern Illinois University. Dr. Carey's research is in the area of Human-Computer Interaction. Her teaching interests are in the area of Cultural Bases for Interface Design, Global Project Management, and Software Globalization. Dr. Carey has published 7 books, 18 book chapters and dozens of refereed journal articles. She is the chair of the Advisory Board for the Special Interest Group in Human-Computer Interaction in the Association of Information Systems and on the review board for the new Transactions in Human Computer Interaction.

Copyright (C) 2009 by the Association for Information Systems. Permission to make digital or hard copies of all or part of this work for personal or classroom use is granted without fee provided that copies are not made or distributed for profit or commercial advantage and that copies bear this notice and full citation on the first page. Copyright for components of this work owned by others than the Association for Information Systems must be honored. Abstracting with credit is permitted. To copy otherwise, to republish, to post on servers, or to redistribute to lists requires prior specific permission and/or fee. Request permission to publish from: AIS Administrative Office, P.O. Box 2712 Atlanta, GA, 30301-2712 Attn: Reprints or via e-mail from ais@aisnet.org. 


\section{Transactions on Human-Computer Interaction}

\section{Editors-in-Chief}

Dennis Galletta, U. of Pittsburgh, USA

\section{Advisory Board}

Izak Benbasat

U. of British Columbia, Canada

Paul Gray

Claremont Graduate U., USA

Ben Shneiderman

U. of Maryland, USA

\section{Senior Editor Board}

Fred Davis

U.of Arkansas, USA

Lorne Olfman

Claremont Graduate U., USA

Viswanath Venkatesh

U. of Arkansas, USA

\section{Associate Editor Board}

Michel Avital

U. of Amsterdam, The Netherlands

Carina de Villiers

U. of Pretoria, South Africa

Milena Head

McMaster U., Canada

Netta livari

Oulu U., Finland

Sherrie Komiak

Memorial U. of Newfoundland, Canada

Scott McCoy

College of William and Mary, USA

Stefan Smolnik

European Business School, Germany

Jason Thatcher

Clemson U., USA

Ozgur Turetken

Ryerson U., Canada

\section{Managing Editor}

Michael Scialdone, Syracuse U., USA

\section{SIGHCI Chairs}

2001-2004: Ping Zhang

2006-2007: Traci Hess

2009-2010: Khawaja Saeed

\section{http://thci.aisnet.org/}

Ping Zhang, Syracuse U., USA

John M. Carroll
Penn State U., USA
Jenny Preece
U. of Maryland, USA
Jane Webster
Queen's U., Canada

Mohamed Khalifa

Abu Dhabi U., United Arab Emirates

Kar Yan Tam

Hong Kong U. of Science \& Technology, China

Susan Wiedenbeck

Drexel U., USA
Phillip Ein-Dor

Tel-Aviv U., Israel

Gavriel Salvendy,

Purdue U., USA, \& Tsinghua U., China

K.K Wei

City U. of Hong Kong, China
Jane Carey

Arizona State U., USA

Matt Germonprez

U. of Wisconsin Eau Claire, USA

Traci Hess

Washington State U., USA

Zhenhui Jack Jiang

National U. of Singapore, Singapore

Paul Benjamin Lowry

Brigham Young U., USA

Fiona Fui-Hoon Nah

U. of Nebraska Lincoln, USA

Jeff Stanton

Syracuse U., USA

Noam Tractinsky

Ben-Gurion U. of the Negev, Israel

Mun Yi

U. South Carolina, USA
Anne Massey

Indiana U., USA

Dov Te'eni

Tel-Aviv U., Israel
Hock Chuan Chan

National U. of Singapore

Khaled Hassanein

McMaster U., Canada

Shuk Ying (Susanna) Ho

Australian Nat. U., Australia

Weiling Ke

Clarkson U., USA

Ji-Ye Mao

Renmin U., China

Sheizaf Rafael

U. of Haifa, Israel

Heshan Sun

U. of Arizona, USA

Horst Treiblmaier

Vienna U. of Business Admin. \& Economics, Austria
2004-2005: Fiona Fui-Hoon Nah

2007-2008: Wei-yin Hong http://sigs.aisnet.org/sighci

2005-2006: Scott McCoy

2008-2009: Eleanor Loiacono

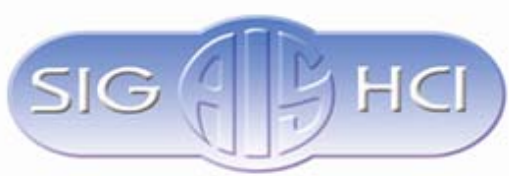

